
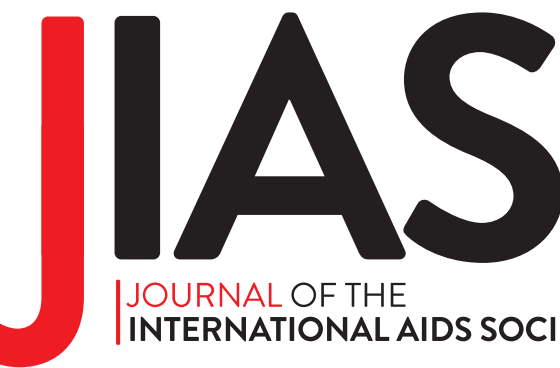

INFECTIONS \& MORBIDITIES

JOURNAL OF THE

INTERNATIONAL AIDS SOCIETY

Towards global viral hepatitis elimination for all patients in all income settings

Guest Editors: Marina B Klein, Karine Lacombe

Supplement Editor: Marlène Bras

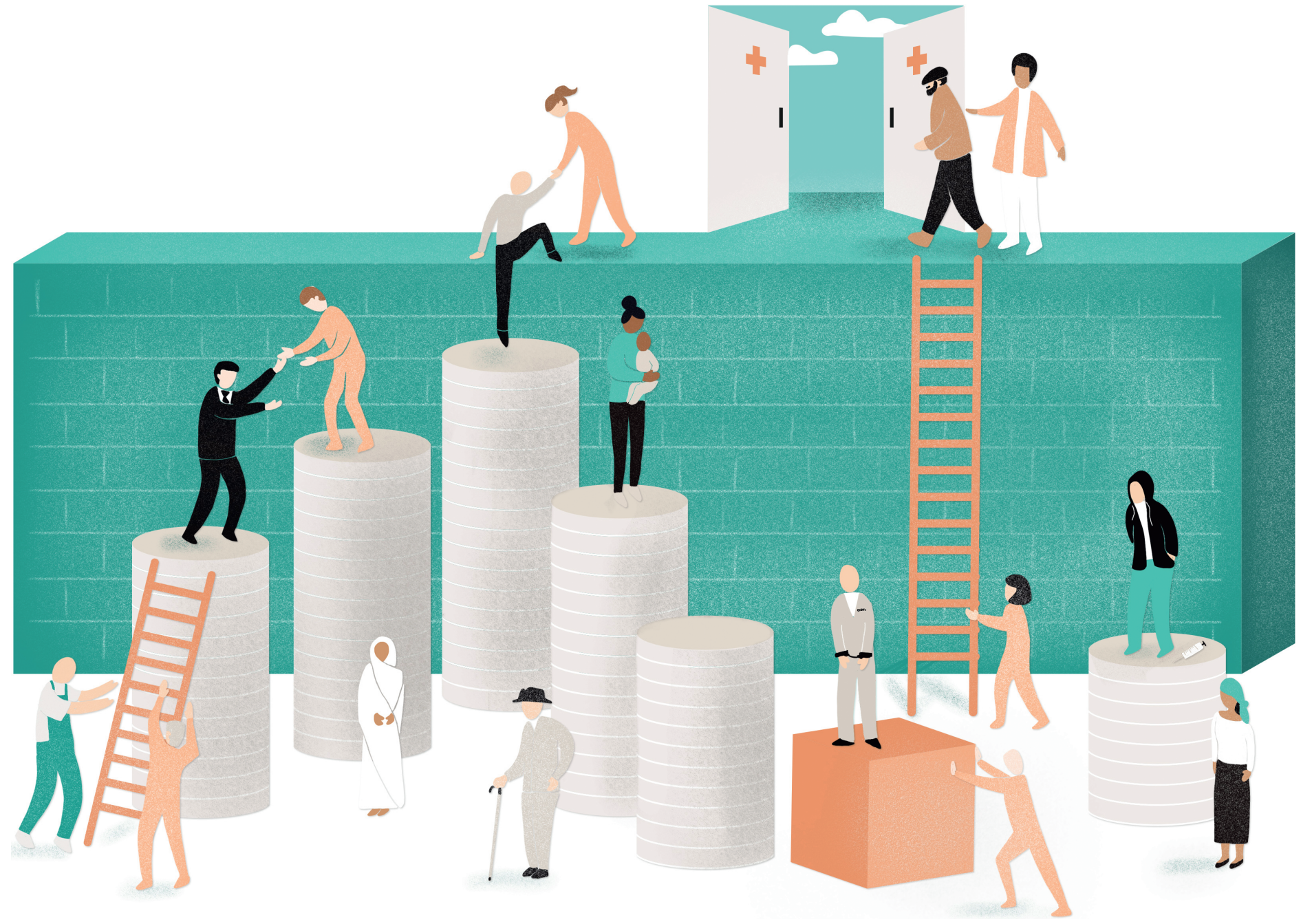




\section{Support}

The publication of this supplement was made possible with support from the CIHR Canadian HIV Trials Network, the European AIDS Clinical Society, the European Association for the Study of the Liver, the US National Institute on Drug Abuse, Abbott, AbbVie, Cepheid, Hetero Drugs, MSD and Pharco; all contributing their support through the 4th International HIVIViral Hepatitis Co-Infection Meeting 


\section{Towards global viral hepatitis elimination for all patients in all income settings}

Guest Editors: Marina B Klein, Karine Lacombe

Supplement Editor: Marlène Bras

\section{Contents}

The Rocky Road to viral hepatitis elimination: assuring access to antiviral therapy for ALL coinfected patients from low- to high-income settings

Karine Lacombe and Marina B Klein

How far are we from viral hepatitis elimination service coverage targets?

Yvan J-F Hutin, Marc Bulterys and Gottfried O Hirnschall

Hep-CORE: a cross-sectional study of the viral hepatitis policy environment reported by patient groups in 25 European countries in 2016 and 2017

Jeffrey V Lazarus, Samya R Stumo, Magdalena Harris, Greet Hendrickx, Kristina L Hetherington, Mojca Maticic, Marie Jauffret-Roustide, Joan Tallada, Kaarlo Simojoki, Tatjana Reic and Kelly Safreed-Harmon on behalf of

the Hep-CORE Study Group

Approaches for simplified HCV diagnostic algorithms

Slim Fourati, Jordan J Feld, Stéphane Chevaliez and Niklas Luhmann

Linkage and retention in HCV care for HIV-infected populations: early data from the DAA era

Rachel Sacks-Davis, Joseph S Doyle, Andri Rauch, Charles Beguelin, Alisa E Pedrana, Gail V Matthews,

Maria Prins, Marc van der Valk, Marina B Klein, Sahar Saeed, Karine Lacombe, Nikoloz Chkhartishvili,

Frederick L Altice and Margaret E Hellard

Treatment advocate tactics to expand access to antiviral therapy for HIV and viral hepatitis C in lowto high-income settings: making sure no one is left behind

Céline Grillon, Priti R Krishtel, Othoman Mellouk, Anton Basenko, James Freeman, Luís Mendão,

Isabelle Andrieux-Meyer and Sébastien Morin

What do clinicians need to watch for with direct-acting antiviral therapy?

Alessio Aghemo, Lionel Piroth and Sanjay Bhagani

Is hepatitis $C$ virus elimination possible among people living with HIV and what will it take to achieve it? Natasha K Martin, Anne Boerekamps, Andrew M Hill and Bart J A Rijnders

Research gaps in viral hepatitis

Anders Boyd, Léa Duchesne and Karine Lacombe 



\title{
The Rocky Road to viral hepatitis elimination: assuring access to antiviral therapy for ALL coinfected patients from low- to high-income settings
}

\author{
Karine Lacombe ${ }^{1,2 \S ;}$ and Marina B Klein $3,4, *$ \\ ${ }^{\S}$ Corresponding author: Karine Lacombe, Service de maladies infectieuses et tropicales, Hôpital St Antoine, 184 rue du Fbg St Antoine, 75012 Paris, France. \\ Tel: +33 1492831 96. (karine.lacombe2@aphp.fr) \\ *These authors have contributed equally to the work.
}

Keywords: antivirals; diagnostic; guidelines; hepatitis B; hepatitis C; HIV; key populations; prevention

Received 18 January 2018; Accepted 19 January 2018; Published 9 April 2018

Copyright $\odot 2018$ The Authors. Journal of the International AIDS Society published by John Wiley \& sons Ltd on behalf of the International AIDS Society. This is an open access article under the terms of the Creative Commons Attribution License, which permits use, distribution and reproduction in any medium, provided the original work is properly cited."

\section{1 | INTRODUCTION}

Chronic viral hepatitis is a leading cause of morbidity and mortality from liver disease worldwide, ranking among the top 10 causes of global mortality in 2013 [1]. Chronic hepatitis B $(\mathrm{CHB})$ and $\mathrm{C}(\mathrm{CHC})$ are responsible for most of this liver disease burden with $\mathrm{CHC}$ being predominant in Europe and the Americas and $\mathrm{CHB}$ more frequent in the other parts of the world. For years, the response to chronic viral hepatitis has been hampered by lack of public knowledge, inadequate screening policies, poor treatment access and low treatment efficacy [2]. However, global inertia has come to a halt in large part due to the advent of curative anti-HCV direct acting antivirals (DAAs) that have the potential to radically impact the HCV epidemic. The resulting paradigm shift in $\mathrm{CHC}$ care and management has mobilized involvement of international global health organizations such as the World Health Organization (WHO) in the fight against viral hepatitis. In 2016, the World Health Assembly of the United Nations called for the elimination of viral hepatitis as a public health threat, with a 90\% reduction in cases of viral hepatitis and 65\% reduction in mortality by 2030 [3]. Because of shared routes of transmission, more than four million individuals are estimated to be dually infected with the human immunodeficiency virus (HIV) and either $\mathrm{CHC}$ or $\mathrm{CHB}$ worldwide [4,5]. Most of these people belong to key populations such as men who have sex with men (MSM) and people who inject drugs (PWID) where specific interventions will need to be implemented to reach elimination of viral hepatitis, including prevention of reinfection. Against this backdrop, a workshop preceding the opening of the ninth IAS conference of HIV Science was held in Paris in July 2017. The meeting brought together researchers studying the epidemiology and modelling of viral hepatitis, professionals caring for those infected, as well as community researchers and advocates. The aim of the meeting was to pave the Rocky Road to viral hepatitis elimination by leaving no one behind (https://www.iasociety.org/Co-Infections/Hepa titis). This special issue of the Journal of the International AIDS Society has gathered landmark papers on viewpoints, reviews and original data that were presented and debated during the Workshop. It provides a comprehensive overview of the challenges faced by scientists, stakeholders and the community in addressing questions of why, how and when viral hepatitis will be eliminated, with a specific focus on HIV coinfection and key populations.

As with HIV infection, the approach to viral hepatitis elimination necessitates increasing prevention and implementing action along all the points of the care and treatment cascade. Specific service targets will need to be met along all these points to ensure success. In the commentary by Hutin and colleagues, it is evident that considerable progress is being made with respect to implementing some existing tools for prevention such as improved blood and medical injection safety and birth dose vaccination for HBV, whereas harm reduction targets are falling far short of requirements [6]. Diagnosis rates remain appallingly low and without rapid increases in the number of people tested and diagnosed, little progress in the very low treatment rates can be expected.

One of the key aspects for successful implementation of the WHO global health sector strategy on HBV and HCV will be the establishment of national and local policies and programmes that support elimination efforts across sectors. Lazarus and colleagues report on country-specific responses to viral hepatitis (including public awareness and engagement and the presence of explicit policies for prevention, diagnosis, monitoring and treatment) from the unique perspective of patient groups in Europe (Hep-CORE) comparing 2016 and 2017 [7]. While, in general, there was a reported increase in policies and programmes for viral hepatitis over time, more than half of countries did not have national strategies in place 
to address these epidemics and programming gaps for prevention (e.g. needle exchange) and treatment were notable. The study also highlights the important gaps that remain for engaging civil society in the efforts to eliminate viral hepatitis.

To reach elimination of viral hepatitis, the first major obstacle is identification of the estimated $80 \%$ of HCV-infected persons globally who have not yet been diagnosed. Fourati and colleagues review diagnostic algorithms that might simplify and enhance decentralized diagnostic testing, particularly in low- and middle-income settings [8]. For example, the development of reliable HCV core antigen tests and new nucleic acid amplification technologies could permit a one-step screening and diagnosis strategy. The availability of pangenotypic antiviral therapy may soon obviate the need to perform HCV genotyping prior to treatment which could further simplify management. While promising, these new technologies are currently too costly for widespread deployment.

Once having performed HCV screening in targeted populations, the next critical step is linking those found to be infected to care, retaining them in the healthcare system and ensuring access to treatment. This is particularly challenging in key populations who are at high risk of becoming reinfected (e.g. people who use drugs, men having sex with men) or developing $\mathrm{CHC}$-associated complications (e.g. HIV coinfected). Sacks-Davis and colleagues have gathered data from numerous local and national initiatives working towards HCV elimination in HIV coinfected populations globally [9]. They show that while treatment has increased substantially in the era of DAAs (mostly in high-income countries) two-thirds of people still have not accessed treatment. Even in settings where treatment is largely available, such as most parts of Western Europe, criminalization, discrimination and stigmatization are strong barriers to treatment for all.

One of the major barriers to increasing treatment for $\mathrm{HCV}$ has been the high cost of DAAs creating a fundamental paradox: the most expensive antivirals (on a per pill basis) are needed by some of the most marginalized groups least able to advocate for their health. The expansion of HIV therapy has served as a catalyst for change in the financing of anti-infective therapies and for drug pricing more widely. While the HIV response necessitated the development of creative pricing strategies for brand name drugs and expanded access to lowcost generic therapies, it is the exorbitant cost of HCV treatment that is forcing a re-examination of government's role in negotiating prices and the roles of generic companies and NGOs in drug development. Grillon and colleagues propose several practical actions that have been successfully used by treatment advocates that could help increase access to DAAs, especially for people who inject drugs [10].

Alongside the cascade of care for CHC, DAAs are a cornerstone on the road to HCV elimination. The scale up of $\mathrm{HCV}$ treatment will require moving treatment beyond specialty settings and necessitate the greater involvement of a broad range of health professionals. In a very practical paper, Aghemo and colleagues review recent treatment recommendations for HCV and provide guidance for clinicians on key management issues including the pretreatment assessment of liver severity, on-treatment monitoring and follow-up after reaching sustained virological response [11].

Bringing several lines of evidence together, Martin and colleagues review modelling and cost data for the feasibility achieving HCV elimination in HIV-positive previously mentioned MSM and previously mentioned PWID [12]. They also present a real world example from the Netherlands which demonstrates that a very rapid decline in $\mathrm{HCV}$ prevalence can be achieved in HIV-positive MSM through DAA scale up. Incidence appears to be declining as a result but likely will not reach the $90 \%$ reduction in incidence required for elimination. They conclude that elimination is achievable in these key populations, but that treatment alone, despite being cost effective, will be insufficient and must be paired with harm reduction and behavioural changes to prevent reinfections.

Finally, in a commentary that aims to pave the future of research in the field of viral hepatitis, Boyd and colleagues highlight the main evidence gaps that still need to be filled so the United Nations for the Millennium goals of combating viral hepatitis may be reached [13]. More tools are needed for preventing ongoing transmission, identifying undiagnosed infections (raising awareness and developing innovative screening tools), to broaden indications for treatment and facilitate access to drugs worldwide, as well as continued investment in the design of new drugs and approaches for HBV cure; all are complementary steps that may eventually lead to hepatitis elimination.

\section{CONCLUSION}

The availability of safe, all-oral and curative therapies for $\mathrm{HCV}$ is having a transformative influence on the course of the global response to $\mathrm{CHC}$. Lessons learned in striving towards viral hepatitis elimination can also inform responses to HIV, HBV and other emerging infectious disease threats. The expanding response to viral hepatitis has, on the one hand, uncovered health inequities globally, between and within countries, and, on the other hand, provided opportunities to develop new community-based models of integrated health services that could have wide impact beyond HIV and HCV. At its best, the $\mathrm{HCV}$ treatment revolution can be used as a tool to draw marginalized peoples into health services that have frequently been hostile to them and adapt them to their realities thereby acting on a wide array of health and social services needs for vulnerable populations. We are well along the road to viral hepatitis elimination. However, to reach the ultimate goal of elimination, continued mobilization of, and advocacy for, the communities affected, increased investment into research and development of diagnostics and new medicines that are affordable and sustained political engagement will be needed.

\section{AUTHORS' AFFILIATIONS}

${ }^{1}$ Sorbonne Université, INSERM, Institut Pierre Louis d'Épidémiologie et de Santé Publique, Paris, France; ${ }^{2}$ AP-HP, Hôpital Saint Antoine, Infectious Diseases Unit, Paris, France; ${ }^{3}$ Research Institute of the McGill University Health Centre, Montréal, Québec, Canada; ${ }^{4}$ Division of Infectious Diseases, Department of Medicine, McGill University Health Centre, Montréal, Québec, Canada

\section{COMPETING INTERESTS}

$\mathrm{KL}$ participates in advisory boards for Gilead Sciences, Abbvie, Janssen and Merck Sharp and Dome. She receives research grants from Gilead Sciences, Merck and Janssen. MK receives research grants for investigator-initiated trials from Merck and ViiV Healthcare; consulting fees from ViiV Healthcare, Merck and Gilead Sciences. 


\section{AUTHORS' CONTRIBUTIONS}

$\mathrm{KL}$ and $\mathrm{MK}$ conceptualized and outlined the paper. They wrote the introduction, summarized the articles and contributed to the conclusions. Both authors approved the final draft.

\section{ACKNOWLEDGEMENTS}

$\mathrm{KL}$ received research funds from the French National Agency for Research in HIV and Hepatitis (ANRS) and Sidaction. She is a member of an international consortium for research on HIV vaccine supported by a European H2O2O grant.

\section{FUNDING}

MK receives funding from the Canadian Institutes of Health Research (FDN143270), Fonds de recherche Québec- Santé, Réseau SIDA/maladies infectieuses (FRQ-S), and the Canadian Institutes of Health Research-Canadian HIV Trials Network (CTN-222).

\section{REFERENCES}

1. Stanaway JD, Flaxman AD, Naghavi M, Fitzmaurice C, Vos T, Abubakar I, et al. The global burden of viral hepatitis from 1990 to 2013: findings from the Global Burden of Disease Study 2013. Lancet. 2013;388(10049):1081-8.

2. Lemoine M, Eholie S, Lacombe K. Reducing the neglected burden of viral hepatitis in Africa: strategies for a global approach. J Hepatol. 2014;62(2):469-76. 3. Global Hepatitis Report 2017. Geneva: World Health Organization, 2017. Available from: http://www.who.int/hepatitis/publications/global-hepatitis-report2017/en/ 2017.
4. Platt L, Easterbrook P, Gower E, McDonald B, Sabin K, McGowan C, et al. Prevalence and burden of $\mathrm{HCV}$ co-infection in people living with HIV: a global systematic review and meta-analysis. Lancet Infect Dis. 2016;16(7): 797-808.

5. Ott JJ, Stevens GA, Groeger J, Wiersma ST. Global epidemiology of hepatitis $B$ virus infection: new estimates of age-specific HBsAg seroprevalence and endemicity. Vaccine. 2012;30(12):2212-9.

6. Hutin YJ-F, Bulterys M, Hirnschall GO. How far are we from viral hepatitis elimination service coverage targets? J Int AIDS Soc. 2018;21 Suppl 2:e25050.

7. Lazarus JV, Stumo SR, Harris M, Hendrickx G, Hetherington KL, Maticic M, et al. Hep-CORE: a cross-sectional study of the viral hepatitis policy environment reported by patient groups in 25 European countries in 2016 and 2017. J Int AIDS Soc. 2018;21 Suppl 2:e25052.

8. Fourati S, Feld JJ, Chevaliez S, Luhmann N. Approaches for simplified HCV diagnostic algorithms. J Int AIDS Soc. 2018;21 Suppl 2:e25058.

9. Sacks-Davis R, Doyle JS, Rauch A, Beguelin C, Pedrana AE, Matthews GV, et al. Linkage and retention in HCV care for HIV-infected populations: early data from the DAA era. J Int AIDS Soc. 2018;21 Suppl 2:e25051.

10. Grillon C, Krishtel PR, Mellouk O, Basenko A, Freeman J, Mendão L, et al. Treatment advocate tactics to expand access to antiviral therapy for HIV and viral hepatitis C in low- to high-income settings: making sure no one is left behind. J Int AIDS Soc. 2018;21 Suppl 2:e25060.

11. Aghemo A, Piroth L, Bhagani S. What do clinicians need to watch for with direct-acting antiviral therapy? J Int AIDS Soc. 2018;21 Suppl 2:e225076.

12. Martin NK, Boerekamps A, Hill AM, Rijnders BJA. Is hepatitis C virus elimination possible among people living with HIV and what will it take to achieve it? J Int AIDS Soc. 2018;21 Suppl 2:e25062.

13. Boyd A, Duchesne L, Lacombe K. Research gaps in viral hepatitis. J Int AIDS Soc. 2018;21 Suppl 2:e25054. 


\title{
How far are we from viral hepatitis elimination service coverage targets?
}

\author{
Yvan J-F Hutin ${ }^{1 \S}$, Marc Bulterys ${ }^{1}$ and Gottfried $O$ Hirnschall ${ }^{1}$ \\ ${ }^{\S}$ Corresponding author: Yvan J.-F. Hutin, Global Hepatitis Programme, WHO, Avenue Appia, Geneva 1211, Switzerland. Tel: +41795959641. (hutiny@who.int)
}

\begin{abstract}
Introduction: In 2016, the Global Health Sector Strategy (GHSS) on viral hepatitis called for elimination of viral hepatitis as a major public health threat by 2030 (i.e. 90\% reduction in incidence and 65\% in mortality). In 2017, WHO's first-ever Global Hepatitis Report presented the baseline values for each of the core indicators of the strategy. We review the challenges and opportunities that lie ahead in order to reach the 2030 service coverage targets.

Discussion: Three-dose coverage of hepatitis B vaccine in infancy reached 84\% in 2015 (2030 target: 90\%); however, only $39 \%$ received the timely birth dose (2030 target: 90\%). Blood safety (97\% of blood units screened with quality assurance, 2030 target: 100\%) and injection safety (5\% unsafe injections, 2030 target: 0\%) had made substantial progress while harm reduction fell short (27 syringe and needle sets distributed per person who injects drugs per year, 2030 target: 300 ). Worldwide, $9 \%$ and $20 \%$ of the HBV- and HCV-infected population respectively, were aware of their status (2030 targets: $90 \%$ ). In the short term, to reach the 2020 target of diagnosing 50\% of those infected, 107 million HBV infected persons and 15 million HCV infected persons should be urgently diagnosed. Overall, in 2015, less than 10\% of known infected persons were on HBV treatment or had started HCV treatment (2030 targets: 80\%).

Conclusions: The prevention component of elimination is on track with respect to hepatitis $\mathrm{B}$ vaccination, blood safety, and injection safety. However, coverage of the hepatitis B vaccine timely birth dose requires a substantial increase, particularly in sub-Saharan Africa, and harm reduction needs to be taken to scale as injecting drug use accounts for a third of mortality from $\mathrm{HCV}$ infection. A promising but limited start in hepatitis testing and treatment needs to be followed by immediate and sustained action so that we reach the service coverage targets required to achieve elimination by 2030. Treating persons coinfected with HIV and hepatitis viruses is particularly urgent and needs to be promoted in the context of the HIV response.
\end{abstract}

Keywords: viral hepatitis; elimination; strategy; public health; indicators; monitoring; evaluation; hepatitis B; hepatitis C; treatment access

Received 7 July 2017; Accepted 19 December 2017; Published 9 April 2018

Copyright @ 2018 World Health Organization; licensed by IAS. This is an open access article distributed under the terms of the Creative Commons Attribution IGO License https://creativecommons.org/licenses/by/3.0/igo/legalcode which permits unrestricted use, distribution and reproduction in any medium, provided that the original work is properly cited. In any reproduction of this article there should not be any suggestion that WHO or the article endorse any specific organization or products. The use of the WHO logo is not permitted. This notice should be preserved along with the article's URL.

\section{1 | INTRODUCTION}

The public health consequences of hepatitis B virus (HBV) and hepatitis $\mathrm{C}$ virus (HCV) infections have long been neglected [1]. Till the 1980s, little had been undertaken in the field of prevention or treatment for viral hepatitis. In 1992, a World Health Assembly (WHA) resolution (WHA 45.17) called for introduction of hepatitis B vaccine in all WHO member states by 1997 . This, along with financial support from the Global Alliance for Vaccine and Immunization (GAVI) and facilitated procurement of vaccines through the revolving fund of the region of the Americas led to a major increase in vaccine coverage in the 2000s [1]. Prevention also took off through other initiatives on blood safety [2], injection safety [3] and harm reduction [4]. However, it is only recently that more attention has been given to testing and treatment, following the availability of direct acting anti-virals (DAAs) for $\mathrm{HCV}$ infection in 2014. Ultimately, in 2016, the WHA adopted the
Global Health Sector Strategy (GHSS) on viral hepatitis. The GHSS calls for the elimination of viral hepatitis as a major public health threat by 2030 (defined as 90\% reduction in incidence and 65\% in mortality) [5]. This breakthrough resolution led to subsequent resolutions by $\mathrm{WHO}$ regional committees and the development of regional action frameworks for hepatitis. As a result, many countries have initiated work to formulate national action plans, starting with initial assessments.

In 2014, the World Health Assembly requested the WHO Secretariat to examine the feasibility of eliminating hepatitis B and C. In 2015, the Sustainable Development Goals (SDGs) also committed to combating viral hepatitis as part of the target 3.3 [6]. WHO therefore commissioned a mathematical model that suggested that if the viral hepatitis response were to reach five synergistic prevention and treatment service coverage targets, hepatitis $\mathrm{B}$ and $\mathrm{C}$ could be eliminated as a major public health threat $[7,8]$. These five interventions are 
(1) hepatitis B immunization, (2) hepatitis B vaccine timely birth dose and other interventions for the prevention of mother to child transmission of HBV, (3) blood and injection safety, (4) prevention of transmission among persons who inject drugs (PWIDs) through comprehensive harm reduction and (5) testing and treatment for chronic HBV and HCV infection. Reducing the number of new infections and deaths requires a comprehensive health sector approach. It is expected that the implementation of these five priority interventions in the context of the universal health coverage framework will strengthen health systems, which is the overarching target for the Sustainable Development Goal 3 on health [9].

In April 2017, WHO published its first-ever Global Hepatitis Report [1] to describe the worldwide situation in terms of viral hepatitis in 2015. The report summarizes the epidemiological situation in terms of prevalence (257 and 71 million persons living with chronic HBV and HCV infection respectively), incidence, and mortality (1.34 million deaths) in 2015. One of the objectives of this report was to estimate the baseline values of each of the core service coverage indicators of the GHSS on viral hepatitis, in relation to the proposed service coverage targets for 2030 (Figure 1). In this commentary, we review the challenges and opportunities that lie ahead for the global efforts to reach the 2030 service coverage targets that are key to achieving elimination. The core principle of the HIV/AIDS response - that no one should be denied treatment by accident of geography or income - is our overarching objective [10].

\section{DISCUSSION}

\subsection{Prevention}

\subsection{1 | Infant hepatitis B immunization}

In 2015, the global reported coverage for the third dose of hepatitis B vaccine among infants was 84\% [1], close to the 2020 (90\%) and 2030 (90\%) targets of the GHSS. However, there were substantial variations across $\mathrm{WHO}$ regions. The Western Pacific region (90\%), the American region (89\%) and the South East Asia regions (87\%) were above the global average and close to the target of the GHSS while the European region (81\%), the Eastern Mediterranean region (80\%) and the African region (75\%) had lower coverage. In Asia, a higher prevalence of HBV infection and higher burden from

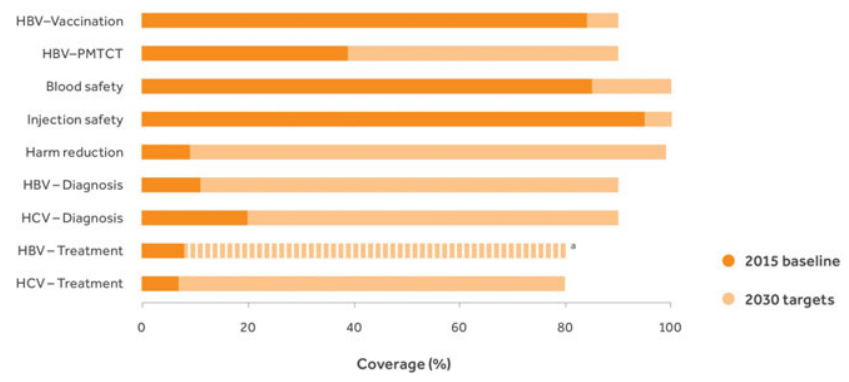

Figure 1. Global Health Sector Strategy on viral hepatitis: 2015 baseline towards the 2030 service coverage targets for the core interventions.
HBV-associated cirrhosis and hepatocellular carcinoma may explain the mobilization in countries that has led to the rapid scale-up for the control of hepatitis B through immunization [11]. In the Americas, a long-standing tradition of investment in immunization systems may explain the high reported coverage. In the European region, the situation is split. On the one hand, the European Union includes a number of countries that have not yet included hepatitis B vaccine into their routine immunization schedule. On the other hand, a number of Eastern European countries that have been going through rapid economical transition have faced difficulties in maintaining high immunization coverage. In the Eastern Mediterranean region, coverage has also been heterogeneous. In the African region, where the prevalence of chronic infection remains high in the general population, three-dose infant hepatitis B vaccine coverage remained relatively low as a number of low-income countries are still dependent on international development assistance to maintain immunization services and some others are facing war or civil unrest.

To achieve the $90 \%$ coverage targets of the GHSS on viral hepatitis, stronger immunization delivery systems will be needed, in the context of the Global Vaccine Action Plan [12]. Most importantly, and to achieve equity, coverage exceeding $90 \%$ should be achieved not only at the global level, but also at the regional, national and sub-national levels, and if possible, in each of the poorer districts so that no children are left behind in reducing the incidence of HBV infections in early childhood.

\subsubsection{Prevention of mother to child transmission of HBV infection}

The current mainstay of the prevention of mother to child HBV transmission is the administration of a timely birth dose of hepatitis B vaccine (i.e. within 24 hours of birth) [13]. In 2015 [1], the global coverage reported was 39\% (for a 2030 target of 90\%). In the Western Pacific Region, coverage with the timely birth dose increased from $2 \%$ in 2000 to $83 \%$ in 2015 as a result of a commitment towards a goal for the control of HBV infection [14]. In the region of the Americas, coverage also increased dramatically as a result of strong immunization services. In the African region, which is characterized by high HBV prevalence, coverage remains very low (10\%), as a result of a combination of obstacles, particularly the low proportion of births that take place in the healthcare setting [15] and misconceptions among many health care staff and policymakers regarding the presumed benefit of the timely birth dose. This low birth dose coverage is problematic as those infections acquired at birth in Sub-Saharan Africa are the ones that account for the majority of chronic liver disease later in life [16]. New tools are becoming available to prevent transmission of HBV from mothers to children, including use of Tenofovir for mothers with high viral load [17]. Further examination of evidence, values and preferences is needed before WHO can make a decision to recommend them for large-scale use. In the meantime, the WHO Western Pacific Region proposes to engage in prevention of mother to child transmission of HBV infection in an incremental manner, starting with universal immunization of infants with hepatitis B vaccine (including a timely birth dose), and adding progressively and sequentially, testing and follow up and pregnant women, 
use of hepatitis B immune globulin and anti-viral medicine for women with high viral load [18]. Use of anti-virals in pregnant women with high HBV viral load may be a higher priority in Asia as perinatal transmission of HBV is more common in this region [19].

\subsection{3 | Blood and injection safety}

In 2013, among the 137 countries that reported data on this indicator to the Global Database on Blood Safety, 97\% were screening all blood donations using basic quality procedures, which included documented standard operating procedures and participation in an external quality assurance scheme (ahead of the 2020 target of 95\%) [20]. However, blood transfusion safety is still a concern, especially in low- and middle income countries, where the prevalence of transfusion transmissible infections is high, and quality and coverage of blood screening are inadequate [21,22]. Hence, further work is needed on the screening of blood units, in the broader context of national blood safety policies that also ensure (a) recruitment of safe, voluntary, non-remunerated blood donors and (b) appropriate clinical use of blood.

There was substantial improvement in the safety of healthcare injections in the world between 2000 and 2010. In these ten years, the proportion of injections given with equipment re-used in the absence of sterilization decreased from 33\% to 8\% [23]. According to 2010 data, healthcare injections remained particularly unsafe in some countries of the Eastern Mediterranean Region, with 14\% re-use still detected and a large number of unsafe injections per capita. This persisting driver of transmission needs to be addressed through safer healthcare, introduction of reuse-prevention devices [24] and a reduction in unnecessary healthcare injections [25], particularly in the Eastern Mediterranean and South-East Asia regions where unsafe injection practices could lead to reinfection after HCV cure [26]. More recent and better quality data are also needed to monitor the evolution of injection safety since 2010 .

\subsubsection{Harm reduction}

Injection drug use accounts for close to a third of new HCV infections and also for about a third of the mortality from the sequelae of HCV infection [27]. However, harm reduction suffers from poor documentation and very low coverage in most countries around the world. In terms of the core indicator of the GHSS for viral hepatitis (i.e. the number of syringe and needle sets distributed by person who inject drugs each year), the most recent data are from 2010 [28] with an estimated 27 sets per user and per year, against 200 and 300 targets for 2020 and 2030 respectively. If viral hepatitis is to be eliminated, [29] an approach combining prevention and treatment will be needed with sufficient coverage of both [30]. Integrated, high-impact interventions recommended by $\mathrm{WHO}$ and other United Nations agency [31] require a policy context that prevents stigma and discrimination [32].

\subsection{Diagnosis and treatment}

Few people with viral hepatitis have been diagnosed (9\% [22 million] of HBV-infected persons and 20\% [20 million] of
HCV-infected persons) [1]. In the short term, to reach the 2020 target of diagnosing 50\% of those infected, 107 of the 257 million HBV-infected persons and 15 of the 71 million $\mathrm{HCV}$ infected persons should be urgently diagnosed. Among those diagnosed, treatment has reached only a small fraction. In 2015, 8\% of those diagnosed with HBV infection were on treatment, while $7.4 \%$ of those diagnosed with HCV infection had started treatment [1]. While the cumulative number of persons treated for HCV reached 5.5 million in 2015, only about half a million of these persons had received the newer, more effective and better tolerated classes of medicines called DAAs. There were more new HCV infections than patients who were started on treatment in 2015 [1]. Testing and treatment for viral hepatitis could build on the experience acquired with HIV in terms of health service delivery models. WHO published testing guidelines that clarify who to test and how to test [33]. As the cost of treatment is rapidly decreasing in countries with access to generics, the high cost of HCV tests will become the next bottle-neck for implementation. However, these service coverage figures have different implications for HBV and HCV.

For HBV, we lack solid estimates on the proportion of HBV infected persons that are eligible for treatment as the information on fibrosis, HBeAg status, HBV DNA values and liver function tests is often missing from epidemiological studies that report population-based prevalence. Published studies suggest that this proportion might not exceed $10 \%$ in community-based, rather than hospital-based, settings [34-36]. This uncertainty and the expected low proportion of persons eligible for treatment have two practical implications. First, community based testing programmes for HBV infection might be limited by a low yield in terms of persons actually eligible for treatment. Second, we cannot precisely interpret the gaps towards reaching the 2030 goal that proposes to place $80 \%$ of eligible persons on treatment. In the coming years, the availability of new treatments that could lead to a functional cure for HBV could increase the proportion of those eligible for treatment. A higher proportion of patients eligible for treatment would increase the yield of testing services and would change the perspective of the GHSS. In the meantime, patients with chronic HBV infection that meet the WHO criteria for treatment [37] can benefit from treatment with anti-nucleos(t)ides with a high barrier to resistance, such as Tenofovir or Entecavir. The WHO guidelines [37] also make provision for the management of patients when access to HBV DNA testing is not possible. Other anti-viral medicines that can rapidly lead to resistance, such as Lamivudine, are no longer recommended. As Tenofovir is available as a generic preparation in many countries on the international market from WHO-pre-qualified manufacturers for a price as low as USD 48 per year of treatment, substantial progress in terms of treatment could be achieved fast, which would lead to a short-term impact in terms of morbidity and mortality reduction. Cost-effectiveness studies should help to secure support from decision makers [38]. In areas where hepatitis D virus (HDV) co-infection is common (e.g. Mongolia or the Amazon in Brazil or Peru) among persons with HBV infection, testing for HDV DNA is also needed, in view of specific treatment considerations $[39,40]$.

For $\mathrm{HCV}$, about one in five infected persons knows their status, and among those identified with infection, a large 
majority of patients remains untreated. Hence, the promising start of the new public health initiative to place persons on treatment needs a substantial scale-up to place more identified persons on treatment first. The high price of DAAs has been an obstacle to scaling up treatment in many countries. However, over 100 countries can now access generic medicines for about USD 200 per curative treatment or less. At such prices, treatment is cost saving [41]. Hence, appropriate and effective treatment can be provided to patients, including in most low and middle income countries, at a reasonable cost if procurement of generic medication is optimized. Increasing access to treatment requires simultaneously scaling up coverage of testing services, including to HCV RNA or HCV core antigen, which are required to make treatment decisions [33]. As of 2017, the situation was evolving fast with new initiatives in Australia [1] and more persons placed on treatment in Egypt.

Among the 36.7 million persons who were living with HIV in 2015, an estimated 2.7 million had chronic HBV infection and an estimated 2.3 million had been co-infected with HCV. Liver diseases represent a major cause of morbidity and mortality among persons living with HIV, and appropriate treatment of co-infections with HBV and HCV has a durable impact on disease progression. If diagnosed, people should be placed on effective hepatitis treatment in the context of the HIV response.

\section{3 $\mid$ Monitoring impact}

WHO published a monitoring and evaluation framework to measure progress towards elimination [42]. In addition to prevention indicators for which systems are usually already in place, countries will require patient databases that can be aggregated into cascades of care and surveillance for viral hepatitis, including (a) acute hepatitis, (b) chronic infections and (c) mortality from cirrhosis and hepatocellular carcinoma [43].

\section{CONCLUSIONS}

WHO's elimination strategy calls for a $65 \%$ reduction in mortality from chronic infection with hepatitis B and $C$ viruses by 2030. A review of the 2015 baseline of the service coverage target indicators generates a contrasting picture. From a prevention perspective, global efforts are, for the most part, on track for hepatitis B vaccination, blood safety and injection safety. However, the coverage of the timely birth dose of the hepatitis B vaccine will require a major focused effort to increase coverage, particularly in Africa; and harm reduction needs to be taken to scale as injection drug use accounts for a third of HCV related mortality. With respect to testing and treatment for chronic HBV and HCV infections, there has been a promising start in a number of countries; however, access to diagnosis and treatment remains too low. Limited funding is available at the international level to support national hepatitis elimination plans. Therefore, countries will need to finance their response primarily through domestic resources. Treatment can be cost-effective, or even cost-saving, from a healthcare perspective $[38,41]$. The 2015 service coverage indicators are a clear call for immediate and sustained action so that these life-saving services can be integrated in the universal health coverage package in order to achieve elimination by 2030. Finally, treating persons coinfected with HIV and hepatitis viruses is particularly urgent and should be done in the context of the HIV response.

\section{AUTHORS' AFFILIATIONS}

${ }^{1}$ Department of HIV and Hepatitis, World Health Organization, Geneva, Switzerland

\section{COMPETING INTERESTS}

The authors have no competing interests.

\section{AUTHORS' CONTRIBUTIONS}

$\mathrm{YH}$ drafted the manuscript. $\mathrm{MB}$ and $\mathrm{GH}$ conceptualized the main messages and provided comments on the paper.

\section{ACKNOWLEDGEMENTS}

We are grateful to Sarah Hess who provided assistance to the 2017 Global Hepatitis Report and who provided comments and suggestions on this manuscript.

\section{FUNDING}

United States Centers for Disease Control and prevention, Atlanta, GA, USA.

\section{REFERENCES}

1. WHO. Global hepatitis report, 2017 [cited 2017 Jun 19]. Available from: http://www.who.int/hepatitis/publications/global-hepatitis-report2017/en/

2. Resolution WHA58.13. Blood safety: proposal to establish World Blood Donor Day. In: Fifty-eighth World Health Assembly, Geneva, 16-25 May 2005. Resolutions and decisions, annexes. Geneva: World Health Organization; 2005 [cited 2017 Mar 10]. Available from: http://www.who.int/bloodsafety/WHA58_ 13-en.pdf?ua $=1$

3. Hutin Y, Chen RT. Injection safety: a global challenge. Bull World Health Organ. 1999:77(10):787-8.

4. Global state of harm reduction. London: Harm Reduction International; 2016.

5. WHO. Global Health Sector Strategy on Viral hepatitis, 2016-2021. Geneva: World Health Organization; 2016 [WHO/HIV/2016.06] [cited 2017 Mar 10]. Available from: http://apps.who.int/iris/bitstream/10665/246177/1/WHO-HIV2016.06-eng.pdf?ua=1

6. Sustainable Development Goals. In: Sustainable Development Knowledge Platform (webpage). New York: United Nations; 2015 [cited 2016 Feb 29]. Available from: https://sustainabledevelopment.un.org/sdgs

7. WHO. Combating hepatitis $B$ and $C$ to reach elimination by 2030. Advocacy brief. May 2016. WHO/HIV/2016.04 [cited 2016 Jun 21]. Available from: http://apps.who.int/iris/bitstream/10665/206453/1/WHO_HIV_2016.04_eng. pdf?ua=1

8. Nayagam S, Thursz M, Sicuri E, Conteh L, Wiktor S, Low-Beer D, et al. Requirements for global elimination of hepatitis B: a modelling study. Lancet Infect Dis. 2016;16:1399-408.

9. United Nations. Sustainable Development Goals. New York: United Nations; 2015 [cited 2017 Mar 10]. Available from: https://sustainabledevelopment.un. org/sdgs

10. Vella S, Wilson D. Access to medicines: lessons from the HIV response (Comment). Lancet. 2017;4:e147-9.

11. Rani M, Yang B, Nesbit R. Hepatitis B control by 2012 in the WHO Western Pacific Region: rationale and implications. Bull World Health Organ. 2009:87:707-13.

12. WHO. Global Vaccine Action Plan. Monitoring Evaluation and Accountability, Secretariat Annual report, 2016 [cited 2017 Jun 27]. Available from : http:// www.who.int/immunization/global_vaccine_action_plan/gvap_secretariat_report_ 2016.pdf?ua $=1$

13. WHO. Hepatitis B vaccines: WHO position paper -July 2017. Week Epidemiol Rec. 2017;92:369-92.

14. Wiesen E, Diorditsa S, Li X. Progress towards hepatitis B prevention through vaccination in the Western Pacific, 1990-2014. Vaccine. 2016;34 (25):2855-62 
15. Miyahara R, Jasseh M, Gomez P, Shimakawa Y, Greenwood B, Keita K, et al. Barriers to timely administration of birth dose vaccines in The Gambia, West Africa. Vaccine. 2016;34:3335-41.

16. Shimakawa Y, Lemoine M, Njai HF, Bottomley C, Ndow G, Goldin RD, et al. Natural history of chronic HBV infection in West Africa: a longitudinal population-based study from The Gambia. Gut. 2016;65(12):2007-16.

17. Hyun MH, Lee YS, Kim JH, Je JH, Yoo YJ, Yeon JE, et al. Systematic review with meta-analysis: the efficacy and safety of tenofovir to prevent mother-to-child transmission of hepatitis B virus. Aliment Pharmacol Ther. 2017;45:1493-505.

18. WHO Western Pacific Region: Regional Framework for the Triple Elimination of Mother-to-child Transmission of HIV, Hepatitis B and Syphilis in Asia and the Pacific 2018-2030. Annex to resolution WPR/RC68/7 [cited 2017 Dec 6]. Available from: http://www.wpro.who.int/about/regional_committee/68/docume nts/wpr_rc68_7_annex_hiv_hepa_syphilis.pdf

19. Edmunds WJ, Medley GF, Nokes DJ, O'Callaghan CJ, Whittle HC, Hall AJ. Epidemiological patterns of hepatitis B virus (HBV) in highly endemic areas. Epidemiol Infect. 1996;117:313-25.

20. Global status report on blood safety and availability 2016. Geneva: World Health Organization; 2017 [cited 2017 Apr 7]. Available from: http://apps.who. int/iris/bitstream/10665/254987/1/9789241565431-eng.pdf

21. Kiani RA, Anwar M, Waheed U, Asad MJ, Abbasi S, Abbas Zaheer H. Epidemiology of transfusion transmitted infection among patients with beta-thalassaemia major in Pakistan. J Blood Transfus. 2016;2016:8135649.

22. Tagny $C T$, Owusu-Ofori S, Mbanya D, Deneys $V$. The blood donor in subSaharan Africa: a review. Transfus Med. 2010;20:1-10.

23. Pépin J, Abou Chakra CN, Pépin E, Nault V. Evolution of the global use of unsafe medical injections, 2000-2010. PLoS One. 2013;8(12):e80948.

24. WHO guideline on the use of safety-engineered syringes for intramuscular, intradermal and subcutaneous injections in health-care settings. Geneva: World Health Organization; 2016 [cited 2017 Mar 19]. Available from: http://apps. who.int/iris/bitstream/10665/250144/1/9789241549820-eng.pdf

25. Gore C. Lazarus JV, Peck RJ, Sperle I, Safreed-Harmon K. Unnecessary injecting of medicines is still a major public health challenge globally. Trop Med Int Health. 2013;18:1157-9.

26. Trickey A, May MT, Davies C, Qureshi H, Hamid S, Mahmood H, et al. Importance and contribution of community, social, and healthcare risk factors for hepatitis C infection in Pakistan. Am J Trop Med Hyg. 2017;97:1920-8.

27. Degenhardt L, Charlson F, Stanaway J, Larney S, Alexander LT, Hickman M, et al. Estimating the burden of disease attributable to injecting drug use as a risk factor for HIV, hepatitis C, and hepatitis B: findings from the Global Burden of Disease Study 2013. Lancet Infect Dis. 2016;16:1385-98.

28. Mathers BM, Degenhardt L, Ali H, Wiessing L, Hickman M, Mattick RP, et al. HIV prevention, treatment, and care services for people who inject drugs: a systematic review of global, regional, and national coverage. Lancet. 2010;375 (9719):1014-28.

29. Hutin YJ, Wiktor SZ. Prioritising treatment among people who inject drugs in order to eliminate hepatitis C: addressing reluctance with sound economic analyses. Gut. 2016;66:2052-3.
30. Fraser H, Zibbell J, Hoerger T, Hariri S, Vellozzi C, Martin NK, et al. Scaling-up HCV prevention and treatment interventions in rural United Statesmodel projections for tackling an increasing epidemic. Addiction. 2017;113:17382.

31. WHO, UNODC, UNAIDS technical guide for countries to set targets for Universal access to HIV prevention, Treatment and care for injecting Drug users [cited 2017 Apr 2]. Available from: http://apps.who.int/iris/bitstream/10665/ 77969/1/9789241504379_eng.pdf

32. Csete J, Kamarulzaman A, Kazatchkine M, Altice F, Balicki M, Buxton J, et al. Public health and international drug policy. Lancet. 2016;387 (10026):1427-80.

33. Guidelines on hepatitis B and C testing. Geneva: World Health Organization; 2017 [cited 19 Mar 2017]. Available from: http://www.who.int/hepatitis/ publications/guidelines-hepatitis-c-b-testing/en/

34. Lemoine M, Shimakawa Y, Njie R, Taal M, Ndow G, Chemin I, et al. Acceptability and feasibility of a screen-and-treat programme for hepatitis B virus infection in The Gambia: the Prevention of Liver Fibrosis and Cancer in Africa (PROLIFICA) study. Lancet Glob Health. 2016;4(8):e559-67.

35. Shankar H, Blanas D, Bichoupan K, Ndiaye D, Carmody E, Martel-Laferriere $\checkmark$, et al. A novel collaborative community-based hepatitis B screening and linkage to care program for African immigrants. Clin Infect Dis. 2016;62(Suppl 4): S289-97.

36. Spradling PR, Xing J, Rupp LB, Moorman AC, Gordon SC, Teshale ET, et al. Infrequent clinical assessment of chronic hepatitis B patients in United States general healthcare settings. Clin Infect Dis. 2016;63:1205-8.

37. Guidelines for the prevention, care and treatment of persons with chronic hepatitis B infection. Geneva: World Health Organization; March 2015. [cited 2017 Mar 10]. Available from: http://apps.who.int/iris/bitstream/10665/ 154590/1/9789241549059_eng. pdf?ua=1\&ua=1

38. Toy M, Hutton DW, So SK. Cost-effectiveness and cost thresholds of generic and brand drugs in a national chronic hepatitis B treatment program in China. PLoS One. 2015;10:e0139876.

39. Farzi P. Delta hepatitis: an update. J Hepatol. 2003;39:S212-9.

40. Wranke A, Hardtke S, Borzacov LMP, Borzacov R, Parana C, Lobato S, et al. Diversity of clinical presentation and virological characteristics of hepatitis delta in different regions worldwide: results of the Hepatitis Delta International Network. J Hepatol. 2017;66:S257-8

41. Aggarwal R, Chen Q, Goel A, Seguy N, Pendse R, Ayer T, et al. Cost-effectiveness of hepatitis $C$ treatment using generic direct-acting antivirals available in India. PLoS One. 2017;12(5):e0176503.

42. Monitoring and evaluation for viral hepatitis B and C: recommended indicators and framework. Technical report. Geneva: World Health Organization; 2016 [cited 2017 Mar 10]. Available from: http://apps.who.int/iris/bitstream/ 10665/204790/1/9789241510288_eng.pdf

43. WHO, 2016. Technical considerations and case definitions to improve surveillance for viral hepatitis Surveillance document. Technical report. ISBN ISBN 978924154954 [cited 2016 Jun 21]. Available from: http://apps.who. int/iris/bitstream/10665/204501/1/9789241549547_eng.pdf?ua=1 


\title{
Hep-CORE: a cross-sectional study of the viral hepatitis policy environment reported by patient groups in 25 European countries in 2016 and 2017
}

Jeffrey $\vee$ Lazarus $^{1,2 \S}$, Samya R Stumo ${ }^{1}$, Magdalena Harris ${ }^{3}$, Greet Hendrickx ${ }^{4}$, Kristina L Hetherington ${ }^{1}$, Mojca Maticic ${ }^{5,6}$, Marie Jauffret-Roustide ${ }^{7}$, Joan Tallada ${ }^{8}$, Kaarlo Simojoki ${ }^{9}$, Tatjana Reic ${ }^{10}$ and Kelly Safreed-Harmon ${ }^{1}$ on behalf of the Hep-CORE Study Group

§Corresponding author: Jeffrey $\vee$ Lazarus, Barcelona Institute for Global Health (ISGlobal), Hospital Clínic, University of Barcelona, Calle Roselló 132, $4^{\text {th }}$ floor, ES-08036 Barcelona, Spain. Tel: (+34) 608703573. (jeffrey.lazarus@isglobal.org)

\begin{abstract}
Introduction: The first World Health Organization (WHO) global health sector strategy on hepatitis B and C viruses (HBV and HCV) has called for the elimination of viral hepatitis as a major public health threat by 2030. This study assesses policies and programmes in support of elimination efforts as reported by patient groups in Europe.

Methods: In 2016 and 2017, hepatitis patient groups in 25 European countries participated in a cross-sectional survey about their countries' policy responses to HBV and HCV. The English-language survey addressed overall national response; public awareness/engagement; disease monitoring; prevention; testing/diagnosis; clinical assessment; and treatment. We performed a descriptive analysis of data and compared 2016 and 2017 findings.

Results: In 2017, $72 \%$ and 52\% of the 25 European study countries were reported to not have national HBV and HCV strategies respectively. The number of respondents indicating that their governments collaborated with civil society on viral hepatitis control increased from 13 in 2016 to 18 in 2017. In both 2016 and 2017, patient groups reported that 9 countries (36\%) have disease registers for HBV and 11 (44\%) have disease registers for HCV. The number of countries reported to have needle and syringe exchange programmes available in all parts of the country dropped from 10 (40\%) in 2016 to 8 in 2017 (32\%). In both 2016 and 2017, patient groups in 5 countries (20\%) reported that HCV treatment is available in non-hospital settings. From 2016 to 2017, the reported number of countries with no restrictions on access to direct-acting antivirals for HCV increased from $3(12 \%)$ to 7 (28\%), and 5 fewer countries were reported to refuse treatment to people who are currently injecting drugs.

Conclusions: The patient-led Hep-CORE study offers a unique perspective on the readiness of study countries to undertake comprehensive viral hepatitis elimination efforts. Viral hepatitis monitoring should be expanded to address policy issues more comprehensively and to incorporate civil society perspectives, as is the case with global HIV monitoring. Policy components should also be explicitly added to the WHO framework for monitoring country-level progress against viral hepatitis.
\end{abstract}

Keywords: coinfection; drug therapy; health policy; hepatitis B; hepatitis C; viral hepatitis prevention and control

Additional Supporting Information may be found online in the Supporting Information tab for this article.

Received 12 July 2017; Accepted 20 December 2017; Published 9 April 2018

Copyright $\odot 2018$ The Authors. Journal of the International AIDS Society published by John Wiley \& sons Ltd on behalf of the International AIDS Society. This is an open access article under the terms of the Creative Commons Attribution License, which permits use, distribution and reproduction in any medium, provided the original work is properly cited.

\section{1 | INTRODUCTION}

Viral hepatitis is a major public health problem, with more deaths annually attributable to this group of diseases than to HIV, malaria or tuberculosis [1]. Hepatitis B virus (HBV) and hepatitis C virus (HCV) infections account for $47 \%$ and $48 \%$ of viral hepatitis mortality respectively [2]. Both HBV and $\mathrm{HCV}$ infections can lead to cirrhosis and liver cancer, and most HBV- and HCV-related deaths occur as a direct result of one of these two diseases [1]. HBV and HCV together are estimated to account for almost $80 \%$ of deaths from liver cancer $[3,4]$, which was the third most common cause of cancer mortality in 2013 [5].

In the WHO European Region an estimated 18.5 million people are chronically infected with $\mathrm{HBV}$, and an estimated 15 million people are chronically infected with $\mathrm{HCV}[6,7]$. The annual number of deaths from viral hepatitis-related causes in the Region is thought to exceed 170,000 [8]. With HBV vaccination now widespread in younger age groups, HBV tends to be seen more in older Europeans and in migrants from 
countries with high HBV prevalence [8]. Practices associated with unsafe injecting drug use are a major contributor to the HCV epidemic in the European Region. There are high levels of HCV transmission among HIV-positive men who have sex with men, and healthcare-related transmission of HCV continues to occur in some countries $[9,10]$. The recent introduction of highly effective direct-acting antiviral (DAA) drugs has made HCV much easier and safer to cure, but concern has been raised about whether health systems in Europe and globally will be able to overcome the numerous barriers to scaling up DAA treatment [10-12].

In 2014, in response to increasing recognition of the large disease burden imposed by viral hepatitis, the World Health Assembly approved a resolution calling on WHO Member States to enact various viral hepatitis control measures. The same resolution charged WHO with examining "the feasibility of and strategies needed for the elimination of hepatitis B and hepatitis C with a view to potentially setting global targets" [13]. In this policy context, the European Liver Patients' Association (ELPA) published 43 key recommendations for European governments [14]. ELPA subsequently commissioned the Hep-CORE ("Hepatitis Community, Opinion, Recommendations, Experts") study to assess the extent to which these recommendations are being followed on a national level in European countries. As the Hep-CORE study was being planned, other major policy developments occurred. In 2015, United Nations Member States included a commitment to combat viral hepatitis in the Sustainable Development Goals [15] and in 2016, WHO launched its first global health sector strategy on viral hepatitis [2]. The strategy sets forth the ambitious targets of achieving a $90 \%$ reduction in new cases of chronic HBV and $\mathrm{HCV}$ and a $65 \%$ reduction in HBV and $\mathrm{HCV}$ deaths, all by 2030 [2].

To reach the targets and achieve WHO's overarching goal of eliminating viral hepatitis as a major public health threat by 2030, governments around the world must first consider whether they have the necessary policies and programmes in place. Scant information is available regarding the current policy landscape. The 2013 Global Policy Report on the Prevention and Control of Viral Hepatitis in WHO Member States presents findings from a policy survey completed by representatives of 126 national governments [16]. A follow-up survey of civil society organizations found that numerous respondents questioned the accuracy of the information reported by their governments [17].

Policy monitoring of national responses to major health issues has been approached in a variety of ways [18,19]. A key example is the global HIV policy monitoring process coordinated by the Joint United Nations Programme on HIV/AIDS (UNAIDS) for more than a decade. Governments are asked to prepare periodic reports on their countries' progress in combating HIV, with some of the information gathered using a survey known as the National Commitments and Policy Instrument (NCPI) [20]. Significantly, one part of the NCPI is completed by governments and the other by in-country civil society stakeholders.

With no ongoing government or multi-stakeholder policy monitoring process for viral hepatitis in place at the global or regional level, ELPA sought to fill a gap by implementing the Hep-CORE study in the countries where it had member organizations. These patient groups were responsible for reporting information to the study team. ELPA's goal was twofold: (1) to help liver patient groups identify key policy shortcomings in study countries; and (2) to engage liver patient groups in a regional policy monitoring initiative that will help hold countries accountable to their pledges to work towards viral hepatitis elimination. The following article reports findings from the 2016 and 2017 Hep-CORE surveys.

\section{METHODS}

A research team based at the University of Barcelona and the University of Copenhagen implemented the Hep-CORE study in consultation with a multidisciplinary study group of viral hepatitis experts and carried out two rounds of data collection: one from July to October 2016 and another from August to November 2017.

The original study instrument, a 39-item English-language online survey (Additional File 1), reflected ELPA's recommendations to European governments [14]. We developed and revised the survey in accordance with multiple rounds of input from study group members. The 2016 survey questions addressed issues relating to all seven categories of recommendations: overall national response, public awareness and engagement, monitoring and data collection, prevention, testing and diagnosis, clinical assessment, and treatment. The study instrument was piloted in June 2016. Four prospective study participants completed the survey and provided feedback, which guided final revisions. The Hep-CORE 2017 study instrument comprised 11 questions derived from the 2016 survey (Additional File 2). We piloted it in August 2017 with five study group members. The pilot responses and additional feedback guided survey modifications.

As in 2016, the main survey questions in 2017 were closed-ended, as were most sub-questions. For both rounds of data collection, we asked study participants to complete the survey using Research Electronic Data Capture (REDCap), a web-based data collection tool that enables responses to be saved and edited over the course of multiple sessions [21]. The survey instructions asked respondents to conduct research as needed to answer survey questions accurately, and recommended contacting sources such as government officials and viral hepatitis experts. Respondents were able to pause work on their surveys and log back into them to change or add information using unique access codes.

The study cohort was recruited through a purposive sampling process. We emailed an invitation to participate in the survey to one liver patient group in each of the 24 European countries where ELPA had members at the time of 2016 study recruitment. In countries with more than one patient group, we selected the most representative group that was involved in viral hepatitis advocacy. We also emailed the invitation to a liver patient group in Denmark, since the patient group was just about to join ELPA, and did so in 2017. The same 25 patient groups that accepted the invitation and contributed data in 2016 were invited to respond to the 2017 survey. Many of the same individuals completed the survey in both years, although personnel changes in some patient groups meant that in some cases different individuals represented those groups in 2017. 
Following the close of each round of data collection, we reviewed data and queried study participants via email about incomplete, inconsistent or unclear information. We compiled and descriptively analysed final data using Microsoft Excel. We reported 2016 findings in The 2016 HepCORE Report, published by ELPA in early 2017 [22]. The analysis presented in this paper directly compares 2017 findings to findings from parallel 2016 survey questions. Additional File 3 provides country responses to the 2016 and 2017 surveys in comparative tables.

\section{3 | RESULTS}

In both 2016 and 2017, the 25 European liver patient groups that received study invitations all submitted surveys, for a 100\% response rate. Box 1 identifies the countries represented by these groups.

\subsection{National coordination}

In 2017, patient groups in seven countries (28\%) reported that their countries have written national strategies for HBV, and patient groups in 12 countries (48\%) reported the same for HCV (Table 1). These findings were similar to 2016 findings, although the survey questions were formulated slightly differently in 2016 and 2017 (Additional Files 1 and 2). The number of patient groups reporting government collaboration with in-country civil society groups to carry out viral hepatitis prevention and control programmes increased from 13 (52\%) in 2016 to 18 (72\%) in 2017. In both 2016 and 2017, patient groups reported that nine countries (36\%) have disease registers for HBV and 11 (44\%) have disease registers for $\mathrm{HCV}$.

\subsection{Prevention}

While patient groups in most study countries reported opioid substitution therapy (OST) to be available in all parts of the country in both 2016 and 2017, far fewer reported needle and syringe programmes (NSPS) to be available in all parts of the country - 10 (40\%) in 2016 and 8 (32\%) in 2017 (Table 1). Drug consumption rooms were reported to be available in either all or some parts of the country in four countries (16\%) in 2016 and six countries (24\%) in 2017.

\section{3 $\quad$ Testing}

$\mathrm{HBV} / \mathrm{HCV}$ risk assessment was reported to be included in routine medical check-ups in six countries (24\%) in 2017, and liver enzyme testing in 14 countries (56\%) (Table 1).

Patient groups were asked to indicate whether free and anonymous HBV and HCV testing services targeting the general population and high-risk populations are available in their countries (Figure 1). From 2016 to 2017, large increases occurred in the number of countries reported to have anonymous HBV and HCV testing for the general population, with anonymous HBV testing up from six to twelve countries and anonymous HCV testing up from six to eleven countries. There also were large increases for free HBV and HCV testing for the general population, and for anonymous HCV testing for high-risk populations.

Eighteen countries (72\%) reported HBV testing availability outside of hospitals in 2017, with the same number of countries reporting HCV testing/screening availability outside of hospitals in that year though with slight variation for HBV and $\mathrm{HCV}$ (data not shown). Types of testing sites included general practitioner clinics (HBV, 11 countries; HCV, 10 countries), OST clinics (HBV, 9 countries; HCV, 10 countries) and NSPS (HBV, 5 countries; HCV 7 countries). In 2016, study participants were asked about non-hospital-based HBV and HCV testing and screening in a different way, with separate survey questions addressing the general population and high-risk populations. Eleven countries (44\%) in 2016 were reported to have HBV testing sites outside of hospitals for the general population, and 16 (64\%), for high-risk populations. Regarding $\mathrm{HCV}$ testing, the reported numbers of countries with non-hospital-based sites in 2016 were 13 for the general population (52\%) and 16 for high-risk populations (64\%).

\section{4 $\quad$ Treatment}

In 2017, patient groups in 19 countries (76\%) reported that HBV treatment is provided in prisons, up from 18 countries (72\%) in 2016 (Table 1). In both 2016 and 2017, patient groups in five countries (20\%) reported that HCV treatment is available in non-hospital settings. These included general practitioner clinics (three countries in both 2016 and 2017), liver specialist clinics (one country in 2016 and two countries in 2017), and addiction/OST clinics (three countries in 2016 and two countries in 2017) (data not shown).

\section{Box 1.}

\section{Hep-CORE European study countries}

Austria
Belgium
Bosnia and Herzegovina
Bulgaria
Croatia
Denmark
Finland
France
Germany

Greece
Hungary
Italy
Macedonia
Netherlands
Poland
Portugal
Romania
Serbia

Slovakia

Slovenia

Spain

Sweden

Turkey

Ukraine

United Kingdom 
Table 1. National coordination, monitoring, prevention, screening and treatment policies reported for hepatitis B and hepatitis C in study countries $(\mathrm{N}=\mathbf{2 5})$

\begin{tabular}{|c|c|c|c|c|c|c|c|c|}
\hline & \multicolumn{4}{|c|}{2016} & \multicolumn{4}{|c|}{2017} \\
\hline & \multicolumn{2}{|c|}{ Yes } & No & $\begin{array}{l}\text { Do not } \\
\text { know }\end{array}$ & \multicolumn{2}{|c|}{ Yes } & No & $\begin{array}{l}\text { Do not } \\
\text { know }\end{array}$ \\
\hline \multicolumn{9}{|l|}{ National coordination } \\
\hline Written national HBV strategy & \multicolumn{2}{|c|}{$8(32 \%)$} & $17(68 \%)$ & 0 & \multicolumn{2}{|c|}{$7(28 \%)$} & $18(72 \%)$ & 0 \\
\hline $\begin{array}{l}\text { Government or government- } \\
\text { related institution has national } \\
\text { HBV disease register }\end{array}$ & \multicolumn{2}{|c|}{$9(36 \%)$} & $16(64 \%)$ & 0 & \multicolumn{2}{|c|}{$9(36 \%)$} & $15(60 \%)$ & $1(4 \%)$ \\
\hline \multicolumn{9}{|l|}{ Prevention } \\
\hline $\begin{array}{l}\text { Harm reduction services } \\
\text { available: Needle and syringe } \\
\text { programmes (all parts of } \\
\text { country, some parts of country) }\end{array}$ & \multicolumn{2}{|r|}{$10(40 \%)$} & $4(16 \%)$ & $1(4 \%)$ & All: 8 (32\%) & Some: 12 (48\%) & $3(12 \%)$ & $2(8 \%)$ \\
\hline $\begin{array}{l}\text { Harm reduction services } \\
\text { available: Opioid substitution } \\
\text { therapy (all parts of country, } \\
\text { some parts of country) }\end{array}$ & All: 22 (88\%) & Some: 1 (4\%) & 0 & $2(8 \%)$ & All: 20 (80\%) & Some: 4 (16\%) & 0 & $1(4 \%)$ \\
\hline $\begin{array}{l}\text { Liver enzyme testing included in } \\
\text { routine medical check-ups }\end{array}$ & \multicolumn{2}{|c|}{$17(68 \%)$} & $8(32 \%)$ & 0 & \multicolumn{2}{|c|}{$14(56 \%)$} & $10(40 \%)$ & $1(4 \%)$ \\
\hline \multicolumn{9}{|l|}{ Treatment } \\
\hline $\begin{array}{l}\text { HBV treatment provided in } \\
\text { prisons }\end{array}$ & \multicolumn{2}{|c|}{$18^{\mathrm{C}}(75 \%)$} & $5^{c}(21 \%)$ & $1^{\mathrm{c}}(4 \%)$ & \multicolumn{2}{|c|}{19 (76\%) } & $5(20 \%)$ & $1(4 \%)$ \\
\hline $\begin{array}{l}\text { HCV patients have option to be } \\
\text { treated in non-hospital settings }{ }^{d}\end{array}$ & \multicolumn{2}{|c|}{$5(20 \%)$} & $20(80 \%)$ & 0 & \multicolumn{2}{|c|}{$5(20 \%)$} & $20(80 \%)$ & 0 \\
\hline
\end{tabular}

HBV, hepatitis B virus; HCV, hepatitis C virus.

a Survey respondents were advised that the following are not considered in-country civil society groups: United Nations agencies, international non-governmental organizations, government ministries, university programmes and military programmes.

${ }^{b} 2017$ responses to this question total 24 instead of 25 because there was one non-response.

${ }^{c} 2016$ responses to this question total 24 instead of 25 because there was one non-response.

dSettings that are not within either inpatient or outpatient hospital facilities.

In both 2016 and 2017, survey respondents were asked to choose one or more answers to the question, "In practice, what restrictions are there on access to direct-acting antivirals for the treatment of HCV infection in your country?" (Figure 2). From 2016 to 2017 the reported number of countries with no restrictions increased from 3 (12\%) to 7 (28\%). Countries with a reported fibrosis level restriction dropped from $18(72 \%)$ to 13 (52\%), and countries reported to refuse treatment to people who are currently injecting drugs dropped from $13(52 \%)$ to 8 (32\%). 


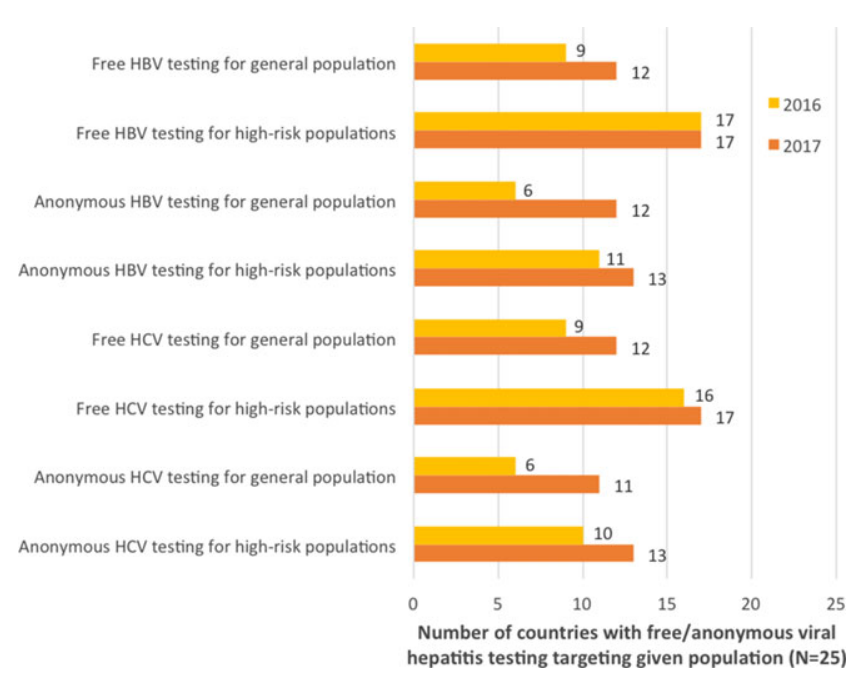

Figure 1. Reported availability of free and anonymous viral hepatitis testing services in study countries $(\mathrm{N}=25)$

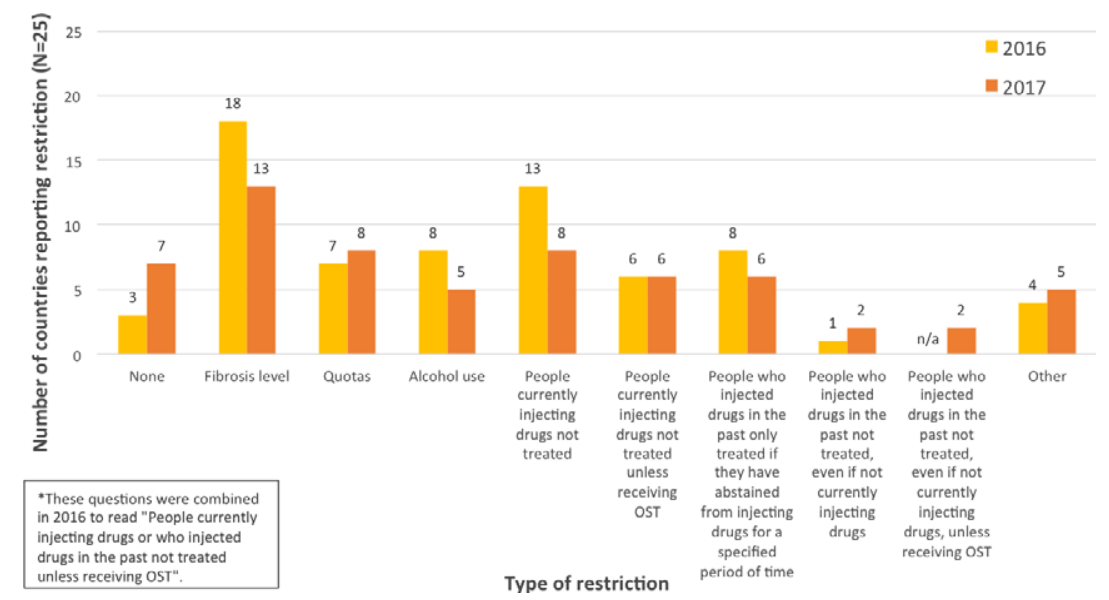

Figure 2. Reported restrictions on access to direct-acting antivirals for the treatment of hepatitis $\mathrm{C}$ in study countries ( $\mathrm{N}=\mathbf{2 5}$ )

\section{DISCUSSION}

The Hep-CORE study was conducted in 2016 and 2017 against the backdrop of rapid changes in the field of viral hepatitis. It found that, from the perspective of liver patient groups, many European countries have shortcomings across the spectrum of elements that constitute a comprehensive policy response to viral hepatitis, including national coordination, public awareness, disease surveillance, prevention, testing and treatment. At the time of 2017 data collection, only 28\% and $48 \%$ of the 25 European study countries were reported to have national HBV and HCV strategies respectively. National disease registers were reported to be lacking in many countries as well. Some key prevention, testing and treatment recommendations did not appear to be widely reflected in national viral hepatitis control efforts, suggesting that governments may be missing important opportunities to limit disease transmission, disease progression and mortality.

Despite the availability of many simple operational interventions to improve the continuum of care for people with chronic $\mathrm{HBV}$ and $\mathrm{HCV}$, relatively few of these people are offered treatment [23,24]. At the same time, there are problematic gaps in disease prevention efforts [23]. The Hep-CORE study provides a patient group perspective on policy barriers that may be undermining progress against $\mathrm{HBV}$ and $\mathrm{HCV}$ in the European Region, while at the same time offering a model for how patient groups might contribute to policy monitoring in other regions. Findings indicate that few study countries are sufficiently attuned to the importance of addressing the HBV and HCV prevention and treatment needs of the key populations most affected by these diseases in Europe, such as people who inject drugs (PWID). NSPs can contribute substantially to reducing transmission of blood-borne viruses among PWID $[25,26]$, yet less than one-third of study countries were reported to have NSPs available in all parts of their countries in 2017. The presence of injecting drug use-related restrictions on access to DAAs for the treatment of $\mathrm{HCV}$ in several study countries is also a matter of concern, and other research has similarly documented such restrictions [27]. European and global experts concur that injecting drug use 
does not constitute a valid reason for withholding treatment [28-30] - indeed, global HCV elimination strategies depend on the reductions in transmission that are expected to occur when large numbers of chronically HCV-infected people who currently inject drugs are cured with DAAs [31].

Hep-CORE 2016 and 2017 study findings differ regarding the number of countries reported to have components of the recommended HBV and HCV policy infrastructure in place. We hypothesise that some small changes from 2016 to 2017 may be attributable to how respondents interpreted questions differently from one year to the next, or in some cases to changes in how questions were formulated in the study instrument. It is also possible that respondents became more knowledgeable and thus provided more accurate information about some issues in the second round of reporting. We are therefore disinclined to interpret small changes from 2016 to 2017 as trends. The magnitude of some changes, however, is notable. The number of respondents indicating that their governments collaborated with civil society on viral hepatitis control increased considerably from 2016 to 2017, as did the number of respondents reporting the availability of free and anonymous HBV and HCV testing for the general population. Also, the number of study countries reported to have no restrictions on access to DAAs for HCV treatment increased from three to seven, with fewer countries reported to restrict access according to fibrosis or drug injecting status. These changes might partially reflect efforts to encourage European governments to align their responses to viral hepatitis with global and regional guidance. Patient groups' research inquiries for the 2016 survey and ELPA's extensive dissemination of study findings may have influenced governments as well.

Researchers have proposed that the global HIV policy monitoring process led by UNAIDS can serve as a useful model for other monitoring initiatives, such as those that will be needed to track countries' efforts to achieve the Sustainable Development Goals [32]. The UNAIDS reporting framework repeats some of the same questions in surveys that are completed separately by government and civil society representatives. This makes it possible to examine points of disagreement. Interestingly, an assessment of differences between government reporting and civil society reporting in the aforementioned NCPI found that civil society stakeholders generally characterize national HIV responses less favourably than governments do [33]. The discrepancies are allowed to stand as part of the evidence presented in the final country reports [20]. This point may be instructive for the viral hepatitis field, where civil society stakeholders have challenged some governments' accounts of their countries' policy and programmatic responses to viral hepatitis [16,17]. Researchers have documented increased collaboration between governments and civil society stakeholders on NCPI reporting over time, and have concluded that this approach has strengthened the overall response to HIV [32,33].

In the field of viral hepatitis, $\mathrm{WHO}$ has proposed a monitoring framework for countries to track progress towards the targets in the WHO global strategy [34]. The 10 core indicators recommended by WHO ask about disease incidence, prevalence and mortality, as well as a number of key interventions. The emphasis is thus on outputs rather than on indicators of a strong policy environment. It is not known how many countries have adopted the $\mathrm{WHO}$ monitoring framework since it was published in April
2016, or when WHO will establish mechanisms for countries to publicly report their monitoring findings. We must consider how such monitoring should be expanded to address policy issues more comprehensively, and how future monitoring processes should be structured, with consideration given to the role of civil society stakeholders such as the patient groups that participated in the Hep-CORE study. Furthermore, we are not aware of similar data being collected in other regions of the world; conducting such an exercise in other regions would provide the basis for comparative analyses.

Arguably, the central limitation of this study is that patient groups were the only participants. Patient groups, especially those that lack established communication channels with government officials or viral hepatitis experts, may not always be the most well-placed to report accurately on national policies. However, patients have a distinctly different perspective from other stakeholders, arising from unique motivations. This may enable them to report on policy shortcomings that other observers have failed to identify. In designing a study that gathered policy information only from ELPA patient groups, the research team was both seeking to make optimal use of limited resources and also to emphasize the importance of patient engagement in the viral hepatitis policy discourse. It is hoped that government representatives in all Hep-CORE study countries will review the information reported for their countries (Additional File 3) and will share their perspectives on this information with the reporting patient groups. Ultimately, governments and other viral hepatitis stakeholders in Europe and elsewhere should have the goal of establishing an ongoing viral hepatitis policy monitoring process that incorporates the expertise of all stakeholders.

Additional study limitations should be noted. The questionnaire was exclusively in English, which may have led to the misinterpretation of questions, despite the study team inviting respondents to ask for clarification on any survey questions that they did not understand. Only one patient group, or in the case of the United Kingdom a coalition of two groups, served as a respondent from each country; thus, the information provided might not reflect the perspectives of other patient groups in the study countries. Because the study focused on patient group reporting, survey answers were not checked against other sources of information, and it is not possible to know whether the information reported is accurate. Some respondents may have been hampered in their reporting efforts by inadequate government communication about existing policies.

\section{5 | CONCLUSIONS}

Although planning for the Hep-CORE study commenced before the official launch of the WHO global health sector strategy on viral hepatitis, it anticipated many of the strategy's key points. As such, Hep-CORE offers unique insights into the readiness of study countries to pursue hepatitis elimination targets. The finding that warrants the most urgent attention is the reported absence of written national HBV and HCV strategies in many European countries. Other key policy barriers impeding viral hepatitis elimination efforts include widespread restrictions to treatment, limited availability of free and anonymous testing, and insufficient access to testing, prevention and treatment in non-hospital settings. As Hep-CORE 
is driven by patient engagement, it has the potential to foster greater interaction and cooperation between governments and patient groups. Future policy monitoring in the HepCORE countries and elsewhere should incorporate the perspectives of additional stakeholder groups including governments and medical professionals in order to ensure the most reliable reporting, while also reflecting points of disagreement among reporting parties. Frequent rounds of policy monitoring are needed in the light of how rapidly the public health response to viral hepatitis is evolving in Europe and elsewhere.

\section{DECLARATIONS}

Ethics approval and consent to participate: Not applicable.

Consent for publication: Not applicable.

Availability of data and material: The datasets generated in 2016 are available in the 2016 Hep-CORE Report published by the European Liver Patients Association (https://www.elpa-info.org/project/hep-core-study). The datasets generated in 2017 are available from the authors upon request.

\section{AUTHORS' AFFILIATIONS}

${ }^{1}$ Barcelona Institute for Global Health (ISGlobal), Hospital Clínic, University of Barcelona, Barcelona, Spain; ${ }^{2} \mathrm{CHIP}$, Rigshospitalet, University of Copenhagen, Copenhagen, Denmark; ${ }^{3}$ Department of Social and Environmental Health Research, London School of Hygiene and Tropical Medicine, London, United Kingdom; ${ }^{4}$ Viral Hepatitis Prevention Board, Centre for the Evaluation of Vaccination, Vaccine and Infectious Diseases Institute, University of Antwerp, Antwerp, Belgium; ${ }^{5}$ Clinic for Infectious Diseases and Febrile Illnesses, University Medical Centre Ljubljana, Ljubljana, Slovenia; ${ }^{6}$ Faculty of Medicine, University of Ljubljana, Ljubljana, Slovenia; ${ }^{7}$ Cermes3 (Inserm U988 UMR CNRS 8211 EHESS), Paris Descartes University, Paris, France; ${ }^{8}$ European AIDS Treatment Group, Brussels, Belgium; ${ }^{9} \mathrm{~A}-\mathrm{Clinic}$ Foundation, Helsinki, Finland; ${ }^{10}$ European Liver Patients' Association, Brussels, Belgium

\section{COMPETING INTERESTS}

The authors declare that they have no competing interests.

\section{AUTHORS' CONTRIBUTIONS}

JVL was the Hep-CORE study's principal investigator. JVL, SRS and KSH drafted the article with input from the co-authors. KSH also served as the HepCORE study coordinator and SRS as the data manager. MH, GH, MM, MJR, JT, KS and TR were part of the Hep-CORE study group and contributed to the development of the original study instrument as well as providing input on the article. All authors reviewed the full draft of the article and approved the final version for submission.

\section{ACKNOWLEDGEMENTS}

The authors thank the IT Department at CHIP, Rigshospitalet, University of Copenhagen, for its support with the Research Electronic Data Capture (REDCap) survey platform.

\section{FUNDING}

The Hep-CORE study was financed by the European Liver Patients' Association with support from unrestricted grants by AbbVie Inc., Gilead Sciences Inc., and MSD.

\section{REFERENCES}

1. Stanaway JD, Flaxman AD, Naghavi M, Fitzmaurice C, Vos T, Abubakar I, et al. The global burden of viral hepatitis from 1990 to 2013: findings from the Global Burden of Disease Study 2013. Lancet. 2016;388(10049):1081-8.

2. World Health Organization. Global health sector strategy on viral hepatitis, 2016-2021: towards ending viral hepatitis [Internet]. 2016. [cited 9 Jan 2018]. Available from: http://apps.who.int/iris/bitstream/10665/246177/1/WHO-HIV2016.06-eng.pdf?ua=1.
3. GBD 2015 Mortality and Causes of Death Collaborators. Global, regional, and national life expectancy, all-cause mortality, and cause-specific mortality for 249 causes of death, 1980-2015: a systematic analysis for the Global Burden of Disease Study 2015. Lancet. 2016;388(10053):1459-544.

4. Perz JF, Armstrong GL, Farrington LA, Hutin YJ, Bell BP. The contributions of hepatitis $B$ virus and hepatitis $C$ virus infections to cirrhosis and primary liver cancer worldwide. J Hepatol. 2006;45(4):529-38.

5. Global Burden of Disease Cancer Collaboration, Fitzmaurice C, Dicker D, Pain A, Hamavid H, Moradi-Lakeh M, Maclntyre MF, et al. The Global Burden of Cancer 2013. JAMA Oncol. 2015;1(4):505-27.

6. Schweitzer A, Horn J, Mikolajczyk RT, Krause G, Ott JJ. Estimations of worldwide prevalence of chronic hepatitis B virus infection: a systematic review of data published between 1965 and 2013. Lancet. 2015;386 (10003):1546-55.

7. Hope VD, Eramova I, Capurro D, Donoghoe MC. Prevalence and estimation of hepatitis B and C infections in the WHO European Region: a review of data focusing on the countries outside the European Union and the European Free Trade Association. Epidemiol Infect. 2014;142(02):270-86.

8. World Health Organization Regional Office for Europe. Action plan for the health sector response to viral hepatitis in the WHO European Region - DRAFT [Internet]. 2016. [cited 9 Jan 2018]. Available from: http://www.euro.who.int/_da ta/assets/pdf_file/0017/318320/European-action-plan-HS-viral-hepatitis.pdf?ua=1 9. Chan DPC, Sun H-Y, Wong HTH, Lee S-S, Hung C-C. Sexually acquired hepatitis C virus infection: a review. Int J Infect Dis. 2016:49:47-58.

10. Lanini S, Easterbrook PJ, Zumla A, Ippolito G. Hepatitis C: global epidemiology and strategies for control. Clin Microbiol Infect. 2016;22(10):833-8.

11. Lazarus JV, Safreed-Harmon K, Maticic M. HMAP, World Hepatitis Day and the bigger health systems picture. Hepatol Med Pol. 2016;2:4.

12. The Lancet. Eliminating viral hepatitis: time to match visions with action. Lancet. 2017;11(390):2121.

13. Sixty-seventh World Health Assembly. WHA67.6 Hepatitis. [Internet]. 2014. [cited 9 Jan 2018]. Available from: http://apps.who.int/gb/ebwha/pdf_files/ WHA67/A67_R6-en.pdf

14. European Liver Patients' Association. Hepatitis B and C: an action plan for saving lives in Europe. 2015.

15. United Nations. Transforming our world: the 2030 Agenda for Sustainable Development. New York: United Nations; 2015. [cited 9 Jan 2018]. Available from: https://sustainabledevelopment.un.org/post2015/transformingourworld 16. World Health Organization. Global policy report on the prevention and control of viral hepatitis in WHO Member States. 2013. [cited 9 Jan 2018]. Available from: http://apps.who.int/iris/bitstream/10665/85397/1/9789241564632_eng.pdf

17. World Hepatitis Alliance. Global community hepatitis policy report. 2014 [cited 9 Jan 2018]. Available from: http://www.worldhepatitisalliance.org/sites/ default/files/resources/documents/Community policy report.pdf

18. Saxena S, Lora A, van Ommeren M, Barrett T, Morris J, Saraceno B. WHO's Assessment Instrument for Mental Health Systems: collecting essential information for policy and service delivery. Psychiatr Serv. 2007;58(6):816-21.

19. Swinburn B, Vandevijvere S, Kraak V, Sacks G, Snowdon W, Hawkes C, et al. Monitoring and benchmarking government policies and actions to improve the healthiness of food environments: a proposed Government Healthy Food Environment Policy Index. Obes Rev. 2013;14: Suppl 1:24-37.

20. UNAIDS. Global AIDS monitoring 2017: indicators for monitoring the 2016 United Nations Political Declaration on HIV and AIDS. 2016 [cited 9 Jan 2018]. Available from: http://www.unaids.org/sites/default/files/media_asset/2017Global-AIDS-Monitoring_en.pdf

21. Harris PA, Taylor R, Thielke R, Payne J, Gonzalez N, Conde JG. Research electronic data capture (REDCap) - A metadata-driven methodology and workflow process for providing translational research informatics support. J Biomed Inform. 2009:42(2):377-81.

22. European Liver Patients' Association. The 2016 Hep-CORE report: monitoring the implementation of hepatitis B and C policy recommendations in Europe. 2017. [cited 9 Jan 2018]. Available from: https://www.elpa-info.org/project/hepcore-study

23. World Health Organization. Global hepatitis report 2017. [cited 9 Jan 2018]. Available from: http://apps.who.int/iris/bitstream/10665/255016/1/97892415654 55-eng.pdf?ua=1

24. Zhou K, Fitzpatrick T, Walsh N, Kim JY, Chou R, Lackey M, et al. Interventions to optimise the care continuum for chronic viral hepatitis: a systematic review and meta-analyses. Lancet Infect Dis. 2016;16(12):1409-22.

25. Nosyk B, Zang S, Min JE, Krebs E, Lima VD, Milloy MJ, et al. The relative impacts of ART and harm reduction on HIV incidence in British Columbia. Paper presented at: Conference on Retroviruses and Opportunistic Infections; 2017 Feb 13-16; Seattle, WA. 
26. WHO. UNODC, UNAIDS technical guide for countries to set targets for universal access to HIV prevention, treatment and care for injecting drug users - 2012 revision. Geneva: World Health Organization; 2012.

27. Marshall AD, Cunningham EB, Nielsen S, Aghemo A, Alho H, Backmund M, et al. Restrictions for reimbursement of interferon-free direct-acting antiviral drugs for HCV infection in Europe. Lancet Gastroenterol Hepatol. 2017;66: S95-332. Epub 2017 Oct 3.

28. European Association for the Study of the Liver. EASL recommendations on treatment of hepatitis C 2016. J Hepatol. 2017;66(1):153-94

29. EASL Recommendations for Treatment of Hepatitis C 2016 Panel. Electronic address: easloffice@easloffice.euReply to: "Contradictory advice for people who inject drugs in the 2016 EASL Recommendations on Treatment of Hepatitis C". J Hepatol. 2017;66(5):1103.

30. World Health Organization. Guidelines for the screening, care and treatment of persons with hepatitis C infection: updated version. 2016 [cited 31 Jan 2017]. Available from: http://apps.who.int/iris/bitstream/10665/205035/1/ 9789241549615_eng.pdf?ua=1

31. Grebely J, Dore GJ, Morin S, Rockstroh JK, Klein MB. Elimination of HCV as a public health concern among people who inject drugs by 2030 - What wil it take to get there? J Int AIDS Soc. 2017;20(1):22146.

32. Torres MA, Gruskin S, Buse K, Erkkola T, Bendaud V, Alfvén T. Monitoring HIV-related laws and policies: lessons for AIDS and global health in agenda 2030. AIDS Behav. 2017;21:51-61.
33. Peersman G, Ferguson L, Torres MA, Smith S, Gruskin S. Increasing civil society participation in the national HIV response: the role of UNGASS reporting. J Acquir Immune Defic Syndr. 2009;52 Suppl 2:S97-103.

34. World Health Organization. Monitoring and evaluation for viral hepatitis B and C: recommended indicators and framework. 2016. [cited 9 Jan 2018]. Available from: http://apps.who.int/iris/bitstream/10665/204790/1/9789241510288_eng. pdf?ua=1

\section{SUPPORTING INFORMATION}

Additional Supporting Information may be found in the online version of this article:

Additional File 1. Hep-CORE 2016 survey: monitoring the implementation of hepatitis B and C policy recommendations in Europe.

Additional File 2. Hep-CORE 2017 survey.

Additional File 3. Detailed comparative data on national coordination, monitoring, prevention, screening and treatment for Hep-CORE 2016 and 2017 ( $N=25$ countries). 


\title{
Approaches for simplified HCV diagnostic algorithms
}

\author{
Slim Fourati ${ }^{1 \S}$, Jordan J Feld ${ }^{2}$, Stéphane Chevaliez ${ }^{1}$ and Niklas Luhmann ${ }^{3}$ \\ ${ }^{5}$ Corresponding author: Slim Fourati, Department of Virology, Henri Mondor Hospital, National Reference Center for Viral Hepatitis B, C and delta D, INSERM U955, \\ 51 avenue du Maréchal de Lattre de Tassigny, Créteil, France. Tel: +33 1451781 45. (slim.fourati@aphp.fr)
}

\begin{abstract}
Introduction: In the light of the advances in HCV antiviral therapy, global control of HCV infection becomes feasible but depends on the capacity of countries to identify infected people and to offer them treatment. To achieve the WHO goal which targets a diagnosis rate of $90 \%$ by 2030 , simplification of screening and diagnosis will be crucial.

Methods: Published literature, unpublished data and expert consensus were used to determine key parameters, including point-of-care, rapid diagnostic testing, screening, the use of HCV core Ag and dried blood spots; starting from 2008 until November 2017. In addition, a manual search was undertaken to detect relevant papers or websites related to specific data from countries which underwent or are planning a programme of HCV elimination.

Results: Several strategies have been developed and evaluated these last years to simplify and facilitate access to screening and diagnosis, the development of reliable HCV core antigen tests and new nucleic acid amplification technologies for use in decentralized settings. In high prevalence settings, a one-step screening and diagnosis strategy could simplify diagnostic algorithms provided the cost is reduced. Finally, genotyping may no longer be required in the context of availability of pangenotypic antiviral therapy.

Conclusions: Despite relevant advances in HCV screening and diagnosis, the overall diagnosis package is still too expensive today and efforts must be made to allow generalized implementation of reliable tests in low and middle income countries. These efforts will be key factors to foster a real public health approach to HCV elimination.
\end{abstract}

Keywords: HCV; point-of-care; rapid diagnostic test; screening; diagnosis

Received 30 January 2017; Accepted 24 December 2017; Published 9 April 2018

Copyright (C 2018 The Authors. Journal of the International AIDS Society published by John Wiley \& sons Ltd on behalf of the International AIDS Society. This is an open access article under the terms of the Creative Commons Attribution License, which permits use, distribution and reproduction in any medium, provided the original work is properly cited.

\section{1 | INTRODUCTION}

Globally, more than 350000 HCV-infected individuals die each year from HCV, predominantly as result of decompensation of liver cirrhosis or hepatocellular carcinoma [1]. Because chronic hepatitis $\mathrm{C}$ is often asymptomatic until advanced liver disease develops in many countries, a majority of infected persons are unaware of their infection [2]. Today, in contrast to HIV, a generalized systematic approach to HCV testing has not been developed and adopted worldwide. Only national initiatives have been introduced. For instance, the Centers for Disease Control and Prevention (CDC) in the United States initially recommended serology testing in individuals with an identifiable risk factor for $\mathrm{HCV}$ infection [3] and has recently extended the indication of anti-HCV antibody screening to all individuals born between 1945 and 1965, the so-called "baby-boomers"[4]. The European Centre for Disease Prevention and Control (ECDC) plans to issue guidance for reducing the transmission of HCV among vulnerable groups, and especially people who inject drugs (PWID), migrants and prisoners [5]. National screening policies are being implemented across Europe. In
France, healthcare professionals were recommended to offer hepatitis C screening to specified at-risk patient groups, including haemodialysis patients, patients with a history of blood transfusion before 1991, individuals who either injected or sniffed drugs, persons with a history of incarceration, healthcare professionals after occupational exposure to potentially infected blood, persons having unprotected sex with multiple partners, and persons living with an HCV-positive individual [6]. These measures led to the identification of over $70 \%$ of infected patients in the country. More recently, a report from the French Minister of Health recommended systematic screening of men aged 18 to 60 years and pregnant women at the first prenatal visit, in order to diagnose the remaining 30\%, provide therapy and control HCV infection over the next 10 years [7]. Finally, in its recent guidelines for low- to middle-income countries, the World Health Organization (WHO) recommended that HCV and HBV serology testing would be offered to individuals who are part of a population with high prevalence or have a history of risk exposure or behaviour.

Overall, the diagnostic rates in the general population are still low, even in countries that adopted routine, population- 
based HCV screening as in France [8-12] A recent study assessing the prevalence of $\mathrm{HCV}$ in the EU estimated the number of viremic HCV infections in 2015 to be 3 238000 while only an estimated 1180000 (95\% UI: 1 003000 to 1357 000) individuals having already been diagnosed (36.4\%) [13]. The diagnostic rates can be as low as 31\% in Czech Republic, 33\% in Portugal and 16\% in Turkey [14] and much lower in low-to-middle income countries (LMICS) [15]. In the US, the diagnosis rate is estimated around 50\% [16].

Barriers to large-scale screening and diagnosis in the past can be explained, at least in part, by the complexity of algorithms, the costs of the required tests, the absence of reliable alternative tests to classical serological and molecular assays (such as point of care tests), the complexity of ontreatment monitoring with ribavirin and interferon, the cost of treatment, and the limited efficacy of previous treatment regimens. Nowadays, the advent of highly effective direct antiviral agents (DAAs) and the availability of generic versions of these agents have changed the paradigm for the management of $\mathrm{HCV}$ infection. With the excellent safety and tolerability and high cure rates of DAAs (>95\%), the major remaining barrier to treatment is the under-diagnosis of $\mathrm{HCV}$ and limited access to treatment in the diagnosed population. DAA prices are starting to fall due to innovative approaches, to negotiations with industry, as well as continued development of new agents bringing competition to the marketplace.

Current screening of $\mathrm{HCV}$ infection is based on anti-HCV antibody detection using a third-generation enzyme immunoassay (EIA). Third-generation EIA use a multiantigen format including antigens from the core, NS3, NS4 and NS5 regions; these tests show excellent sensitivity and specificity (>99\%) and are considered reference standards to detect anti-HCV antibodies [17,18]. Antibody detection serves only as a screening tool because, it is unable to identify individuals who have an active infection from those who have a resolved infection and are no longer viremic. The anti-HCV antibody detection should then be followed by HCV RNA determination using nucleic acid amplification technologies (NAAT) and completed by HCV genotyping that is required for treatment decision-making [19-21]. However, such a complex set of diagnostic test is not reachable to people who have limited access to the health system (high-income countries - PWID, people in prisons and other closed settings, sex workers and migrants) or in countries where the health system has poor infrastructure for testing (LMICs). In recent years, new tools have been developed to simplify screening, diagnosis and on-treatment monitoring of $\mathrm{HCV}$. These tests include point-of-care (POC) tests [immunological POCT tests with the rapid diagnostic test (RDT) and the non- immunological POC tests based on nucleic acid detection and quantification] and serological assays that detect and quantify $\mathrm{HCV}$ core antigen ( $\mathrm{HCV} \mathrm{CAg}$ ) as an alternative to HCV RNA detection and quantification [22-24]. In addition, the use of dried blood spot (DBS) that allow collecting blood on filter paper is a promising intervention to promote uptake of hepatitis $\mathrm{C}$ testing and linkage to care.

The primary goals of simplifying HCV screening and management are to better identify infected individuals, increase rates of retention and linkage to care and treatment, reduce the costs of diagnosis for patients and the healthcare system with the ultimate goal of reducing viral transmission at a population level, and progression of liver disease and hepatitis-related mortality at an individual level. Dynamic HCV transmission models demonstrate that screening and treatment of HCV-infected individuals in high prevalence settings can reduce the incidence of $\mathrm{HCV}$ by reducing $\mathrm{HCV}$ transmission (termed "cure as prevention") [25-27]. The first global health sector strategy on viral hepatitis that was adopted by $\mathrm{WHO}$ in May 2016 calls for a 90\% diagnosis rate for the year 2030 globally [28] a goal that is unlikely to be achieved unless the screening and diagnostic algorithms for $\mathrm{HCV}$ can be markedly simplified in the near future [29].

The aim of this review is to provide a comprehensive overview of new simplified approaches for screening, diagnosis and monitoring HCV infection within different country-specific settings and to describe key promising tools in future diagnostics.

\section{METHODS}

Published literature, unpublished data and expert consensus were used to determine key parameters consisting of the following terms: sample type (oral fluid, fingerstick, venous blood), point-of-care, rapid diagnostic testing, screening, the use of $\mathrm{HCV}$ cAg and dried blood spots. In addition, a manual search was undertaken to detect relevant papers or websites related to specific data from countries, which planned or are planning a programme for HCV elimination. The literature search was limited to English language, available from 2008 until November 2017.

The study population was analysed in each study (general population or high risk population). The high risk population groups include men who have sex with men, sex workers, PWID and prisoners. Studies that only reported sensitivity or specificity, or those that only used reference assays for positive samples were excluded from the review.

\section{3 | PART 1 - SIMPLIFIED APPROACHES FOR SCREENING HCV}

With the emergence of highly efficacious antiviral treatment, the possibility of curing the vast majority of patients is now a realistic goal [29]. To achieve all required steps in the care cascade, there is a need to increase community awareness of $\mathrm{HCV}$ and to simplify strategies for HCV screening. Until recently, most screening for $\mathrm{HCV}$ has been done within medical settings and relied on rather centralized laboratory structures, which can facilitate the patients' referral to care; but such screening is obviously not sufficient as evidenced by the low screening rates in most countries [15], even those with highly effective healthcare systems. A recent modelling study of $\mathrm{HCV}$ disease burden in the Europe [13] estimated that screening needs to expand from diagnosis of 88800 new cases annually in 2015 in Europe to 180,000 by 2025 to achieve the WHO target.

Much of the challenge lies in the fact that many populations with a high prevalence of $\mathrm{HCV}$, such as people who 
inject drugs (PWID), sex workers, migrants, those with mental health issues and incarcerated individuals often have reduced access to care in traditional medical settings for many reasons. As such, even if screening occurs, linkage to and retention in care is often limited, greatly reducing the overall impact of screening efforts. In LMICs, the situation is compounded by lack of access to high quality medical facilities, particularly for non-acute medical issues. As such, decentralized rapid test-based screening will be crucial to improve screening and linkage in both high and low/middle income countries.

\subsection{Screening access in difficult-to-reach population}

Facilitating access to screening can be achieved by improving serological tests in terms of rapidity and simplicity of performance such as using easy-to-access samples like fingerstick capillary whole blood or oral fluid. Simpler tests are more appealing to those being tested and potentially allow testing to be done by less skilled individuals, greatly increasing testing capacity both in numbers and the locations in which it can be performed. Rapid diagnostic tests (RDTs) have been already been developed for HCV antibody screening, with significant advantages over classical enzyme immunoassays (EIA).

Technically, classical enzyme immunoassays (EIA) require laboratory infrastructure and expertise in their operation. In contrast, RDTs do not require investment in laboratory equipment with minimal maintenance costs and reagents. Therefore, RDTs are suited for decentralized settings to reach individuals at highest risk for $\mathrm{HCV}$ who may remain outside the traditional medical system. To be acceptable for screening, RDTs need to meet the high standard of traditional testing tools in terms of analytical performance for accuracy, reproducibility, sensitivity and specificity and in terms of clinical performances. Clinical performances of individual tests are heterogeneous and vary widely $[30,31]$. Comparisons have shown significant variability depending on the manufacturer, the sample type (i.e. fingerstick whole blood, oral fluid etc.) and pre-analytical conditions (preservation conditions [32]). For example, the clinical sensitivity for the OraQuick ${ }^{\circledR}$ HCV rapid antibody test (OraSure Technologies, PA) was excellent in finger stick whole blood (99.4\%) as well as in oral fluid (97.6\%) while the Labmen HCV test (Turklab, Izmir, Turkey) showed poor sensitivity in fingerstick whole blood (63.1\%) [33]. In addition, all tests showed better positive and negative predictive values in studies that were conducted in developed countries than in developing countries [34] partly explained by variation in disease prevalence of the targeted population. Therefore, caution must be paid regarding poor-quality test kits and reagents and independent studies must be conducted for "real-life conditions" to ensure that the individual RDT approaches work in the specific setting where they will be used. As with standard EIA tests, WHO has taken leadership to evaluate new RDTs and to date have pre-qualified two RDTs that have shown excellent clinical sensitivity and specificity compared to standard EIA assays (i.e. OraQuick HCV Rapid Antibody Test Kit and SD Bioline HCV).

\subsection{Screening access in low-and middle income settings}

In LMICs, the use of classical serological enzyme immunoassays (EIA) for screening may be limited for many reasons including poor laboratory infrastructure, insufficient staff and/ or insufficiently trained staff, and poor-quality management systems for relaying results, all of which hamper the access to accurate and timely screening. In these contexts, point-of-care RDTs appear promising [33]. Initiatives should be taken to decentralize testing and to improve the retention of patients both before and after testing.

Some countries (e.g. Georgia, Egypt) have already engaged partners to develop an efficacious prevention and control plan, which has led to an improved access to diagnostics and treatment for HCV-infected individuals with severe disease. In Georgia, an estimated $5.4 \%$ of the adult population (approximately 150,000 persons) has chronic HCV infection, and most of them were unaware of their infection in 2015 (Georgia Ministry of Labour, Health, and Social Affairs, 2016) [35]. Georgia initiated on the world's first programme to eliminate $\mathrm{HCV}$, defined as a 90\% reduction in HCV prevalence by 2020 $[36,37]$. Control plans include ongoing HCV screening programs since 2015 provided at various settings at no cost (e.g. blood donors, pregnant women, hospitalized patient, PWID...). Persons who screen positive for HCV antibody are referred to the treatment programme for confirmation of chronic $\mathrm{HCV}$; however, unlike initial screening, HCV RNA measurement is not free of charge. Offering free HCV confirmatory testing, support campaigns to expand public awareness will be crucial to achieve the goal of HCV elimination in the country. Information systems capable of linking screening and treatment data are being developed to improve efficiencies.

In Egypt, where the prevalence of hepatitis C virus (HCV) infection is the highest in the world [38], the immediate plans are to focus on treating HCV patients with liver cirrhosis identified in the past few years, followed by screening and treatment programs for high at-risk population. The last stage will include national screening and treatment of patients from the general population.

As each region/country needs to plan its own approach by implementing adequate $\mathrm{HCV}$ testing, the experience from those countries who have taken the first step towards eliminating HCV can help pave the way for other countries experiencing high rates of $\mathrm{HCV}$ infection to undertake similar initiatives, and help curb the global epidemic of viral hepatitis.

\subsection{Use of dried blood spot}

Dried blood spot sampling is an interesting alternative collection method to collect whole blood specimens (either by capillary fingerstick or by venipuncture). The sample is easily transferred onto filter paper and can then be easily transported to a centralized laboratory where testing can take place. The two main advantages of this sample type which can facilitate the expanded access to screening and diagnosis is (i) the option to use fingerstick whole blood and (ii) the stability of the specimen allowing for simple transport (even by regular mail) without the need for an intact cold chain. Once in the central laboratory, DBS samples can be stored long-term at $-20^{\circ}$ or $-80^{\circ} \mathrm{C}$. Once ready for testing, the sample is eluted 
off the filter paper using an appropriate buffer and the eluate can then be used in the same testing systems used for serum or plasma. One other major advantage of DBS is that multiple spots can be taken at once allowing for reflex HCV RNA testing on a second (or third) spot if the initial spot is positive for $\mathrm{HCV}$ antibodies thus avoiding the need to bring individuals back for confirmatory HCV RNA testing, which has consistently been shown to be a major drop-off in the cascade of care of most settings. DBS is particularly attractive for difficult-to-reach populations. Because phlebotomy is not required, testing can be done by peer workers with limited training and venous access, often a challenge for PWID, is less of a concern. Recent studies have confirmed the improved acceptability of DBS over standard testing approaches [39]. The actual testing from DBS samples uses traditional EIA approaches and as such a centralized experienced laboratory is required to process the specimen, however the ease of transport limits the need for multiple central laboratories.

The performance for detection of anti-HCV antibodies in DBS specimens compared to plasma or serum specimens has shown excellent results with sensitivity and specificity generally over 95\% [40]. HCV RNA detection is somewhat less reliable, particularly at low viral titres because of the lower volume of sample acquired after elution off the DBS. A recent study [40] estimated that HCV RNA levels in whole-blood specimens from DBS were lower by $>1.5 \mathrm{log} \mathrm{IU} / \mathrm{ml}$ on average than those in serum specimens; however, HCV RNA can be detected in almost all DBS. Depending on the NAAT used, the limit of detection of HCV RNA from DBS has been estimated between $58 \mathrm{lU} / \mathrm{ml}$ to more than $250 \mathrm{IU} / \mathrm{ml}[41,42]$. While the absolute amount of HCV RNA should not be considered when quantification is performed on DBS, the qualitative HCV RNA results from DBS is reliable as long as $\mathrm{HCV}$ RNA levels are high as it is the case in $>95 \%$ of patients at diagnosis and at relapse.

The main disadvantage of DBS is that the existing commercial assays have not been validated so far or received regulatory approval with this method of sample collection and transport. Some studies published detailed protocols on how to collect and analyze DBS [43]. However, manufacturers have not yet provided specific instructions on how to use their assays with DBS (including processing methods, pre analytical treatment and cutoffs of interpretation) even if no claim for regulatory approval is made until today, which make quality control challenging. There is an urgent need for development of standardized protocols by manufacturers, as well as the elaboration of large studies on use of DBS conducted in different settings and with varying storage conditions (including areas with extreme wet conditions for RNA assessments).

\subsection{Rapid multianalyte testing for other pathogens (HIV, HBV and syphilis)}

Multianalyte testing refers to testing in the same specimen the detection of $\mathrm{HCV}$ along with other pathogens, for example, HIV, syphilis and/or HBV. Such an approach has several obvious advantages including the requirement for a lower specimen volume, fewer fingersticks if capillary whole blood is used, less time required than a series of tests and potentially other cost efficiencies. This approach is promising, but data on clinical sensitivity and specificity of the assays are still required as well as the evaluation of their impact on patient management $[44,45]$. The multianalyte approach has been touted primarily for screening of acute illnesses to help in outbreak settings but may have advantages for the screening of chronic diseases as well.

\section{4 | PART 2 - SIMPLIFIED APPROACHES FOR DIAGNOSIS}

The complexity of current algorithms for HCV diagnosis limits the ability to advance large-scale screening programmes. Even if screening can be done, limited capacity to specialty care is often an additional barrier to care. Simplifying strategies of diagnosis/management of HCV infection will enable the potential transfer of treatment care outside of classical specialty care (i.e. infectious diseases and hepatology clinics) for most patients, likely all but those with advanced liver disease. In addition, in LMICs, lack of simple and affordable HCV diagnostic solutions represents a restraint to ensure broad access to care, as current diagnostic tools are insufficiently developed. Innovations in technologies for point-of-care testing (using nanotechnologies, microfluidics, biosensors and/or synthetic biology) have led to the creation of chip-sized laboratory systems that could be helpful in the future [46]. While there has been huge focus on the cost of antiviral drugs, very little focus has been put on the cost of diagnostics. It is important to note that in many countries (e.g. Kenya), diagnostic tools (including monitoring and testing for cure) might be even more expensive than IFN-free antiviral therapy. In Kenya, the estimated cost of a 3-month treatment regimen with the generic drug of sofosbuvir will be around US\$260 or less [47] while no efforts are made on reducing NAAT costs.

\subsection{Tools for simplified diagnosis strategies}

Probably the three main tools that should bring simplification to diagnosis of $\mathrm{HCV}$ are (i) the availability of reliable $\mathrm{HCV}$ cAg tests, (ii) the availability of new POC tests based on nucleic acid detection and quantification for use in decentralized settings; both of these assays could be used as one-step procedure in diagnosing chronic HCV infection (in high prevalent population if the tests become less expensive) and (iii) the potential to skip the determination of the viral genotype in the context of availability of pangenotypic all oral DAA therapy.

\subsubsection{HCV Core Antigen test for Point of care testing}

The HCV core antigen test ( $\mathrm{HCV}$ cAg) targets the HCV nucleocapsid peptides 22 (p22), released from infected cells into plasma. HCV cAg is detected early and during the natural course of HCV infection as a surrogate marker of viral replication (Table 1) [23,48]. Nowadays, several assays are commercially available for specific detection of HCV cAg [49]. The evaluation of these assays compared to HCV RNA was recently presented in a meta-analysis [49] with Abbott HCV cAg assay and the ORTHO ELISA-Ag test showing the highest sensitivity (up to $93.4 \%$ and $93.2 \%$ respectively), with very 
Table 1. Summary of the main characteristics of virological tools used for simplified diagnosis strategies.

\begin{tabular}{|c|c|c|c|c|}
\hline $\begin{array}{l}\text { Analytical } \\
\text { performances }\end{array}$ & $\begin{array}{l}\text { Excellent sensitivity } \\
<25 \mathrm{IU} / \mathrm{ml}\end{array}$ & $\begin{array}{l}\text { Should only be used as a } \\
\text { qualitative result }\end{array}$ & $\begin{array}{l}\text { Expected to be excellent. } \\
\text { Need to be determined in } \\
\text { real life settings }\end{array}$ & $\begin{array}{l}\text { Equivalent to } 500 \text { to } \\
3000 \mathrm{IU} / \mathrm{ml} \text {, according to } \\
\text { the } \mathrm{HCV} \text { genotype }\end{array}$ \\
\hline Target population & $\begin{array}{l}\text { Centralized settings" } \\
\text { High income countries }\end{array}$ & $\begin{array}{l}\text { Lack of access to sites or } \\
\text { nearby laboratory } \\
\text { facilities for NAAT } \\
\text { Persons with poor } \\
\text { venous access (e.g. in } \\
\text { drug treatment } \\
\text { programs, prisons). }\end{array}$ & $\begin{array}{l}\text { Lack of access to sites or } \\
\text { nearby laboratory facilities } \\
\text { for NAAT } \\
\text { if using fingerstick: Persons } \\
\text { with poor venous access } \\
\text { (e.g. in drug treatment } \\
\text { programs, prisons). }\end{array}$ & $\begin{array}{l}\text { Centralized settings } \\
\text { Low and middle income } \\
\text { countries }\end{array}$ \\
\hline Specimen type & $\begin{array}{l}\text { Serum/plasma requires } \\
\text { venipuncture to obtain } \\
\text { specimen }\end{array}$ & $\begin{array}{l}\text { Fingerstick capillary whole } \\
\text { blood samples }\end{array}$ & $\begin{array}{l}\text { Whole blood samples but } \\
\text { more data are warranted }\end{array}$ & $\begin{array}{l}\text { Serum requires } \\
\text { venipuncture to obtain } \\
\text { specimen. } \\
\text { Whole blood from DBS } \\
\text { but sensitivity is poor }\end{array}$ \\
\hline Time of result & $\begin{array}{l}\text { Time to result: several } \\
\text { hours/days and generally } \\
\text { batched as one run }\end{array}$ & Several days & $<120 \min$ & $<60 \min$ \\
\hline $\begin{array}{l}\text { Laboratory } \\
\text { infrastructure }\end{array}$ & $\begin{array}{l}\text { Requires trained laboratory } \\
\text { technician } \\
\text { Requires laboratory } \\
\text { facilities and equipment }\end{array}$ & $\begin{array}{l}\text { Can be performed in } \\
\text { decentralized settings }\end{array}$ & $\begin{array}{l}\text { Can be performed in } \\
\text { decentralized settings }\end{array}$ & $\begin{array}{l}\text { Requires laboratory } \\
\text { facilities and equipment }\end{array}$ \\
\hline Standardization & & $\begin{array}{l}\text { Need for development of } \\
\text { standardized protocols } \\
\text { by manufacturers }\end{array}$ & & \\
\hline
\end{tabular}

NAAT, nucleic acid amplification technologies; POC, point-of-care; HCV cAg, HCV core antigen.

high specificity (>98\%). In the French ANRS 12336 study [50], the Abbott HCV cAg quantification displayed high performances also in HIV and HBV co-infected patients from Cameroon. Quantitative data are also available with the Abbott HCV cAg assay [23] showing a close correlation between HCV cAg and HCV RNA at viral loads (VL) above $3000 \mathrm{lU} / \mathrm{ml}$. The lower cutoff for the assay corresponds to about 500 to $3000 \mathrm{lU} / \mathrm{ml}$ according to the HCV genotype, which will cover over the vast majority (>95\%) of chronic $\mathrm{HCV}$ infections [51]. The main benefit of using HCV cAg over molecular methods is the cost of testing. In the United Kingdom [52], NAAT cost was evaluated at 108 USD versus 23.4 USD for HCV cAg including kit, staff, and laboratory extras. In an Egyptian study [53], HCV NAAT test cost per individual (including equipment and personnel expenses) was estimated at 141 USD versus 19.8 USD for HCV cAg. A new point of care $\mathrm{HCV}$ cAg Assay (Daktari Diagnostics) is undergoing clinical evaluations; the launch is expected in 2018. Daktari Diagnostics announces the test is likely to cost 10 to 20 USD [54].

Other advantages of HCV cAg over NAAT are the following: serological marker stable at room temperature for 96 hours, short time to obtain (less than 60 minutes) [22]. However, the use of HCV cAg in LMICs still faces the problem of the availability of quite sophisticated laboratory equipment; therefore, point-of-care $\mathrm{HCV}$ CAg, difficult to implement, are still under development.
In summary, HCV cAg represents a reliable HCV diagnosis tool and, being less costly than viral load tests, should facilitate HCV screening and access to care. However, this solution depends on the presence of centralized laboratory machines. In addition, caution must be paid to some limitations of the assay: most studies were conducted in high resource areas within reference laboratories where data for genotypes 4, 5 and 6 are missing [49]. In addition, false negative results can be detected in genotype 3 infected patients, explained by viral polymorphisms failing to detect HCV cAg [55].

\subsubsection{New NAATs for Point of care diagnosis}

Quantitative NAAT is widely used for measuring viral load, identifying those in need of treatment, and to assess treatment response. In the era of short-course, highly effective therapy, there is less need for quantification of HCV RNA for HCV management. Therefore, qualitative assays, in theory less expensive, can replace quantitative NAAT, particularly in LMICs. In addition, new random access NAAT technologies offer potential for POC diagnosis [56,57]. A random access system eliminates the need for batch processing and automates all aspects of nucleic acid testing in a single step. The system integrates sample introduction, nucleic acid extraction, reaction setup, and real-time PCR amplification for the quantitative determination of HCV RNA in human plasma/serum 
specimens. Such a process allows for a rapid response, which is ideal for a single visit diagnosis while using a technology that does not require specific laboratory infrastructure or expertise in its operation. The system is simple enough to be performed reliably by individuals without a background in nucleic-acid diagnostics or virology. Such facilities should be ideal as a two-step strategy after screening with RDTs in places where centralized laboratories are not available and could theoretically enable a one-step diagnosis if price comes down. Until today, approved point-of-care HCV RNA assays require venipuncture $[56,57]$, which may be challenging in settings without access to phlebotomists or among people who inject drugs (PWID), due to poor venous access. The Xpert HCV Viral Load test (Cepheid), a WHO prequalified HCV NAAT test, has been recently shown to accurately detect active infection from fingerstick capillary whole blood samples [39]. Although promising, it is still unclear whether a NAAT assay in a decentralized setting can achieve a price cheap enough to be used as a first-line assay. Cost-effectiveness studies are urgently needed to determine in which settings a one-step versus two-step, with RNA or HCV cAg quantification, laboratory or POC tests would be cost-effective.

\subsection{3 | Skipping HCV genotyping?}

Once diagnosis is confirmed, the current algorithm of $\mathrm{HCV}$ management requires $\mathrm{HCV}$ genotyping before therapy is initiated. However, with the pangenotypic success achieved using next-generation DAAs (e.g. sofosbuvir/velpatasvir, glecaprevir/pibrentasvir) with very high rates of SVR in different clinical conditions (naïve or pretreated patients, with or without liver cirrhosis), pre-genotyping may no longer be required in the future. Whether genotyping can also be skipped when first-generation DAAs (e.g. sofosbuvir/daclatasvir or generics) will be used in LMICs is questionable (at least in cirrhotic patients), as genotype 3 cirrhotic patients need longer duration of treatment and/or the addition or ribavirin when this combination is used [21].

\subsection{Improving HCV testing by a one-sample strategy}

A significant proportion of anti-HCV antibody-positive patients fails to have a confirmatory test in difficult-to-reach populations and are lost to follow-up [58-61]. To avoid this, one strategy consists of testing both anti-HCV antibodies and a confirmatory test (for those with anti-HCV reactive) from the same blood sampling performed on the same day, using a venous blood sample (which requires a centralized laboratory but is already a first step into simplification the cascade of care) or DBS sampling with multiple spots taken (see above "Use of dried blood spot (DBS) specimens for HCV screening").

When DBS sampling is used, HCV RNA NAAT assays are preferred as confirmatory tests over HCV cAg; indeed HCV CAg testing has been shown to possibly have lower sensitivity on DBS compared to serum when only one spot is used [40].

The choice of whether to use DBS sampling for HCV serology or NAAT or both will depend on the healthcare setting and infrastructure, and epidemiological context. Different strategies can be suggested with varying combinations:
1 DBS EIA serology + DBS NAAT (context: No RDTs are available in decentralized settings; difficult-to-reach populations and difficulty in venipuncture);

2 RDT serology + DBS NAAT (context: RDTs are available in decentralized settings but no access to decentralized NAAT)

3 RDT serology + POCT NAAT (context: RDTs and nonimmunological POCTs are available in decentralized settings)

4 EIA serology + plasma/serum-based NAAT (context: high income countries; large hospitals).

An interesting alternative would be a biphasic strategy with first testing anti-HCV antibody (+) patients with $\mathrm{HCV}$ cAg, and reserving NAAT only for those who are anti-HCV antibody (+) but HCV cAg (-). This strategy has been evaluated in a study performed in Toronto (Canada) to determine relapse in HCV infected patients treated with DAAs [62]. In this context, the study showed that the use of HCV cAg could eliminate $>75 \%$ of HCV RNA tests. A recent study [63] further indicates that this biphasic strategy is cost-effective in the context of diagnosing $\mathrm{HCV}$ infection and is feasible in LMICS.

\section{3 | Improving HCV testing by a one-step screening}

To further simplify the diagnosis pathway, the ideal future algorithm would only require one test for both screening and diagnosing $\mathrm{HCV}$. This test is preferably $\mathrm{HCV}$ cAg because of reduced costs or NAAT for HCV RNA (Figure 1) if these assays become affordable and in high prevalence settings, where the strategy should be cost effective. If such $\mathrm{HCV}$ cAg and/or NAAT assays are used at point-of-care settings, this should further improve access to early diagnosis and linkage to care for treatment services, in addition to reducing loss to follow-up.

\section{5 | PART 3 - SIMPLIFIED APPROACHES FOR MONITORING}

The advent of interferon-free DAA therapies has significantly simplified monitoring treatment. In addition to the fact that pangenotypic DAA combinations could eliminate the need for genotyping before starting treatment, there is no further need to monitor viral load during treatment [1] Using new DAAs, the levels of viral load decline no longer correlate with response and the number of virological tests can be reduced to a single post treatment virological test to assess cure (i.e. 12 or 24 weeks post treatment SVR). In this context, a second aspect of simplification is to perform the same test for diagnosis and for monitoring (i.e. either HCV CAg or NAAT for HCV RNA if affordable).

There remains some debate about the ability of $\mathrm{HCV}$ cAg to assess response to DAA treatment. There is emerging data supporting very good performances of the ARCHITECT assay as a test of cure [64]. In a cohort of 181 patients (62\% of whom achieved SVR) [62], HCV cAg was shown to determine SVR with very high accuracy when compared to $\mathrm{HCV}$ RNA in HCV-infected patients receiving DAA 


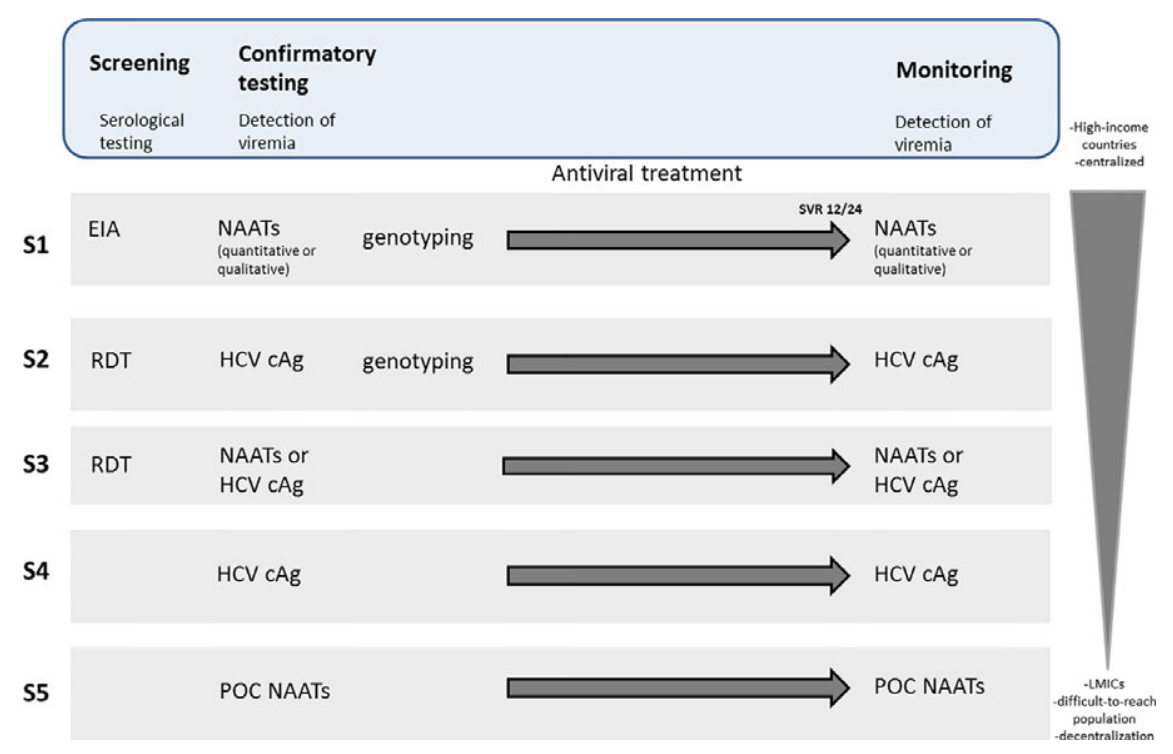

Figure 1. Proposed simplified algorithms using serological and virological tools for HCV screening, diagnosis and treatment follow-up. Several strategies are suggested with varying combinations (S1 to S4). EIA, enzyme immunoassay; RDT, rapid diagnostic test; NAAT, nucleic acid amplification technologies; POC, point-of-care; $\mathrm{HCV}$ cAg, HCV core antigen.

treatment (concordance between $\mathrm{Ag}$ and HCV RNA for determination of SVR was estimated at 97.3\%). Similarly, in a cohort of $411 \mathrm{HCV}$ genotype-1 patients with a pre-treatment $\mathrm{HCV}$ RNA level $>50,000 \mathrm{IU} / \mathrm{ml}$ who received a DAAcontaining regimen [24], concordance between HCV RNA levels and HCV cAg was 99.24\% at follow-up visit 12 weeks after the treatment cessation. Because HCV replication is likely to be higher in patients who relapse late after virological failure, HCV cAg testing might be even more sensitive in detecting treatment failures when performed at W24 post treatment compared to W12 post treatment. However, studies are needed to confirm this strategy. Specificity in antiHCV positive HCV RNA negative samples tested was 100\%. Despite these encouraging results, the clinical performance of HCV cAg to confirm SVR at completion of therapy should be further investigated in particular in specific populations (e.g. HBV/HIV co-infected patients, or infected with $\mathrm{HCV}$ genotypes 4, 5 and 6).

\section{6 | CONCLUSIONS}

Control of HCV will strongly depend on the capacity of countries to identify people who live with chronic hepatitis $C$ and to offer them treatment. Tools for simplified screening and on and post-treatment monitoring will be critical to make such efforts feasible. Currently costs and complexity of diagnostics algorithm are notable and important barriers to screening and treatment monitoring. With the implementation of new treatment regimens, the current pathway for HCV diagnosis can conceivably be simplified from three tests (serology, NAAT and genotyping) to one or two tests if random-access NAAT assays or reliable HCV cAg assays become affordable, particularly in high prevalence settings. A second aspect of simplification is to use the same test for diagnosis and monitoring (one single point at follow-up visit 12 to 24 weeks). Finally, the capacity for decentralization including the use of new randomaccess NAAT for HCV RNA will be crucial to further simplify diagnosis and monitoring. The future challenge will be to implement different diagnostic algorithms in different countries, based on the experience of similar countries who have already taken the first steps towards controlling HCV and explore innovative approaches to reduce the cost of these tests through large-scale projects in different contexts (e.g. HIV or HBV co-infection, difficult-to-reach population).

\section{AUTHORS' AFFILIATIONS}

${ }^{1}$ Department of Virology, Henri Mondor Hospital, National Reference Center for Viral Hepatitis B, C and delta D, INSERMU955, Créteil, France; ${ }^{2}$ Toronto Centre for Liver Disease, Sandra Rotman Centre for Global Health, University of Toronto, Toronto, Canada; ${ }^{3}$ Médecins du Monde France, Paris, France

\section{COMPETING INTERESTS}

SF: scientific consulting from Abbvie, Beckman. JF: grant funding from Abbvie, Abbott, Gilead, Janssen, Merck and Scientific Consulting from Abbvie, Contravir, Gilead and Merck. SC: Grant funding from Gilead, ANRS, Ministry of Health; Scientific Consulting from Abbvie, Gilead, Merck, Abbott Diagnostics, Hologic. $\mathrm{NL}$ : none to declare.

\section{AUTHORS' CONTRIBUTIONS:}

SF and NL wrote the draft of the outline. SF wrote the first draft of the manuscript. JF, SC and NL critically reviewed the manuscript and provided input accordingly.

\section{ACKNOWLEDGEMENTS}

The authors thank the 4th International HIV/Viral Hepatitis Co-Infection Meeting co-chairs Marina Klein (McGill University and IAS Governing Council member, Canada) and Karine Lacombe (Hôpital Saint-Antoine, France) for their invitation to contribute to this supplement.

\section{FUNDING}

None. 


\section{REFERENCES}

1. Abubakar II, Tillmann T, Banerjee A. Global, regional, and national age-sex specific all-cause and cause-specific mortality for 240 causes of death, 19902013: a systematic analysis for the Global Burden of Disease Study 2013. Lancet. 2015;385(9963):117-71.

2. Denniston MM, Klevens RM, McQuillan GM, Jiles RB. Awareness of infection, knowledge of hepatitis $\mathrm{C}$, and medical follow-up among individuals testing positive for hepatitis C: National Health and Nutrition Examination Survey 2001-2008. Hepatology. 2012;55(6):1652-61.

3. Ghany MG, Strader DB, Thomas DL, Seeff LB. Diagnosis, management, and treatment of hepatitis C: an update. Hepatology. 2009;49(4):1335-74.

4. Smith BD, Morgan RL, Beckett GA, Falck-Ytter Y, Holtzman D, Ward JW. Hepatitis C virus testing of persons born during 1945-1965: recommendations from the Centers for Disease Control and Prevention. Ann Intern Med. 2012:157(11):817-22.

5. European Centre for Disease Prevention and Control. Hepatitis C [homepage on the internet]. c2018. Available from https://ecdc.europa.eu/en/hepatitis-c.

6. Association Française pour l'Etude du Foie. Recommandations AFEF sur la prise en charge de l'hépatite virale C [homepage on the internet]. c2017. Available from http://www.afef.asso.fr/ckfinder/userfiles/files/recommandations-textesofficiels/recommandations/RecommandationsAFEFMars2017.pdf.

7. Bottero J, Brouard C, Roudot-Thoraval F, et al. 2014 French guidelines for hepatitis $B$ and $C$ screening: a combined targeted and mass testing strategy of chronic viruses namely HBV, HCV and HIV. Liver Inter. 2016;36(10):1442-9.

8. Easterbrook PJ. Who to test and how to test for chronic hepatitis C infection - 2016 WHO testing guidance for low- and middle-income countries. Hepatol. 2016;65(1 Suppl):S46-S66.

9. Lazarus JV, Sperle I, Spina A, Rockstroh JK. Are the testing needs of key European populations affected by hepatitis $B$ and hepatitis $C$ being addressed? A scoping review of testing studies in Europe. Croat Med J. 2016;57(5):442 56.

10. Bruggmann P, Berg T, Ovrehus AL, et al. Historical epidemiology of hepatitis C virus (HCV) in selected countries. J Viral Hepatitis. 2014;21(Suppl 1):533.

11. Liakina V, Hamid S, Tanaka J, et al. Historical epidemiology of hepatitis C virus (HCV) in select countries - volume 3. J Viral Hepatitis. 2015;22(Suppl 4):4-20.

12. Saraswat $V$, Norris $S$, de Knegt RJ, et al. Historical epidemiology of hepatitis C virus (HCV) in select countries - volume 2. J Viral Hepatitis. 2015;22(Suppl 1):6-25.

13. Collaborators TE. Hepatitis C virus prevalence and level of intervention required to achieve the $\mathrm{WHO}$ targets for elimination in the European Union by 2030: a modelling study. Lancet Gastroenterol Hepatol. 2017;2(5):325-36.

14. Negro F. Epidemiology of hepatitis C in Europe. Dig Liver Dis. 2014;46 (Suppl 5):S158-64.

15. Lemoine M, Nayagam S, Thursz M. Viral hepatitis in resource-limited countries and access to antiviral therapies: current and future challenges. Future Virol. 2013;8(4):371-80.

16. Yehia BR, Schranz AJ, Umscheid CA, Lo Re V III. The treatment cascade for chronic hepatitis $C$ virus infection in the United States: a systematic review and meta-analysis. PLoS ONE. 2014:9(7):e101554.

17. Kamili S, Drobeniuc J, Araujo AC, Hayden TM. Laboratory diagnostics for hepatitis C virus infection. Clin Infect Dis. 2012;55(Suppl 1):S43-8.

18. Colin C, Lanoir D, Touzet S, Meyaud-Kraemer L, Bailly F, Trepo C. Sensitivity and specificity of third-generation hepatitis $C$ virus antibody detection assays: an analysis of the literature. J Viral Hepatitis. 2001;8(2):87-95.

19. Chevaliez S. Virological tools to diagnose and monitor hepatitis $C$ virus infection. Clin Microbiol Infect. 2011;17(2):116-21.

20. Chevaliez S, Rodriguez C, Pawlotsky JM. New virologic tools for management of chronic hepatitis B and C. Gastroenterology 2012; 142(6): 1303-13 e1.

21. EASL. Recommendations on Treatment of Hepatitis C 2016. J Hepatol 2017;66(1):153-94.

22. Chevaliez S, Feld J, Cheng $\mathrm{K}$, et al. Clinical utility of $\mathrm{HCV}$ core antigen detection and quantification in the diagnosis and management of patients with chronic hepatitis $\mathrm{C}$ receiving an all-oral, interferon-free regimen. Antivir Ther 2014 Sep;61(1):145-8.

23. Chevaliez S, Soulier A, Poiteau L, Bouvier-Alias M, Pawlotsky JM. Clinical utility of hepatitis $C$ virus core antigen quantification in patients with chronic hepatitis C. J Clin Virol. 2014;61(1):145-8.

24. Rockstroh JK, Feld JJ, Chevaliez S, et al. HCV core antigen as an alternate test to HCV RNA for assessment of virologic responses to all-oral, interferonfree treatment in HCV genotype 1 infected patients. J Virol Methods. 2017;245:14-8.
25. Martin NK, Vickerman P, Foster GR, Hutchinson SJ, Goldberg DJ, Hickman M. Can antiviral therapy for hepatitis $C$ reduce the prevalence of $\mathrm{HCV}$ among injecting drug user populations? A modeling analysis of its prevention utility. J Hepatol. 2011;54(6):1137-44.

26. Martin NK, Hickman M, Hutchinson SJ, Goldberg DJ, Vickerman P. Combination interventions to prevent HCV transmission among people who inject drugs: modeling the impact of antiviral treatment, needle and syringe programs, and opiate substitution therapy. Clin Infect Dis. 2013;57(Suppl 2):S3945.

27. Grebely J, Matthews GV, Lloyd AR, Dore GJ. Elimination of hepatitis C virus infection among people who inject drugs through treatment as prevention: feasibility and future requirements. Clin Infect Dis. 2013;57(7):1014-20.

28. World Health Organization. Global health sector strategy on viral hepatitis, 2016-2021. Geneva: WHO; 2016. Available from http://apps.who.int/gb/ebwha/ pdf_files/WHA69/A69_32-en.pdf?ua=1.

29. World Health Organisation. Guidelines for the Screening Care and Treatment of Persons with Chronic Hepatitis C Infection: Updated Version. Geneva; 2016.

30. Shivkumar S, Peeling R, Jafari Y, Joseph L, Pant Pai N. Accuracy of rapid and point-of-care screening tests for hepatitis $\mathrm{C}$ : a systematic review and metaanalysis. Ann Intern Med. 2012;157(8):558-66.

31. Khuroo MS, Khuroo NS. Diagnostic accuracy of point-of-care tests for hepatitis C virus infection: a systematic review and meta-analysis. PLoS ONE. 2015;10(3):e0121450.

32. Greenman J, Roberts T, Cohn J, Messac L. Dried blood spot in the genotyping, quantification and storage of HCV RNA: a systematic literature review. J Viral Hepatitis. 2015;22(4):353-61.

33. Chevaliez S, Poiteau L, Rosa I, et al. Prospective assessment of rapid diagnostic tests for the detection of antibodies to hepatitis $C$ virus, a tool for improving access to care. Clin Microbiol Infect. 2016;22:459e1-6.

34. Scalioni Lde P, Cruz HM, de Paula VS, et al. Performance of rapid hepatitis $\mathrm{C}$ virus antibody assays among high- and low-risk populations. J Clin Virol 2014; 60: 200-5.

35. Nasrullah M, Sergeenko D, Gvinjilia L, et al. The role of screening and treatment in national progress toward hepatitis C elimination - Georgia, 2015-2016. MMWR Morb Mortal Wkly Rep. 2017;66(29):773-6.

36. Mitruka K, Tsertsvadze T, Butsashvili M, et al. Launch of a Nationwide Hepatitis C Elimination Program-Georgia, April 2015. MMWR Morb Mortal Wkly Rep. 2015;64(28):753-7.

37. Gvinjilia L, Nasrullah M, Sergeenko D, et al. National Progress Toward Hepatitis C Elimination - Georgia, 2015-2016. MMWR Morb Mortal Wkly Rep. 2016;65(41):1132-5.

38. Kim DD, Hutton DW, Raouf AA, et al. Cost-effectiveness model for hepatitis C screening and treatment: Implications for Egypt and other countries with high prevalence. Global Public Health. 2015;10(3):296-317.

39. Grebely J, Lamoury FMJ, Hajarizadeh B, et al. Evaluation of the Xpert HCV Viral Load point-of-care assay from venepuncture-collected and finger-stick capillary whole-blood samples: a cohort study. Lancet Gastroenterol Hepatol. 2017 Jul;2(7):514-520.

40. Soulier A, Poiteau L, Rosa I, et al. Dried blood spots: a tool to ensure broad access to hepatitis c screening, diagnosis, and treatment monitoring. J Infect Dis. 2016:213(7):1087-95.

41. Marques BLC, do Espirito-Santo MP, Marques VA, et al. Evaluation of dried blood spot samples for hepatitis $C$ virus detection and quantification. J Clin Virol. 2016;82:139-44.

42. Bennett S, Gunson RN, McAllister GE, et al. Detection of hepatitis C virus RNA in dried blood spots. J Clin Virol. 2012;54(2):106-9.

43. Gruner N, Stambouli O, Ross RS. Dried blood spots-preparing and processing for use in immunoassays and in molecular techniques. J Vis Exp. 2015. https://doi.org/10.3791/52619

44. Ming K, Kim J, Biondi MJ, et al. Integrated quantum dot barcode smartphone optical device for wireless multiplexed diagnosis of infected patients. ACS Nano. 2015;9(3):3060-74.

45. Fisher DG, Hess KL, Erlyana E, Reynolds GL, Cummins CA, Alonzo TA. Comparison of rapid point-of-care tests for detection of antibodies to hepatitis C virus. Open Forum Infect Dis 2015; 2: ofv101.

46. Duchesne L, Lacombe K. Innovative technologies for point-of-care testing of viral hepatitis in low-resource and decentralized settings. J Viral Hepatitis. 2017. https://doi.org/10.1111/jvh.12827

47. World Health Organization. Essential medicines and health products: In the lead-up to Paris AIDS conference, WHO prequalifies first generic hepatitis C medicine and first HIV self-test [homepage on internet]. c2017. Available from http://www.who.int/medicines/news/2017/1st generic-hepC 1stHIVself-test-pre qualified/en/. 
48. Bouvier-Alias M, Patel K, Dahari H, et al. Clinical utility of total HCV core antigen quantification: a new indirect marker of HCV replication. Hepatology. 2002;36(1):211-8.

49. Freiman JM, Tran TM, Schumacher SG, et al. Hepatitis C core antigen testing for diagnosis of hepatitis c virus infection: a systematic review and metaanalysis. Ann Intern Med. 2016;165(5):345-55.

50. Duchesne L, Njouom R, Lissock F, et al. HCV Ag quantification as a onestep procedure in diagnosing chronic hepatitis $C$ infection in Cameroon: the ANRS 12336 study. J Int AIDS Soc. 2017;20(1):1-8.

51. Ross RS, Viazov S, Salloum S, Hilgard P, Gerken G, Roggendorf M. Analytical performance characteristics and clinical utility of a novel assay for total hepatitis C virus core antigen quantification. J Clin Microbiol. 2010;48(4):1161-8.

52. Cresswell FV, Fisher M, Hughes DJ, Shaw SG, Homer G, Hassan-Ibrahim MO. Hepatitis $C$ core antigen testing: a reliable, quick, and potentially costeffective alternative to hepatitis $C$ polymerase chain reaction in diagnosing acute hepatitis C virus infection. Clin Infect Dis. 2015;60(2):263-6.

53. Kamal SM, Kassim S, El Gohary E, et al. The accuracy and cost-effectiveness of hepatitis $C$ core antigen assay in the monitoring of anti-viral therapy in patients with chronic hepatitis C genotype 4. Aliment Pharmacol Ther. 2015;42 (3):307-18.

54. Cohn J, Roberts T, Amorosa V, Lemoine M, Hill A. Simplified diagnostic monitoring for hepatitis $\mathrm{C}$, in the new era of direct-acting antiviral treatment. Curr Opin HIV AIDS. 2015;10(5):369-73.

55. Nguyen LT, Dunford L, Freitas I, et al. Hepatitis C Virus Core Mutations Associated with False-Negative Serological Results for Genotype 3a Core Antigen. J Clin Microbiol. 2015;53(8):2697-700.
56. McHugh MP, Wu AHB, Chevaliez S, Pawlotsky JM, Hallin M, Templeton KE. Multicenter evaluation of the cepheid Xpert hepatitis C virus viral load assay. J Clin Microbiol. 2017;55(5):1550-6.

57. Gupta E, Agarwala P, Kumar G, Maiwall R, Sarin SK. Point -of -care testing (POCT) in molecular diagnostics: Performance evaluation of GeneXpert HCV RNA test in diagnosing and monitoring of HCV infection. J Clin Virol. 2017;88:46-51.

58. Patel RC, Vellozzi C, Smith BD. Results of hepatitis c birth-cohort testing and linkage to care in selected U.S. sites, 2012-2014. Public Health Rep. 2016;131(Suppl 2):12-9.

59. Rongey CA, Kanwal F, Hoang T, Gifford AL, Asch SM. Viral RNA testing in hepatitis C antibody-positive veterans. Am J Prev Med. 2009;36(3):235-8.

60. Mera J, Vellozzi C, Hariri S, et al. Identification and clinical management of persons with chronic hepatitis C virus infection - Cherokee Nation, 2012-2015. MMWR Morb Mortal Wkly Rep. 2016;65(18):461-6.

61. Janjua NZ, Kuo M, Yu A, et al. The population level cascade of care for Hepatitis C in British Columbia, Canada: the bc hepatitis testers cohort (BCHTC). EBioMedicine. 2016;12:189-95.

62. Tilborg MV, Almarzooqi S, Maan R, et al. Can HCV core antigen replace HCV RNA testing in the era of directacting antivirals? EASL. 2017;66:S496.

63. Julicher P, Galli C. Identifying cost-effective screening algorithms for active hepatitis C virus infections in a high prevalence setting. J Med Econ. 2017;110. https://doi.org/10.1080/13696998.2017.1369983

64. Lamoury FMJ, Soker A, Martinez D, et al. Hepatitis C virus core antigen: A simplified treatment monitoring tool, including for post-treatment relapse. J Clin Virol. 2017;92:32-8. 


\title{
Linkage and retention in HCV care for HIV-infected populations: early data from the DAA era
}

\author{
Rachel Sacks-Davis ${ }^{1,2 \S}$, Joseph S Doyle ${ }^{1,3}$, Andri Rauch ${ }^{4}$, Charles Beguelin ${ }^{4}$, Alisa E Pedrana ${ }^{1,5}$, Gail $\bigvee$ Matthews $^{6}$, \\ Maria Prins ${ }^{7}$, Marc van der Valk ${ }^{8}$, Marina B Klein ${ }^{9}$, Sahar Saeed ${ }^{10}$, Karine Lacombe ${ }^{11}$, Nikoloz Chkhartishvili ${ }^{12}$, \\ Frederick L Altice ${ }^{13,14,15}$ and Margaret E Hellard ${ }^{1,5}$ \\ ${ }^{\S}$ Corresponding author: Rachel Sacks-Davis, 85 Commercial Rd, Melbourne, 3004, Australia. Tel: +03 9282 2287. (rachel.sacks-davis@burnet.edu.au)
}

\begin{abstract}
Introduction: There is currently no published data on the effectiveness of DAA treatment for elimination of HCV infection in HIV-infected populations at a population level. However, a number of relevant studies and initiatives are emerging. This research aims to report cascade of care data for emerging HCV elimination initiatives and studies that are currently being evaluated in HIV/HCV co-infected populations in the context of implementation science theory.

Methods: HCV elimination initiatives and studies in HIV co-infected populations that are currently underway were identified. Context, intervention characteristics and cascade of care data were synthesized in the context of implementation science frameworks.

Results: Seven HCV elimination initiatives and studies were identified in HIV co-infected populations, mainly operating in high-income countries. Four were focused mainly on HCV elimination in HIV-infected gay and bisexual men (GBM), and three included a combination of people who inject drugs (PWID), GBM and other HIV-infected populations. None were evaluating treatment delivery in incarcerated populations. Overall, HCV RNA was detected in 4894 HIV-infected participants (range within studies: 297 to 994): 48\% of these initiated HCV treatment (range: 21\% to 85\%; within studies from a period where DAAs were broadly available the total is 57\%, range: $36 \%$ to $74 \%$ ). Among studies with treatment completion data, $96 \%$ of 1109 initiating treatment completed treatment (range: 94\% to 99\%). Among those who could be assessed for sustained virological response at 12 weeks (SVR12), 1631 of 1757 attained SVR12 (93\%, range: 86\% to 98\%).

Conclusions: Early results from emerging research on HCV elimination in HIV-infected populations suggest that HCV treatment uptake is higher than reported levels prior to DAA treatment availability, but approximately half of patients remain untreated. These results are among diagnosed populations and additional effort is required to increase diagnosis rates. Among those who have initiated treatment, completion and SVR rates are promising. More data are required in order to evaluate the effectiveness of these elimination programmes in the long term, assess which intervention components are effective, and whether they need to be tailored to particular population groups.
\end{abstract}

Keywords: hepatitis C virus; disease elimination; MSM; IDU; implementation science; barriers; cascade of care

Received 28 June 2017; Accepted 19 December 2017; Published 9 April 2018

Copyright ( 2018 The Authors. Journal of the International AIDS Society published by John Wiley \& sons Ltd on behalf of the International AIDS Society. This is an open access article under the terms of the Creative Commons Attribution License, which permits use, distribution and reproduction in any medium, provided the original work is properly cited.

\section{1 | INTRODUCTION}

Over two million people are estimated to be HIV/HCV coinfected globally [1]. Chronic viral hepatitis accounts for approximately $10 \%$ of mortality among people living with HIV [2]. Injecting drug use is the major risk factor for HCV acquisition among those living with HIV, accounting for over $60 \%$ of infections globally, whereas in many high-income countries, high-risk sexual behaviour among HIV-infected gay and bi-sexual men (GBM), including injecting and non-injecting drug use to enhance the sexual experience, is a key driver of $\mathrm{HCV}$ transmission [1,3,4]. Incarcerated populations are also at elevated risk of HCV and HIV infection due to incarceration of people who inject drugs (PWID) [5].
HCV treatment has been transformed through direct-acting antiviral (DAA) medications that cure $>90 \%$ of individuals using tablets over 8 to 12 weeks [6]. Despite modelling studies suggesting that if HCV treatment can be adequately scaled to need, HCV prevalence and incidence can be reduced $[7,8]$ and optimism that local elimination of HCV might be achieved [9], realworld scale-up of HCV elimination remains largely hypothetical. Though the high price of DAAs has hindered scale-up [10], treatment levels have also been hindered by ineffective strategies to adequately target key populations who would benefit most from HCV treatment as prevention [11].

The HIV co-infected population are more likely to be engaged in medical care than the HCV-mono-infected population given increasingly high levels of HIV ART uptake globally [12]. 
Theoretically, this provides an opportunity for broad coverage of $\mathrm{HCV}$ treatment in this population, particularly given that DAA treatment regimens are similar in co-infected and mono-infected populations with equivalent treatment outcomes [13,14]. However, it is important to note that despite increases in ART coverage, coverage in the key at-risk populations still lags behind in some contexts possibly due to lower levels of engagement in medical care and discriminatory prescribing practices [15,16].

Despite the advantages of DAA therapy, engaging large numbers of HIV/HCV co-infected people in HCV DAA treatment will likely require tailored strategies for each of the three key groups at risk of co-infection: PWID, GBM and prisoners. A number of key barriers will need to be addressed to achieve a comprehensive increase in HCV treatment coverage in these three key populations. Insights from implementation science suggest that the successful and widespread implementation of any innovation is complex, even one that is supported by a high level of evidence $[17,18]$. This is partially due to barriers at the level of the individual health professional, such as lack of knowledge or skill or negative attitudes, but also involves structural barriers, organizational barriers, peer group barriers (differences between the local standard of care and the desired practice) and professional-patient interactions [19]. In the case of HCV, stigmatization and criminalization of the major patient groups and frequent incarceration of PWID add further to the complexity $[20,21]$.
There is currently no published real-world data on the effectiveness of DAA treatment for elimination of HCV infection in HIV-infected populations at a population level. However, a number of relevant studies and initiatives are emerging. This paper aims to describe and report cascade of care data for emerging HCV elimination initiatives and studies that are currently being trialled in HIV/HCV co-infected populations in the context of implementation science theory.

\section{METHODS}

Seven HCV elimination initiatives and studies in HIV coinfected populations that are currently underway were identified in six countries. Eligibility criteria for inclusion were either (a) monitoring an HCV elimination intervention targeted to HIV-infected populations; or (b) monitoring the effects of $\mathrm{HCV}$ elimination interventions in HIV-infected populations. Data on context, intervention characteristics, and initiative/ study-level cascade of care were synthesized using conference abstracts, published manuscripts and personal contact with the investigators. Data collection tools were informed by relevant constructs from the consolidated framework for implementation research (CFIR) [17] and the integrated Promoting Action on Research Implementation in Health Services framework (i-PARIHS; Figure 1) [18]. Cascade of care data from

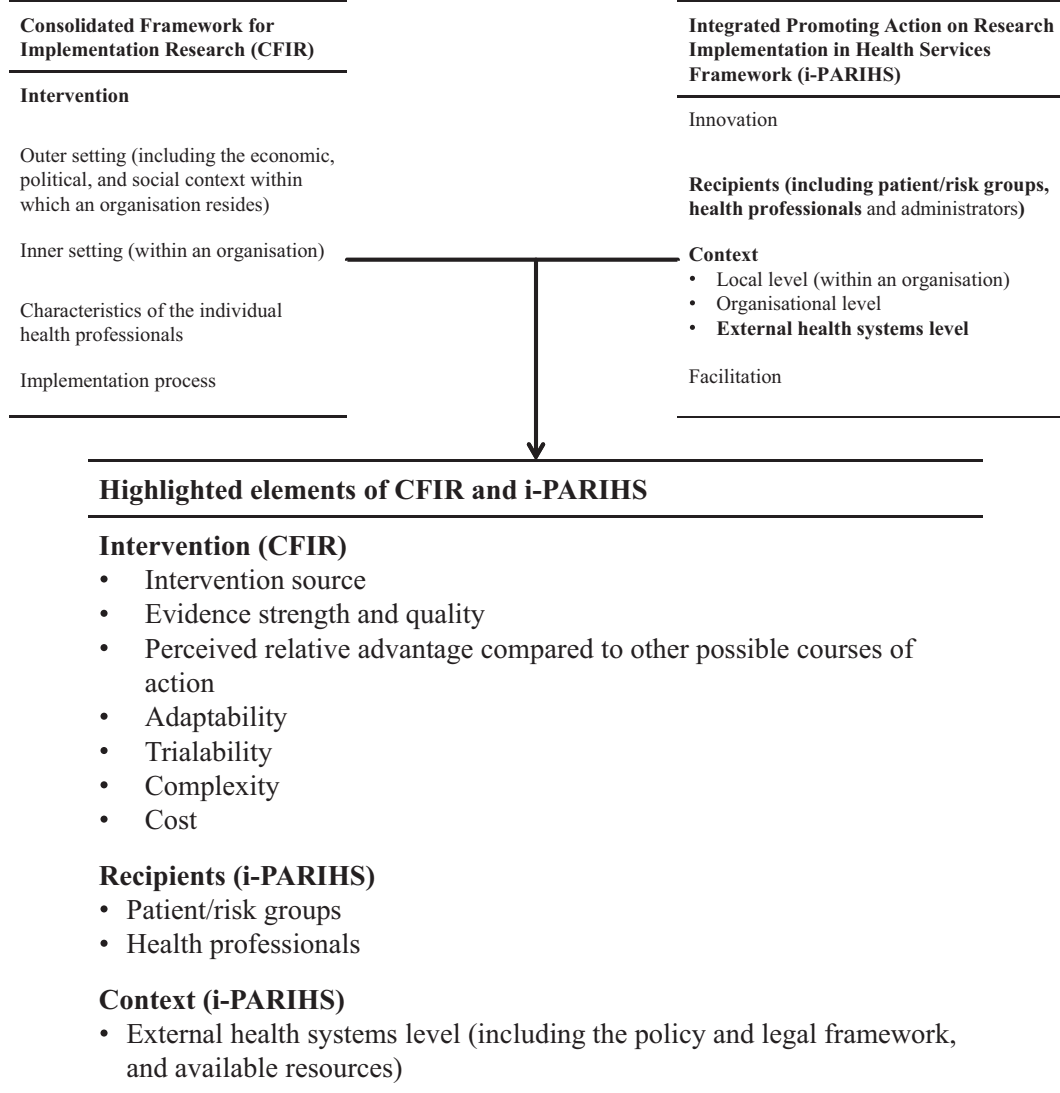

Highlighted elements of CFIR and i-PARIHS

Intervention (CFIR)

- Intervention source

- Evidence strength and quality

- Perceived relative advantage compared to other possible courses of action

- Adaptability

- Trialability

- Complexity

- Cost

Recipients (i-PARIHS)

- Patient/risk groups

- Health professionals

Context (i-PARIHS)

- External health systems level (including the policy and legal framework, and available resources)

Figure 1. Overview of the CFIR and i-PARIHS implementation science frameworks with relevant constructs highlighted. While all constructs in the two implementation science frameworks are potentially relevant to HCV elimination interventions, the highlighted constructs are particularly relevant for describing and analysing progress in HCV elimination in HIV-infected populations, both in the initiatives and studies identified and in the global context. 
initiatives and studies included the number of people with HCV RNA, the proportion of those with HCV RNA who initiated treatment, the proportion of those who initiated treatment that completed treatment, and the SVR rate. Where possible the SVR rate was defined as the proportion of those who were at least 12 weeks past their expected treatment completion date, who had attained SVR. Data on diagnosis rates were not generally available at the initiative/study level.

For each country in which initiatives and studies were included, model-based estimates of the numbers of people living with HIV and the proportion diagnosed with HIV were sourced from peer-reviewed journal manuscripts [22,23], surveillance reports [24-26], and conference presentations [27]. Estimates of HCV antibody prevalence among HIVinfected populations were obtained from cohort studies of people living with HIV [26,28-30], clinical databases of HIV patients [27], and country-level HIV/HCV co-infection management guidelines [31]. The number of people affected by $\mathrm{HCV} / \mathrm{HIV}$ co-infection was calculated by applying the $\mathrm{HCV}$ antibody prevalence estimates to the estimates of the numbers of people living with HIV. An estimate of the proportion of those with HIV/HCV co-infection who were diagnosed for both HIV and HCV was only available for one country, and it was sourced from a conference presentation [27].

All contributing studies had received ethical approval from local ethics review boards in their countries.

\section{3 | RESULTS - PROGRESS TOWARD HCV ELIMINATION IN HIV-INFECTED POPULATIONS}

\subsection{Emerging research}

Seven HCV elimination initiatives and/or studies in HIVinfected populations were identified, mainly in high-income countries (Australia ( $n=2)$, Canada, France, Georgia, the Netherlands and Switzerland). The broader context in which an intervention takes place is highlighted by the i-PARIHS framework (Figure 1). The six countries in which elimination initiatives or studies were identified all have harm reduction programmes for PWID, and protection against discrimination for LGBT populations. [32-33]. However, the coverage of harm reduction programmes varies substantially between countries. According to a recent systematic review, needle and syringe programme coverage was high in Australia and the Netherlands (>200 needles/syringes distributed per PWID per year), moderate in Canada, France and Switzerland (100 to 200 needles/syringes distributed per PWID per year) and low in Georgia (0 to 50 needles/syringes distributed per PWID per year). Opioid substitution therapy coverage was high in Australia, France, the Netherlands and Switzerland (>40 recipients per 100 PWID), moderate in Canada (20 to 40 recipients per 100 PWID), and low in Georgia (0 to 20 recipients per 100 PWID)

Table 1. Country-level context of the identified HCV elimination initiatives and studies in HIV-infected populations

\begin{tabular}{|c|c|c|c|c|c|c|}
\hline \multicolumn{7}{|l|}{ Main population groups affected by HIV/HCV co-infection } \\
\hline PWID & N & Y & Y & Y & Y & $Y^{a}$ \\
\hline GBM & Y & Y & Y & Y & Y & Y \\
\hline Prisoners & N & Y & Y & Y & Y & N \\
\hline Other & N & $Y^{b}$ & N & Y & $\mathrm{N}$ & $\mathrm{N}$ \\
\hline \multicolumn{7}{|l|}{ Availability of subsidized DAAs } \\
\hline Unrestricted in HIV-coinfected population (year) & Y (2016) & $Y(2014 / 2017)^{c}$ & Y (2017) & Y (2015) & Y (2017) & Y (2015) \\
\hline Unrestricted for all chronic HCV patients (year) ${ }^{d}$ & Y (2016) & $N^{e}$ & Y (2017) & Y (2015) & $\mathrm{N}$ & Y (2015) \\
\hline \multicolumn{7}{|l|}{ Prescriber types } \\
\hline Specialists & Y & Y & Y & Y & Y & Y \\
\hline Primary care & Y & $Y / N^{f}$ & N & $N^{g}$ & $\mathrm{~N}$ & $\mathrm{~N}$ \\
\hline
\end{tabular}

aln the Netherlands, HCV/HIV coinfection is mainly observed in former PWID and GBM. Recent transmission has been observed only among GBM. Similar to the situation in other high-income countries, HCV transmission among GBM is thought to be driven partially by sexual transmission and partially by injecting and non-injecting drug use to enhance the sexual experience.

'Indigenous populations (mainly through injecting drug use).

'Simeprevir and sofosbuvir were unrestricted in Quebec for HCV mono-infected patients since 2014. Although HIV infection was a listed restriction, co-infected patients were usually granted access on a case by case basis through the "patient d'exception" process; Ledipasvir and ombitasvir/ paritaprevir/ritonavir; dasabuvir were unrestricted in Quebec from 2016 and velpatasvir from 2017; and the majority of other Canadian provinces since March 2017 [34].

${ }^{\mathrm{d}}$ Generally excluding those who are incarcerated.

eNot currently available but this is expected to change in 2018/9 in the majority of Canadian provinces.

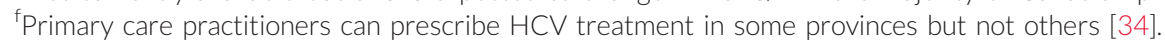

${ }^{g} \mathrm{~A}$ pilot programme is currently underway to evaluate HCV treatment in primary care, which is expected to lead to all primary care providers being allowed to prescribe HCV treatment. 
[32]. HCV elimination strategies operating at the regional or country level were in place in Australia, France, Georgia and the Netherlands (Table 1).

In addition to the broad context, another key aspect is the characteristics of the patient or target group of the intervention (Figure 1). The main population groups affected by HIV/ $\mathrm{HCV}$ co-infection in the countries in which elimination initiatives were identified included PWID, GBM and incarcerated populations. However, the majority of the elimination efforts were targeted elimination efforts in GBM. The two Australian initiatives (CEASE and Co-EC) operate primarily in cities where GBM account for approximately $85 \%$ of HIV/HCV coinfection cases; in Amsterdam, ongoing transmission of HCV infection among HIV-infected populations is only among GBM; and in Switzerland, the Swiss HCVree Trial is a clinic trial with MSM as an eligibility criterion. Notably, the HCVree study is nested in the Swiss HIV Cohort Study which includes PWID, GBM and other HIV-infected participants, and because treatment data are not yet available for HCVree, the cascade of care data presented here are from the Swiss HIV Cohort Study. The nationwide HCV elimination programme in Georgia provides HCV treatment at harm reduction sites for PWID, HIV centres, and prisons. In Canada and France, there are no specific programmes targeting HIV-infected populations but the effects of general HCV elimination programmes are being evaluated in the HIV-infected community. France's national strategy for HCV elimination includes targeted programmes for PWID. Broad availability of DAAs is the only nation-wide elimination initiative in Canada but there are other HCV elimination initiatives in Canada that are targeted to specific subpopulations and geographic areas. The cohort studies and databases being used to evaluate the effects of HCV elimination programmes in Canada, France and Georgia include diverse HIV-infected populations including active PWID and GBM. (Table 2).

One of the characteristics highlighted in the CFIR is the complexity of the intervention (Figure 1). HCV elimination in HIV-infected populations is complex. All of the initiatives and studies include broad access to DAAs and most include additional components, including screening and testing components, treatment access components, training of health professionals, media campaigns and risk reduction components. Screening and testing interventions include nurse supported programmes to identify patients for HCV antibody testing, community-based rapid diagnostics and home-based dried blood spot testing, and study or community-based reinfection monitoring. Treatment access interventions include a case management programme for PWID and marginalized people, broadened prescriber base, treatment provision at harm reduction sites, treatment provision in prison, nurse-led primary healthcare based models of care, and community and cohort-study based test and treat models. Risk reduction components include harm reduction, healthcare-based infection control, behavioural interventions and personalized online tools for those at risk of reinfection. Of the five broad groups of intervention (screening/testing, treatment access, training of health professionals, media campaigns and risk reduction interventions), MC Free and Georgia's nationwide HCV elimination programme involve components from all five groups, Co-EC Australia involves components from four groups, CEASE Australia involves components from three groups, the National Plan for HCV Elimination and the Swiss HCVree trial include components from two groups. Although there are no targeted national elimination interventions in Canada, regional interventions such as the Targeted Disease Elimination $^{\text {TM }}$ programme in British Columbia [35] and a pilot project in Big River First Nation, Saskatchewan are evaluating eliminating $\mathrm{HCV}$ at the community level. Some of the studies and initiatives include multiple components within a group (Table 2).

The ability to trial the intervention at a small-scale is also highlighted in CFIR (Figure 1). In the seven initiatives and studies identified, cohort studies, health information systems and surveillance systems are being used to evaluate HCV elimination interventions in people living with HIV (Table 2). None of the evaluation methods include traditional control groups. However the CCC (Canada) is using quasi-experimental designs to (i) evaluate treatment uptake through natural variations in DAA reimbursement policies across Canada and (ii) pilot elimination interventions at the clinic level, comparing intervention sites with matched control sites within the CCC. Similarly, several of the other studies and initiatives are using nationwide databases and/or cohorts to compare regions/sites with interventions to other regions.

The cost and available resources for implementing an intervention are highlighted in CFIR and i-PAHRIS (Figure 1). With the exception of the Swiss HCVree Trial, where drugs are provided by industry, governments and health insurance provide funding for subsidized DAAs in all of the other HCV elimination initiatives and studies. However, with the exception of the government-funded National Plan for HCV elimination in France and the nationwide HCV elimination programme in Georgia which is partially industry-funded and partially funded by the US CDC among others, additional components of the elimination interventions identified were mainly funded by industry through investigator-initiated research. These components include treatment access interventions, screening/testing, education initiatives for health professionals, media campaigns and risk reduction interventions.

\subsection{Country-level burden of HIV/HCV co-infection and diagnosis}

Model-based estimates of the number of people living with HIV were available for all six countries in which the identified HCV elimination initiatives and studies were based. These ranged from 9600 in Georgia to 149,900 in France. The percent of HIV-infected participants with HCV antibodies ranged from $12 \%$ in the Netherlands to $40 \%$ in Georgia. The number of people living with HIV and HCV antibodies ranged from 2600 in Switzerland to 36,400 in France. The percent of HIVinfected individuals who were HIV diagnosed ranged from $42 \%$ in Georgia to $89 \%$ in Australia (Table 3). An estimate of the percent of co-infected individuals who were diagnosed for both HIV and HCV was reported in a conference presentation for Georgia (33\%) [27], but was not available for any of the other countries. According to systematic reviews and modelling studies, the estimated proportion of people living with $\mathrm{HCV}$ (including those with HCV monoinfection) who were diagnosed prior to DAA availability was 37\% (Switzerland), 57\% (France), 61\% (the Netherlands), 70\% (Canada), 75\% (Australia) [36-39]. However, in some countries these 
Table 2. Intervention characteristics of seven key studies targeting HCV elimination in HIV/HCV co-infected populations

\begin{tabular}{|c|c|c|c|c|}
\hline Name (location) & Scope of intervention & Intervention components & $\begin{array}{c}\text { Who covers the cost of } \\
\text { the intervention }\end{array}$ & $\begin{array}{c}\text { Evaluation method in } \\
\text { HIV-infected } \\
\text { populations }\end{array}$ \\
\hline (Canada) & Nation-wide & $\begin{array}{l}\text { Broad access to DAAs; } \\
\text { additional clinic-level, province- } \\
\text { level, and community-level } \\
\text { interventions }\end{array}$ & $\begin{array}{l}\text { Government/health } \\
\text { insurance }^{a}\end{array}$ & $\begin{array}{l}\text { Canadian co-infection } \\
\text { cohort }[40]\end{array}$ \\
\hline $\begin{array}{l}\text { co-EC (Melbourne, } \\
\text { Australia) }\end{array}$ & $\begin{array}{l}\text { Three high HIV caseload } \\
\text { primary healthcare } \\
\text { clinics, the largest } \\
\text { metropolitan sexual } \\
\text { health centre, and the } \\
\text { two largest hospitals for } \\
\text { care of people living with } \\
\text { HIV, accounting for over } \\
75 \% \text { of people living with } \\
\text { HIV in Victoria }\end{array}$ & $\begin{array}{l}\text { Broad access to DAAs and } \\
\text { broadened prescriber base; } \\
\text { nurse supported programmes to } \\
\text { identify patients for HCV } \\
\text { testing, and support for GPs to } \\
\text { increase testing and treatment; } \\
\text { posters displayed in } \\
\text { participating clinics promoting } \\
\text { HCV testing to patients; } \\
\text { nurse-led model of care in } \\
\text { primary healthcare to increase } \\
\text { access to DAAs; } \\
\text { training programmes for nurses } \\
\text { and physicians }\end{array}$ & $\begin{array}{l}\text { DAA therapy is } \\
\text { government subsidized; } \\
\text { practice nurses are } \\
\text { funded by industry } \\
\text { through investigator } \\
\text { initiated research }\end{array}$ & $\begin{array}{l}\text { An integrated HCV/HIV } \\
\text { clinical and } \\
\text { behavioural } \\
\text { surveillance system } \\
\text { monitors the impact } \\
\text { of the programme at } \\
\text { the local and } \\
\text { statewide level }\end{array}$ \\
\hline $\begin{array}{l}\text { CEASE } \\
\text { (predominantly } \\
\text { Sydney, Australia) }\end{array}$ & $\begin{array}{l}\text { Nation-wide observational } \\
\text { study of HCV viraemia } \\
\text { among HIV-infected } \\
\text { population, with an } \\
\text { implementation project } \\
\text { predominantly operating } \\
\text { in Sydney }\end{array}$ & $\begin{array}{l}\text { Broad access to DAAs and } \\
\text { broadened prescriber base; } \\
\text { HCV Education for HIV } \\
\text { prescribers; } \\
\text { recurrent viraemia: monitoring } \\
\text { of a cohort of high-risk inner } \\
\text { city patients for reinfection }\end{array}$ & $\begin{array}{l}\text { DAA therapy is } \\
\text { government subsidized; } \\
\text { other intervention } \\
\text { components funded by } \\
\text { industry through } \\
\text { investigator initiated } \\
\text { research }\end{array}$ & $\begin{array}{l}\text { Data assessed at three } \\
\text { cross-sectional visits; } \\
\text { at enrolment (2014 } \\
\text { to } 2016 \text { ), follow up } 1 \\
\text { (2017 to 2018) and } \\
\text { follow up } 2 \text { (2019 to } \\
\text { 2020); data include } \\
\text { HCV viraemic } \\
\text { prevalence through } \\
\text { DBS, behavioural risk } \\
\text { and fibrosis } \\
\text { assessment }\end{array}$ \\
\hline $\begin{array}{l}\text { MC FREE } \\
\text { (Amsterdam MSM } \\
\text { HCV Free, } \\
\text { Amsterdam, the } \\
\text { Netherlands) }\end{array}$ & City-wide & $\begin{array}{l}\text { Broad access to DAAs; } \\
\text { home-based HCV RNA dried } \\
\text { blood spot testing service } \\
\text { (subscription-based); } \\
\text { online tools including } \\
\text { information and personal advice } \\
\text { on testing and risk reduction } \\
\text { strategies, and test results } \\
\text { delivered online; } \\
\text { motivational interviewing and } \\
\text { intensification of partner } \\
\text { notification; } \\
\text { online and offline media } \\
\text { campaigns aimed at increasing } \\
\text { HCV awareness; } \\
\text { interventions aimed at } \\
\text { professionals; } \\
\text { behavioural interventions by } \\
\text { trained HIV nurses }\end{array}$ & $\begin{array}{l}\text { DAA Treatment is } \\
\text { government subsidized; } \\
\text { home-based testing and } \\
\text { online/ offline strategies } \\
\text { are supported by } \\
\text { industry through } \\
\text { investigator initiated } \\
\text { research }\end{array}$ & $\begin{array}{l}\text { Through the National } \\
\text { HIV Monitoring } \\
\text { Foundation and the } \\
\text { MOSAIC study, the } \\
\text { different } \\
\text { interventions will be } \\
\text { evaluated according } \\
\text { to predefined } \\
\text { criteria/ deliverables }\end{array}$ \\
\hline
\end{tabular}


Table 2. (Continued)

\begin{tabular}{|c|c|c|c|c|}
\hline Name (location) & Scope of intervention & Intervention components & $\begin{array}{l}\text { Who covers the cost of } \\
\text { the intervention }\end{array}$ & $\begin{array}{c}\text { Evaluation method in } \\
\text { HIV-infected } \\
\text { populations }\end{array}$ \\
\hline $\begin{array}{l}\text { National Plan for } \\
\text { HCV Elimination } \\
\text { (France) }\end{array}$ & $\begin{array}{l}\text { Nation-wide, community- } \\
\text { based intervention }\end{array}$ & $\begin{array}{l}\text { Broad access to DAAs; } \\
\text { community-based test and treat } \\
\text { model involving implementation } \\
\text { of rapid diagnostics at the } \\
\text { community level; } \\
\text { educators and social workers } \\
\text { who link PWID / marginalized } \\
\text { people to healthcare centres, } \\
\text { through a case management } \\
\text { (parcours) programme }\end{array}$ & $\begin{array}{l}\text { Government/health } \\
\text { insurance }\end{array}$ & $\begin{array}{l}\text { Several cohorts of HIV- } \\
\text { infected patients and } \\
\text { HIV/HCV co-infected } \\
\text { patients in addition to } \\
\text { national surveillance } \\
\text { systems }\end{array}$ \\
\hline $\begin{array}{l}\text { National HCV } \\
\text { elimination } \\
\text { programme } \\
\text { (Georgia) }\end{array}$ & $\begin{array}{l}\text { Nation-wide multi- } \\
\text { component programme }\end{array}$ & $\begin{array}{l}\text { Broad access to treatment and } \\
\text { increased access to treatment } \\
\text { through primary care, harm } \\
\text { reduction sites, HIV centres and } \\
\text { prisons'; } \\
\text { advocacy, awareness and } \\
\text { education; } \\
\text { harm reduction among PWID, } \\
\text { blood safety and infection } \\
\text { control in traditional and non- } \\
\text { traditional healthcare settings; } \\
\text { national HCV screening } \\
\text { Laboratory diagnostics capacity } \\
\text { building; } \\
\text { surveillance }\end{array}$ & $\begin{array}{l}\text { Gilead and the CDC among } \\
\text { others }\end{array}$ & $\begin{array}{l}\text { Georgian National AIDS } \\
\text { health information } \\
\text { system (AIDS HIS, a } \\
\text { secure web-based } \\
\text { system connecting all } \\
\text { HIV care providers } \\
\text { countrywide) }\end{array}$ \\
\hline $\begin{array}{l}\text { The Swiss HCVree } \\
\text { Trial (Switzerland) }\end{array}$ & $\begin{array}{l}\text { Research study-based } \\
\text { elimination effort among } \\
\text { HIV/HCV co-infected } \\
\text { MSM, operating } \\
\text { nationwide }\end{array}$ & $\begin{array}{l}\text { Cohort study based test and treat } \\
\text { model; delivery of Elbasvir/ } \\
\text { Grazoprevir treatment to } \\
\text { patients infected with } \\
\text { genotypes } 1 \text { and } 4 \text { through } \\
\text { clinical trial (Swiss HCVree } \\
\text { Trial); behavioural intervention } \\
\text { delivered to patients reporting } \\
\text { inconsistent condom use with } \\
\text { occasional partners; the } \\
\text { remaining patients received } \\
\text { standard of care and written } \\
\text { and oral information on } \\
\text { prevention of HCV reinfection. }\end{array}$ & $\begin{array}{l}\text { Investigator initiated trial } \\
\text { nested in the Swiss HIV } \\
\text { Cohort Study (SHCS); } \\
\text { SHCS mainly funded by } \\
\text { the Swiss National } \\
\text { Science Foundation, } \\
\text { HCVree mainly funded } \\
\text { by industry }\end{array}$ & $\begin{array}{l}\text { The Swiss HCVree } \\
\text { Trial: all study } \\
\text { participants tested } \\
\text { for HCV RNA at } \\
\text { beginning and end of } \\
\text { the HCVree trial, } \\
\text { change in risk } \\
\text { behaviour is } \\
\text { evaluated, see } \\
\text { ClinicalTrials.gov } \\
\text { NCTO2785666; } \\
\text { effects on HCV } \\
\text { incidence within HIV- } \\
\text { infected populations } \\
\text { evaluated using the } \\
\text { Swiss HIV Cohort } \\
\text { Study }\end{array}$ \\
\hline
\end{tabular}

\footnotetext{
${ }^{a}$ Although all Canadian citizens and permanent residents have insurance coverage for in-hospital and physician services, medication coverage varies across the 10 provinces and 3 territories, with a mix of both public and private sources of insurance depending on individual characteristics. For example, people on social assistance receive public coverage for medications with no or minimal co-payments and Indigenous people receive medication coverage from the First Nations and Inuit Health Branch (FNIHB).

${ }^{b}$ Provision of HCV treatment through primary care and harm reduction sites is currently being piloted and will be implemented nationwide in the future.
} 
Table 3. Country-level burden of HIV/HCV co-infection and diagnosis

\begin{tabular}{|c|c|c|c|c|c|c|}
\hline Estimated number of people living with HIV & $26,400[24]$ & $65,000[25]$ & $149,900[22]$ & $9600[27]$ & $15,200[23]$ & $22,900[26,41]$ \\
\hline Estimated number with $\mathrm{HCV}$ antibodies & 3500 & 16,300 & 36,400 & 3900 & 2600 & 2700 \\
\hline $\begin{array}{c}\text { Estimated \% of those living with } \\
\text { HIV who are HIV diagnosed }\end{array}$ & $89[24,28]$ & $80[25]$ & 81 [22] & $42[27]$ & 81 [23] & $89[26,41]$ \\
\hline
\end{tabular}

All numbers are rounded to the nearest 100 and percentages are rounded to the nearest percent. Estimated numbers with HCV antibodies are calculated by applying the estimated \% with HCV antibodies to the estimated number of people living with HIV. Percent HIV diagnosed is among all HIV-infected people.

diagnosis rates may be quite different in the HIV-infected population.

\section{3 | Initiative-level partial cascade of care}

Overall, HCV RNA was detected in 4894 HIV-infected participants across the seven studies and initiatives (range within studies: 297 to 994). Of these 2338 initiated HCV treatment (48\%; range: $21 \%$ to $85 \%$ ). Among studies with treatment completion data, 1061 of 1109 initiating treatment (96\%, range: $94 \%$ to $99 \%$ ), completed treatment. Of those who were treated with DAAs and could be assessed for SVR12, 1631 of 1757 attained SVR12 (93\%, range: 86\% to 98\%). Of the seven studies and initiatives, four reported cascade of care data from a period where DAAs were broadly available (CEASE and Co-EC - Australia, ATHENA - The Netherlands and AIDS HIS-Georgia), and three included data from prior to DAAs becoming broadly available (CCCS - Canada, SHCS - Switzerland, and HEPAVIH- France). Four initiatives/studies included a considerable proportion of PWID in addition to GBM and other patient groups (CCCS, AIDS HIS, HEPAVIH and SHCS), and three were composed mainly of GBM and former PWID (CEASE, Co-EC and ATHENA). In studies and initiatives with cascade of care data from a period where DAAs were broadly available, 1398 of 2460 (57\%, range: 36\% to 74\%) initiated HCV treatment, 160 of 169 (95\%: data from one study only) completed HCV treatment, and 1042 of 1110 (94\%, range: $88 \%$ to $98 \%)$ attained SVR12. In studies and initiatives that include a considerable proportion of current PWID, 1271 of 3349 (38\%, range: 21\% to 85\%) initiated treatment, 901 of 940 (96\%: range: 94\% to 99\%), completed HCV treatment, and 885 of 978 (90\%, range: 86\% to 96\%) attained SVR12; however, two of these studies and initiatives include data from prior to DAAs becoming broadly available (Table 4 and Figure 2). These data include diagnosed patients, who are in care (France, the Netherlands, Sydney), were in care previously (Melbourne, Georgia) and/or are enrolled in a cohort study (Canada, France, the Netherlands and Switzerland).

\section{4 | DISCUSSION}

Early results were synthesized from seven $\mathrm{HCV}$ elimination initiatives and studies in HIV-infected populations. These results demonstrate increased linkage to HCV care, successful retention in care, and high cure rates among those diagnosed with HCV/HIV co-infection. However, these are early data and the majority of initiatives and studies identified were in highincome countries with relatively low levels of criminalization of risk behaviours and discrimination and stigma of PWID and GBM. Furthermore, the majority of initiatives and studies identified were either primarily treating GBM and/or former PWID or include data from prior to broad DAA availability. None of the studies operate in incarcerated populations and treatment in this context may be more challenging. More data will be required to evaluate the effects of treatment scale-up on HCV prevalence and incidence, and confirm that these high rates of linkage and retention in care can be replicated in PWID, incarcerated populations, and in countries with greater levels of criminalization of risk behaviours and discrimination and stigma of the groups at risk. Different strategies may be required for linkage and retention in care in different populations.

Overall, approximately 50\% of HCV diagnosed individuals in the seven initiatives and studies were linked to HCV treatment. This represents a substantially higher treatment uptake than prior to DAA therapies becoming available. In the Swiss HIV cohorts, treatment uptake increased fourfold after the introduction of second-generation DAAs [42]. In Georgia, approximately $100 \mathrm{HCV} / \mathrm{HIV}$ co-infected people were treated per year in the three and a half years prior to DAA availability, compared to approximately 265 treatments/year in the first 15 months of the nationwide $\mathrm{HCV}$ elimination programme [27]. In the CCC (Canada), treatment uptake increased from 8 per 100 person years to 28 per 100 person years after the introduction of DAA therapies. [43]. This is consistent with increases in treatment uptake following the introduction of DAA therapies in predominantly HCV-monoinfected populations [44]. However, it is not clear that these increases in treatment rates will be sustained. In the Netherlands, treatment numbers increased substantially from November 2015 when DAA therapy became available until July 2016 (on average, $>150$ treatments/quarter) but then returned to pre-DAA levels (<50 treatments/quarter) [45]. Moreover, although substantial increases in treatment uptake were observed after the introduction of DAA therapy, treatment uptake varied substantially between studies (21\% to 91\%). This is partially due to variations in when broad access to DAA therapy was attained: in Canada, France, and Switzerland, although DAA therapies were available to selected subgroups earlier, broad access to DAA therapies was only attained in 2017 and cascade of care data was either not yet available or included data 
Table 4. Partial cascade of care in the HCV elimination interventions/studies identified in HIV-infected populations

\begin{tabular}{|c|c|c|c|c|c|c|c|}
\hline & $\begin{array}{c}\text { CEASE } \\
\text { Australia }\end{array}$ & $\begin{array}{c}\text { Co-EC } \\
\text { Australia }\end{array}$ & $\begin{array}{c}\text { CCC } \\
\text { Canada }\end{array}$ & $\begin{array}{l}\text { HEPAVIH } \\
\text { France }\end{array}$ & $\begin{array}{l}\text { AIDS HIS } \\
\text { Georgia }^{a}\end{array}$ & $\begin{array}{c}\text { SHCS }^{b} \\
\text { Switzerland }\end{array}$ & $\begin{array}{c}\text { ATHENA }^{\mathrm{c}} \\
\text { The Netherlands }\end{array}$ \\
\hline Number HCV RNA positive & $297^{d}$ & $305^{e}$ & $994^{f}$ & 564 & 915 & 876 & $943^{g}$ \\
\hline Number initiated HCV treatment (\%) ${ }^{\mathrm{h}}$ & $196(66)$ & $169(55)$ & $278(28)$ & $482(85)^{i}$ & $331(36)$ & $180(21)$ & $702(74)$ \\
\hline Number completed HCV treatment (\%) & - & $160(95)$ & $271(97)^{k}$ & $451(94)$ & - & $179(99)$ & - \\
\hline Number attained SVR12 (\%) & $15(88)^{\prime}$ & $133(89)^{\mathrm{m}}$ & $240(86)^{n}$ & $176(93)^{\circ}$ & $296(89)$ & $173(96)$ & $598(98)^{\mathrm{p}}$ \\
\hline
\end{tabular}

CEASE, Control and Elimination within AuStralia of HEpatitis C from people living with HIV; co-EC Study, Eliminating HCV/HIV co-infection; CCC, Canadian Co-infection Cohort; HEPAVIH, the French national prospective cohort of patients co-infected with HIV and HCV (ANRS CO13 HEPAVIH); AIDS HIS, AIDS health infection system; SHCS, Swiss HIV Cohort Study; ATHENA, AIDS Therapy Evaluation in the Netherlands (ATHENA) cohort.

aData from the Georgian National AIDS health information system (a secure web-based system connecting all HIV care providers countrywide), June 2015 to August 2016. DAAs were broadly available.

${ }^{b}$ Cascade of care in the Swiss HIV Cohort Study because cascade of care data are not yet available for the Swiss HCVree Trial. Data are from 2014 to 2015. Second-generation DAAs were available but restricted by liver disease stage [42].

${ }^{c}$ Cascade of care from the ATHENA cohort of people diagnosed with HIV in the Netherlands from a period where DAAs were broadly available but prior to MC Free, Amsterdam [45]. A cascade of care at the two largest HIV clinics in Amsterdam (a subset of the ATHENA cohort) is available for the same period [46].

d2014 to 2016 [47].

'These are patients who have been tested for HCV in the past but may not currently be in HCV care. Among those who have been tested for HCV within the study period ( $n=194)$, the treatment uptake is $87 \%$.

${ }^{\mathrm{f}}$ As of 21 November 2013 (Health Canada's approval of second-generation DAAs), cohort participants who were eligible to initiate DAAs.

IIncludes those who have tested HCV RNA positive, were treated with DAAs, have never been treated, or were treated with interferon-based therapies and failed treatment but have not yet been retreated [45].

hOf those HCV RNA positive.

IIncludes initiations with interferon-based therapies during a period when DAAs were available in France but restricted [48]

jOf those initiating HCV treatment.

${ }^{k}$ Data collected up to December 2016.

'Up to end 2015 (17 had initiated treatment).

mOf those who are 12 weeks past the date of planned treatment completion. 136 of these were tested for HCV RNA at 12 weeks after treatment, and of those the SVR rate was 98\%. It is likely that more participants will be tested for HCV RNA at their next HIV clinic visit.

nIncludes DAA regimens including interferon, data collected up to July 2017 [43].

${ }^{\circ}$ Of those initiating DAA therapy prior to February (24 week therapy)/May 2015 (12 week therapy) [49].

POf those who were assessed for SVR.

from before broad access was attained. Treatment rates may have increased since DAAs became broadly available.

However, even in initiatives and studies that attained broad access to DAA therapies earlier, treatment uptake ranged from 36\% in Georgia to $75 \%$ in the Netherlands indicating that there are significant barriers to care other than simply

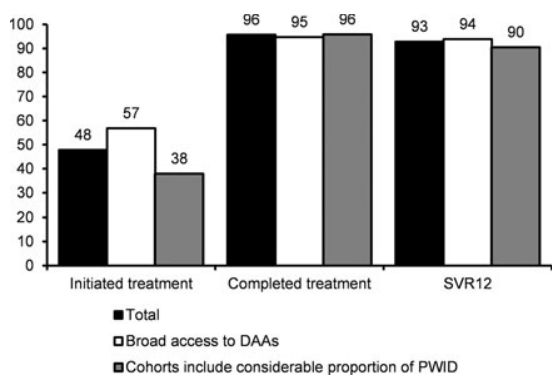

Figure 2. Partial cascade of care data from seven initiatives and studies implementing and evaluating HCV elimination interventions in HIV-infected populations. Percent of HCV RNA positive participants in care or enrolled in cohort studies initiating treatment, percent of those initiating treatment who have completed treatment, and percent of those who can be assessed for SVR12 who attained SVR12. access to DAA therapy, including provider-level, patient-level and structural barriers ([19-21], Table 5). Overall, more than half of diagnosed HIV/HCV co-infected individuals had not received treatment. While the data included only reflect a short timeframe after the introduction of DAAs, this suggests that substantial effort is still required to achieve HCV elimination in HIV-infected populations. In order to overcome the potential barriers to HCV elimination, it is likely that complex interventions will be required. These are likely to include interventions related to linkage and retention in care, diagnosis and screening, training of health professionals, risk reduction and identification and treatment of reinfection cases. Notably, currently the majority of intervention components in the identified studies and initiatives other than DAA therapy are funded by industry through investigator-initiated research. In order to attain HCV elimination globally, sustainable financing structures will be required to monitor the effectiveness of $\mathrm{HCV}$ elimination efforts and for widespread implementation of interventions that are proven to be effective.

All treatment linkage data reflect HIV and HCV diagnosed populations. Population-wide proportions of those diagnosed with HIV/HCV co-infection who have received treatment are likely to be lower than those presented here. HCV diagnosis rates among HIV-infected populations are not currently well understood and additional research is required to estimate 
Table 5. Barriers and enablers of HCV elimination in HIV-infected populations: list structure based on the CFIR and i-PARIHS frameworks

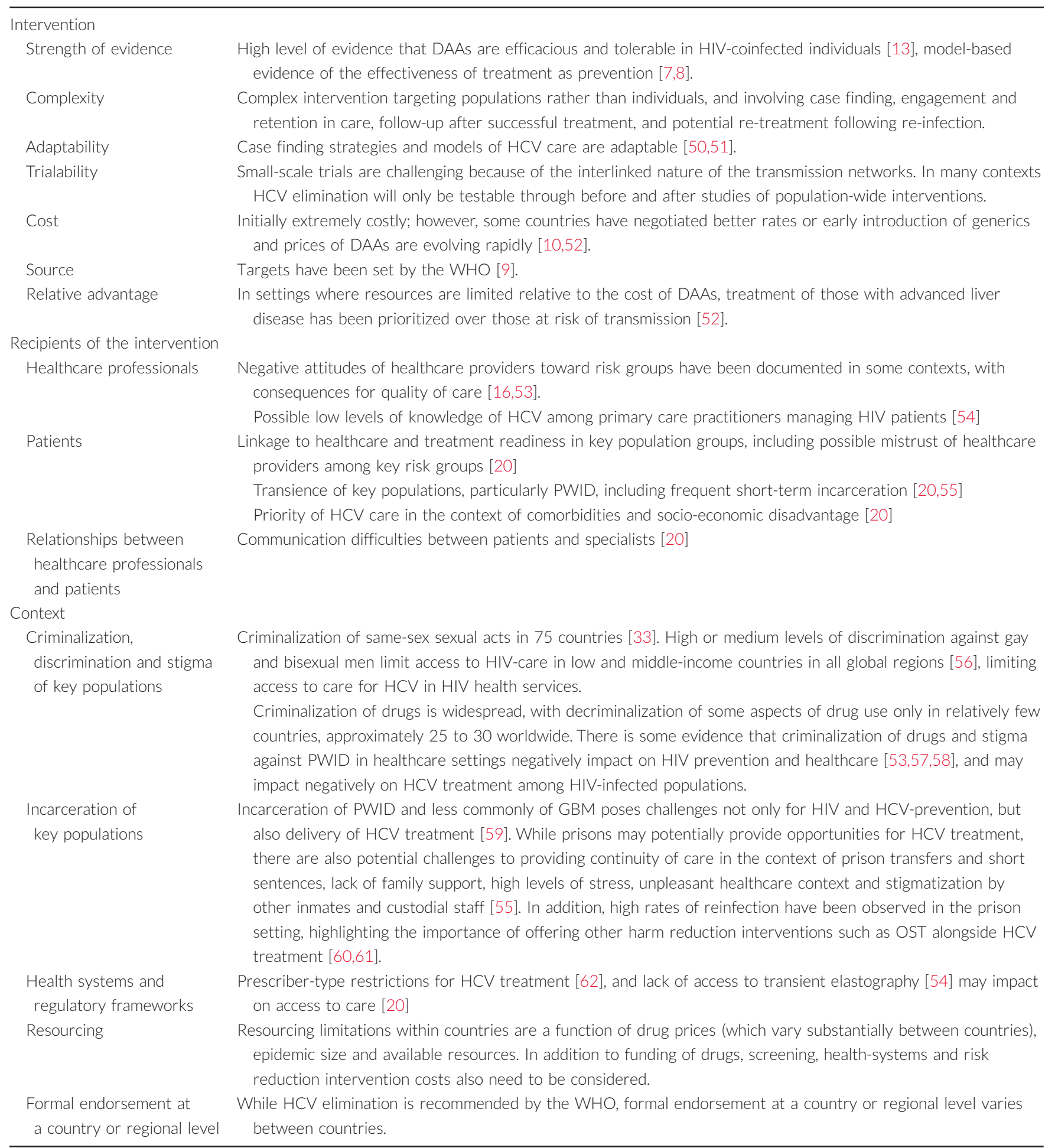

these. Two of the initiatives and studies identified included interventions to increase HCV diagnosis in HIV diagnosed populations using community-based rapid diagnostics and home-based dried blood spot testing. Dried blood spot testing administered by professionals has previously been found to increase $\mathrm{HCV}$ testing uptake in populations at high risk of HCV monoinfection [63]. In Georgia, where the rate of HIV diagnosis is relatively low (approximately 40\%), efforts are being made to increase diagnosis through integration of HIV, $\mathrm{HCV}$ and TB testing services [64]. 
It is likely that appropriate strategies to improve linkage to care and maintenance in care will differ by population group regardless of whether they are HIV/HCV co-infected or HCV monoinfected. For PWID, prior to the introduction of DAA therapy, a meta-analysis of determinants of HCV treatment completion and efficacy in drug users found that addiction treatment and support services during HCV therapy predicted treatment completion, and the involvement of a multidisciplinary team predicted SVR [51]. A subsequent meta-analysis that included studies of drug-using and other populations found that coordinated mental health, substance use and HCV treatment services had a modest effect on treatment completion and SVR but not on treatment uptake. The level of evidence was rated as very low on the GRADE scale although that is partially due to the difficulties of conducting blinded randomized controlled trials of these interventions. The same meta-analysis failed to find any effect of directly observed therapy on SVR [50]. Since the introduction of DAAs, conference abstracts describing a range of models of care for PWID including directly observed therapy $[65,66]$, addiction treatment and support services during HCV therapy [67,68], support groups [65], integration of HCV treatment clinic and harm reduction services [69], community-based clinic conducting outreach at rehab clinics [70] have all reported high levels of SVR in PWID with HCV mono-infection.

Four of the HCV elimination initiatives identified in this study are implementing models of care targeting GBM. These involve integrating HCV treatment with HIV care, and targeted risk reduction strategies. Prevention of reinfection was highlighted as an important component of HCV elimination efforts in HIVinfected GBM in a mathematical model based on data from the Swiss Cohort study. In light of empirical evidence of increases in HCV-related risk behaviours in GBM being enrolled in the Swiss Cohort Study, the model suggested that if the trend toward increasing risk behaviours persist, high rates of reinfection will mean that even very high treatment rates will not result in reductions in $\mathrm{HCV}$ incidence unless treatment is combined with behavioural interventions to reduce risk behaviours after treatment [71]. The HCVree study includes an RCT trialling a behavioural intervention to prevent reinfection. Results are not yet available.

Prisoners are another complex population likely to require targeted approaches for HCV elimination. More research is required to understand strategies for linkage to care in this context. In addition, indigenous peoples, heterosexuals infected with HIV, and migrants from high prevalence HIV and HCV countries are other groups that may also require targeted approaches for linkage to care and maintenance in care. Further research is also required to understand the impact on $\mathrm{HCV}$ elimination strategies in HIV-infected populations of reinfection following successful HCV treatment [72,73], transmission of HCV between HIV infected and uninfected populations [74] and migration- and travel-related transmission of HCV between countries [75]. Furthermore, randomized controlled trials are needed to evaluate the efficacy of strategies to enhance diagnosis, linkage to care and maintenance in care, and risk reduction where feasible and ethical.

This study has a number of limitations. HCV elimination initiatives and studies in HIV-infected populations were not identified through a systematic search and the list presented here is not exhaustive. As previously indicated data on treatment linkage were all early data and represent different stages of DAA treatment availability.
Early data from the DAA era suggest that HCV treatment uptake has increased in HIV-infected populations compared to previous levels, but there is still considerable work to do on the pathway to HCV elimination in this population. This includes efforts to quantify the numbers of undiagnosed infections, and increase diagnosis rates and linkage to care. It is likely that different strategies will be required for different populations including PWID, GBM and prisoners among others. Among those who have been treated with DAAs, treatment completion and treatment success has been consistently high across a variety of settings.

\section{AUTHORS' AFFILIATIONS}

${ }^{1}$ Disease Elimination Program, Burnet Institute, Melbourne, Australia; ${ }^{2}$ Department of Medicine, The University of Melbourne, Melbourne, Australia; ${ }^{3}$ Department of Infectious Diseases, The Alfred and Monash University, Melbourne, Australia; ${ }^{4}$ Department of Infectious Diseases, University Hospital and University of Bern, Bern, Switzerland; ${ }^{5}$ Department of Epidemiology and Preventive Medicine, Monash University, Melbourne, Australia; ${ }^{6}$ The Kirby Institute, University of New South Wales, Sydney, Australia; ${ }^{7}$ Public Health Service Amsterdam, Amsterdam, the Netherlands: ${ }^{8}$ International Antiviral Therapy Evaluation Center and Department of Infectious Diseases, Tropical Medicine and AIDS, Academic Medical Centre, Amsterdam, the Netherlands; ${ }^{9}$ Division of Infectious Diseases and Chronic Viral IIIness Service, McGill University Health Centre, Montreal, Canada; ${ }^{10}$ Department of Epidemiology, Biostatistics and Occupational Health, McGill University, Montreal, Canada; ${ }^{11}$ Infectious Diseases, AP-HP, Sorbonne Universités and Inserm UMR-S1136, Paris, France; ${ }^{12}$ Infectious Diseases, AIDS and Clinical Immunology Research Center, Tbilisi, Georgia; ${ }^{13}$ Section of Infectious Diseases, Yale School of Medicine, New Haven, CT, USA; ${ }^{14}$ Epidemiology of Microbial Diseases, Yale School of Public Health, New Haven, CT, USA; ${ }^{15}$ Centre of Excellence in Research in AIDS, University of Malaya, Kuala Lumpur, Malaysia

\section{COMPETING INTERESTS}

JSD and MEH report grants from Gilead Sciences, Abbvie and BMS to support investigator initiated research. JD and JD's institution have also received honoraria from Gilead, BMS and MSD. AR and CB report grants from MSD during the conduct of the study to support investigator initiated research. GVM reports grants from Abbvie, Gilead Sciences and BMS to support investigator initiated research. MP's institute received speaker's fees and unrestricted grants that contribute to several research projects from Gilead, Roche, MSD and Abbvie. MvdV's institute received speaker's fees and unrestricted grants that contribute to several research projects from Gilead, Roche, MSD and Abbvie. MBK has received research grants for investigator-initiated trials from Merck and ViiV Healthcare; consulting fees from ViiV Healthcare, Bristol-Meyers Squibb, Merck, Gilead and AbbVie. FLA reports grant support from the Gilead Foundation, Merck. NIDA, NIAAA, SAMHSA and HRSA, speakers bureau fees from Gilead Sciences, and advisory board/consultation fees from Gilead, Merck, and BMS. RSD, AP, SS, KL, and NC have no competing interests to declare.

\section{AUTHORS' CONTRIBUTIONS}

RSD, JSD, AR, FLA and MEH designed the data collection tool and manuscript concept; JSD, AR, CB, GVM, MP, MvdV, MBK, SS, KL, NC and MEH provided data on their HCV elimination in HIV co-infected populations initiatives and studies; RSD wrote the first draft of the manuscript; JSD, AR, CB, AEP, GVM, MP, MvdV, $\mathrm{MBK}, \mathrm{SS}, \mathrm{KL}, \mathrm{FLA}, \mathrm{NC}$ and $\mathrm{MEH}$ read and critically reviewed the manuscript draft.

\section{ACKNOWLEDGEMENTS}

We acknowledge Julia Cutts for extracting cascade of care data for the Co-EC study, and the ATHENA, Co-EC, CEASE, Canadian Co-infection Cohort, Georgian AIDSHIS, ANRS CO13 HEPAVIH, the Swiss HIV Cohort study, Swiss HCVree Trial, and MC Free participants and study teams.

\section{FUNDING}

Co-EC is funded by BMS. HCVree is funded by MSD. The Swiss HIV Cohort study is funded by the Swiss National Science Foundation (grant no. 148522), and by the SHCS Research Foundation. CEASE is funded by Gilead Sciences and BMS. MC Free is funded by Abbvie, Gilead Sciences, Johnson \& Johnson, 
Merck Sharp \& Dohme, and Roche. The Canadian Co-infection Cohort Study is funded by the Canadian Institutes of Health Research (CIHR; FDN-143270), the CIHR Canadian HIV Trials Network (CTN-222) and the Fonds de recherche Québec- Santé, Réseau SIDA/maladies infectieuses (FRQ-S). Georgian AIDSHIS is co-funded by the Georgian national HIV/AIDS Management Program and the Global Fund to Fight AIDS, Tuberculosis and Malaria. ANRS CO13 HEPAVIH is funded by the French National Agency for Research on AIDS and Viral Hepatitis (ANRS) and also receives funding from Roche, Schering-Plough, GSK, BMS, and Merck-Serono. RSD is supported by an Early Career Fellowship from the Australian National Health and Medical Research Council. JD is supported by a Clinical Fellowship from the Australian National Health and Medical Research Council. MBK is supported by a Chercheur National career award from the FRQ-S. MH is supported by a Principal Research Fellowship from the Australian National Health and Medical Research Council. The Burnet Institute is supported by the Victorian Operational Infrastructure Support Program.

\section{REFERENCES}

1. Platt L, Easterbrook P, Gower E, McDonald B, Sabin K, McGowan C, et al. Prevalence and burden of $\mathrm{HCV}$ co-infection in people living with HIV: a global systematic review and meta-analysis. Lancet Infect Dis. 2016;16(7):797-808.

2. Smith CJ, Ryom L, Weber R, Morlat P, Pradier C, Reiss P, et al. Trends in underlying causes of death in people with HIV from 1999 to 2011 (D:A:D): a multicohort collaboration. Lancet. 2014;384(9939):241-8.

3. Mahony AA, Donnan EJ, Lester RA, Doyle JS, Knox J, Tracy SL, et al. Beyond injecting drug use: investigation of a Victorian cluster of hepatitis $C$ among HIVinfected men who have sex with men. Med J Aust. 2013;198(4):210-4

4. Hegazi A, Lee MJ, Whittaker W, Green S, Simms R, Cutts R, et al. Chemsex and the city: sexualised substance use in gay bisexual and other men who have sex with men attending sexual health clinics. Int J STD AIDS. 2017;28(4):362-6. 5. Dolan K, Wirtz AL, Moazen B, Ndeffo-mbah M, Galvani A, Kinner SA, et al. Global burden of HIV, viral hepatitis, and tuberculosis in prisoners and detainees. Lancet. 2016; 388(10049):1089-102.

6. Doyle JS, Aspinall E, Liew D, Thompson AJ, Hellard ME. Current and emerging antiviral treatments for hepatitis C infection. Br J Clin Pharmacol. 2013;75 (4):931-43.

7. Martin NK, Hickman M, Hutchinson SJ, Goldberg DJ, Vickerman P. Combination interventions to prevent HCV transmission among people who inject drugs: modeling the impact of antiviral treatment, needle and syringe programs, and opiate substitution therapy. Clin Infect Dis. 2013;57 Suppl 2:S39-45.

8. Martin NK, Thornton A, Hickman M, Sabin C, Nelson M, Cooke GS, et al, Can hepatitis $\mathrm{C}$ virus $(\mathrm{HCV})$ direct-acting antiviral treatment as prevention reverse the HCV epidemic among men who have sex with men in the united kingdom? epidemiological and modeling insights. Clin Infect Dis. 2016;62 (9):1072-80.

9. World Health Organization. Global Health Sector Stratgy on Viral Hepatitis 2016-2021. Towards Ending Viral Hepatitis. Geneva, Switzerland; 2016.

10. Lynch SM, Wu GY. Hepatitis C virus: a review of treatment guidelines, costeffectiveness, and access to therapy. J Clin Transl Hepatol. 2016;4(4):310-9.

11. Hickman M, De Angelis D, Vickerman P, Hutchinson S, Martin NK. Hepatitis $C$ virus treatment as prevention in people who inject drugs: testing the evidence. Curr Opin Infect Dis. 2015;28(6):576-82.

12. UNAIDS. Global AIDS update 2016. Geneva, Switzerland: 2016.

13. Taylor LE, Swan T, Matthews GV. Management of hepatitis C virus/HIV coinfection among people who use drugs in the era of direct-acting antiviralbased therapy. Clin Infect Dis. 2013;57 Suppl 2:S118-24.

14. Janjua NZ, Kuo M, Yu A, Alvarez M, Wong S, Cook D, et al. The population level cascade of care for hepatitis C in British Columbia, Canada: the BC Hepatitis Testers Cohort (BC-HTC). EBioMedicine. 2016;12:189-95.

15. Mathers BM, Degenhardt L, Ali H, Wiessing L, Hickman M, Mattick RP, et al. HIV prevention, treatment, and care services for people who inject drugs: a systematic review of global, regional, and national coverage. Lancet. 2010;375 (9719):1014-28.

16. Ferro EG, Culbert GJ, Wickersham JA, Marcus R, Steffen AD, Pauls HA, et al. Physician decisions to defer antiretroviral therapy in key populations: implications for reducing human immunodeficiency virus incidence and mortality in Malaysia. Open Forum Infect Dis. 2017;4(1):ofw219.

17. Damschroder LJ, Aron DC, Keith RE, Kirsh SR, Alexander JA, Lowery JC. Fostering implementation of health services research findings into practice: a consolidated framework for advancing implementation science. Implement Sci. 2009;4:50.

18. Harvey G, Kitson A. PARIHS revisited: from heuristic to integrated framework for the successful implementation of knowledge into practice. Implement Sci. 2016;11(1):33.
19. Grimshaw J, Eccles M, Tetroe J. Implementing clinical guidelines: current evidence and future implications. J Contin Educ Health Prof. 2004;24(S1): S31-7.

20. Harris M, Rhodes T. Hepatitis C treatment access and uptake for people who inject drugs: a review mapping the role of social factors. Harm Reduct $J$. 2013;10:7.

21. Bruggmann P, Grebely J. Prevention, treatment and care of hepatitis $C$ virus infection among people who inject drugs. Int J Drug Policy. 2015;26 Suppl 1:S22-6.

22. Raymond A, Hill A, Pozniak A. Large disparities in HIV treatment cascades between eight European and high-income countries - analysis of break points. J Int AIDS Soc. 2014;17 4Suppl 3:19507.

23. Kohler P, Schmidt AJ, Cavassini M, Furrer H, Calmy A, Battegay M, et al. The HIV care cascade in Switzerland: reaching the UNAIDS/WHO targets for patients diagnosed with HIV. AIDS. 2015;29(18):2509-15.

24. Kirby Institute. HIV, viral hepatitis and sexually transmissible infections in Australia: annual surveillance report 2017. Sydney: Kirby Institute, UNSW Sydney; 2017.

25. Public Health Agency of Canada. Summary: Measuring Canada's Progress on the 90-90-90 HIV Targets. Centre for Communicable Diseases and Infection Control: Public Health Agency of Canada; 2017.

26. van Sighem Al, Boender TS, Wit FWNM, Smit C, Matser A, Reiss P. Monitoring Report 2017. Human Immunodeficiency Virus (HIV) Infection in the Netherlands. Amsterdam: Stichting HIV Monitoring. 2017 [cited 28 November 2017]. Available from: www.hiv-monitoring.nl

27. Chkhartishvili N, Abutidze A, Bolokadze N, Chokoshvili O, Dvali N, Sharvadze L, et al. Hepatitis C Care Cascade for People Living With HIV in the Country of Georgia. IAS 2017; Paris, France; 2017.

28. Cowie B, Dore G, Sasadeusz J. Co-infection: HIV \& Viral Hepatitis a guide for clinical management. Sydney: Australasian Society for HIV Medicine; 2010.

29. Larsen C, Pialoux G, Salmon D, Antona D, Le Strat Y, Piroth L, et al. Prevalence of hepatitis C and hepatitis B infection in the HIV-infected population of France, 2004. Eurosurveillance. 2008;13(22):18888.

30. Swiss HIV Cohort Study \& Swiss Mother and Child HIV Cohort Study: Hepatitis C [cited 201714 November]. Available from: http://www.shcs.ch/2816-hepatitis-c

31. Hull M, Shafran S, Wong A, Tseng A, Giguere P, Barrett L, et al. CIHR Canadian HIV trials network coinfection and concurrent diseases core research group: 2016 updated Canadian HIV/hepatitis C adult guidelines for management and treatment. Can J Infect Dis Med Microbiol. 2016;2016:4385643.

32. Larney S, Peacock A, Leung J, Colledge S, Hickman M, Vickerman P, et al. Global, regional, and country-level coverage of interventions to prevent and manage HIV and hepatitis C among people who inject drugs: a systematic review. Lancet Glob Health. 2017; 5(12):e1208-20.

33. International Lesbian G, Bisexual, Trans and Intersex Association: Carroll, A., Itaborahy LP. State Sponsored Homophobia 2015: A world survey of laws: criminalisation, protection and recognition of same-sex love Geneva: ILGA, 2015 May.

34. Marshall AD, Saeed S, Barrett L, Cooper CL, Treloar C, Bruneau J, et al. Restrictions for reimbursement of direct-acting antiviral treatment for hepatitis C virus infection in Canada: a descriptive study. CMAJ Open. 2016;4(4): E605.

35. British Columbia Centre for Excellence in HIV/AIDS. Targeted disease elimination [cited 27 June 2017 ]. Available from: http://www.cfenet.ubc.ca/researc h/epidemiology-population-health/hepatitis-c-research-program/targeted-diseaseelimination

36. Bruggmann P, Berg T, Ovrehus AL, Moreno C, Brandao Mello CE, RoudotThoraval F, et al. Historical epidemiology of hepatitis $C$ virus $(\mathrm{HCV})$ in selected countries. J Viral Hepat. 2014;21 Suppl 1:5-33.

37. Wedemeyer H, Dore GJ, Ward JW. Estimates on HCV disease burden worldwide - filling the gaps. J Viral Hepat. 2015;22:1-5.

38. Pioche C, Pelat C, Larsen C. Desenclos J-C, Jauffret-Roustide M, Lot F, et al. Estimation de la prévalence de l'hépatite $C$ en population générale, France métropolitaine, 2011. Bull Epidémiol Hebd. 2016;13-14:224-9.

39. Hajarizadeh B, Grebely J, McManus H, Estes C, Razavi H, Gray RT, et al. Chronic hepatitis $C$ burden and care cascade in Australia in the era of interferon-based treatment. J Gastroenterol Hepatol. 2017;32(1):229-36.

40. Klein MB, Saeed S, Yang H, Cohen J, Conway B, Cooper C, et al. Cohort profile: the Canadian HIV-hepatitis C co-infection cohort study. International journal of epidemiology. 2010;39(5):1162-9.

41. Op de Coul ELM, Schreuder I, Conti S, van Sighem A, Xiridou M, Van Veen $M G$, et al. Changing patterns of undiagnosed HIV infection in the Netherlands: who benefits most from intensified HIV test and treat policies? PLoS One. 2015;10(7):e0133232. 
42. Béguelin C, Suter A, Bernasconi E, Fehr J, Kovari H, Bucher HC, et al. Trends in HCV treatment uptake, efficacy and impact on liver fibrosis in the Swiss HIV Cohort Study. Liver Int. 2017;00:1-8.

43. Saeed S, Strumpf EC, Moodie EEM, Young J, Nitulescu R, Cox J, et al. Disparities in direct acting antivirals uptake in HIV-hepatitis C co-infected populations in Canada. J Int AIDS Soc. 2017;20(3):e25013.

44. Hill AM, Nath S, Simmons B. The road to elimination of hepatitis C: analysis of cures versus new infections in 91 countries. J Virus Erad. 2017;3(3):117-23. 45. Boerekamps A, Newsum AM, Smit C, Arends JE, Richter C, Reiss P, et al. High treatment uptake in HIV/HCV-coinfected patients after unrestricted access to direct-acting antivirals in the Netherlands. Clin Infect Dis. 2017; In press. Published online 23 November 2017.

46. Saris J, Van den Berk G, Ait Moha D, Van Der Meer J, Brinkman K, Van Der Valk M. Successful implementation of HCV treatment in two large HIV clinics in Amsterdam: HCV treatment cascade of care. AIDS. 2017;31(12):1779-80, 47. Martinello M, Dore GJ, Bopage RI, Finlayson R, Baker D, Bloch M, et al., editors. DAA treatment scale-up in HIV/HCV co-infection: characterising a population at risk for reinfection. International Liver Congree (EASL); 2017 April; Amsterdam

48. Salmon D. Retour d'expérience, Cohorte ANRS CO13. Foie et VIH 9 Nov; Rencontres Sainte Marguerite, Marseille, France; 2017.

49. Sogni P, Gilbert C, Lacombe K, Piroth L, Rosenthal E, Miailhes P, et al. Alloral direct-acting antiviral regimens in HIV/hepatitis $C$ virus-coinfected patients with cirrhosis are efficient and safe: real-life results from the prospective ANRS CO13-HEPAVIH cohort. Clin Infect Dis. 2016;63(6):763-70.

50. Zhou K, Fitzpatrick T, Walsh N, Kim JY, Chou R, Lackey M, et al. Interventions to optimise the care continuum for chronic viral hepatitis: a systematic review and meta-analyses. Lancet Infect Dis. 2016;16(12):1409-22.

51. Dimova RB, Zeremski M, Jacobson IM, Hagan H, Des Jarlais DC, Talal AH. Determinants of hepatitis $C$ virus treatment completion and efficacy in drug users assessed by meta-analysis. Clin Infect Dis. 2013;56(6):806-16.

52. World Health Organization. Global hepatitis report 2017. Geneva; 2017.

53. van Boekel LC, Brouwers EPM, van Weeghel J, Garretsen HFL. Stigma among health professionals towards patients with substance use disorders and its consequences for healthcare delivery: Systematic review. Drug Alcohol Depend. 2013;131(1-2):23-35.

54. Wade A, Draper B, Doyle J, Allard N, Grinzi P, Thompson A, et al. A survey of hepatitis $\mathrm{C}$ management by Victorian GPs after PBS-listing of direct-acting antiviral therapy. Aust Fam Physician. 2017;46(4):235-40.

55. Yap L, Carruthers S, Thompson S, Cheng W, Jones J, Simpson P, et al. A descriptive model of patient readiness, motivators, and hepatitis $C$ treatment uptake among Australian prisoners. PLoS One. 2014;9(2):e87564.

56. Caceres C, Pecheny M, Frasca T, Raupp Rios R. Review of Legal Frameworks and the Situation of Human Rights related to Sexual Diversity in Low and Middle Income Countries. Report commissioned by UNAIDS, 2008.

57. DeBeck K, Cheng T, Montaner JS, Beyrer C, Elliott R, Sherman S, et al. HIV and the criminalisation of drug use among people who inject drugs: a systematic review. Lancet HIV. 2017;4(8):e357-74.

58. Wolfe D, Carrieri MP, Shepard D. Treatment and care for injecting drug users with HIV infection: a review of barriers and ways forward. Lancet. 2010;376(9738):355-66.

59. Dolan K, Wirtz AL, Moazen B, Ndeffo-mbah M, Galvani A, Kinner SA, et al. Global burden of HIV, viral hepatitis, and tuberculosis in prisoners and detainees. Lancet. 2016;388(10049):1089-102.
60. Marco A, Esteban JI, Solé C, da Silva A, Ortiz J, Roget M, et al. Hepatitis C virus reinfection among prisoners with sustained virological response after treatment for chronic hepatitis C. J Hepatol. 2013;59(1):45-51.

61. Bate JP, Colman AJ, Frost PJ, Shaw DR, Harley HAJ. High prevalence of late relapse and reinfection in prisoners treated for chronic hepatitis C. J Gastroenterol Hepatol. 2010;25(7):1276-80.

62. Lazarus JV, Safreed-Harmon K, Stumo SR, Jauffret-Roustide M, Maticic M, Reic $T$, et al. Restrictions on access to direct-acting antivirals for people who inject drugs: The European Hep-CORE study and the role of patient groups in monitoring national HCV responses. International Journal of Drug Policy. 2017:47:47-50.

63. Coats JT, Dillon JF. The effect of introducing point-of-care or dried blood spot analysis on the uptake of hepatitis $\mathrm{C}$ virus testing in high-risk populations: a systematic review of the literature. Int J Drug Policy. 2015;26(11):1050-5.

64. Nasrullah M, Sergeenko D, Gamkrelidze A, Averhoff F. HCV elimination lessons learned from a small Eurasian country, Georgia. Nat Rev Gastroenterol Hepatol. 2017;14(8):447-8.

65. Litwin AH, Agyemang L, Akiyama MJ, Norton BL, Heo M, Ning Y, et al. The PREVAIL study: intensive models of HCV care for people who inject drugs. Jersey City, USA: INHSU; 2017.

66. Boyle A, Marra F, Fox R, Fleming C, Reilly E, Heydtmann M, et al. Successful treatment of patients on opiate replacement therapy utilising partial directly observed therapy of DAAs in community pharmacies. Jersey City, USA: INHSU; 2017.

67. Valente R, Sousa M, Nunes J, Gomes C, Gouveia C, Ferreira AM. Hepatitis $\mathrm{C}$ treatment in people receiving opiod substitution therapy: a difficult population? Jersey City, USA: INHSU; 2017.

68. Thierfelder C, Gotthardt F, Huber C, Jochum A. High DAA-treatment uptake and success in clients with chronic HCV-infection under OST despite structural and individual challenges. Jersey City, USA: INHSU; 2017.

69. Ulstein K, Backe O, Midgard H, Vennesland K, Wusthoff L, Darlgard O. Feasability and efficacy of direct-acting antiviral hepatitis $C$ treatment in a low threshold setting. Jersey City, USA: INHSU; 2017.

70. Robert J, Tremblay J, Bissonnet H, Zeagman T, Latour E. Linking PWUD to hepatitis C care and prevention. Jersey City, USA: INHSU; 2017.

71. Salazar-Vizcaya L, Kouyos RD, Zahnd C, Wandeler G, Battegay M, Darling KEA, et al. Hepatitis $C$ virus transmission among human immunodeficiency virus-infected men who have sex with men: modeling the effect of behavioral and treatment interventions. Hepatology (Baltimore, MD). 2016;64(6):1856-69. 72. Lambers FA, Prins M, Thomas X, Molenkamp R, Kwa D, Brinkman K, et al. Alarming incidence of hepatitis $C$ virus re-infection after treatment of sexually acquired acute hepatitis C virus infection in HIV-infected MSM. AIDS. 2011;25 (17):F21-7.

73. Simmons B, Saleem J, Hill A, Riley RD, Cooke GS. Risk of late relapse or reinfection with hepatitis C virus after achieving a sustained virological response: a systematic review and meta-analysis. Clin Infect Dis. 2016;62 (6):683-94.

74. Hoornenborg E, Achterbergh R, Schim Van Der Loeff M, Davidovich U, Hogewoning A, Vries $\mathrm{H}$, et al. MSM starting pre-exposure prophylaxis are at risk of hepatitis C virus infection. AIDS. 2017;31(11):1603-1610.

75. van de Laar T, Pybus O, Bruisten S, Brown D, Nelson M, Bhagani S, et al. Evidence of a large, international network of HCV transmission in HIV-positive men who have sex with men. Gastroenterology. 2009;136(5):1609-17. 


\title{
Treatment advocate tactics to expand access to antiviral therapy for HIV and viral hepatitis $C$ in low- to high-income settings: making sure no one is left behind
}

\author{
Céline Grillon ${ }^{1}$, Priti R Krishtel ${ }^{2}$, Othoman Mellouk ${ }^{3}$, Anton Basenko ${ }^{4}$, James Freeman ${ }^{5}$, Luís Mendão ${ }^{6}$, \\ Isabelle Andrieux-Meyer ${ }^{7}$ and Sébastien Morin ${ }^{8 \S}$ \\ §Corresponding author: Sébastien Morin, International AIDS Society, Avenue de France 23, Geneva CH-1202, Switzerland. Tel: +41 227100868. \\ (sebastien.morin@iasociety.org)
}

\begin{abstract}
Introduction: Worldwide, 71 million people are infected with hepatitis C virus (HCV), which, without treatment, can lead to liver failure or hepatocellular carcinoma. HCV co-infection increases liver- and AIDS-related morbidity and mortality among HIV-positive people, despite ART. A 12-week course of HCV direct-acting antivirals (DAAs) usually cures HCV - regardless of HIV status. However, patents and high prices have created access barriers for people living with HCV, especially people who inject drugs (PWID). Inadequate access to and coverage of harm reduction interventions feed the co-epidemics of HIV and $\mathrm{HCV}$; as a result, the highest prevalence of HCV is found among PWID, who face additional obstacles to treatment (including stigma, discrimination and other structural barriers). The HIV epidemic occurred during globalization of intellectual property rights, and highlighted the relationship between patents and the high prices that prevent access to medicines. Indian generic manufacturers produced affordable generic HIV treatment, enabling global scale-up. Unlike HIV, donors have yet to step forward to fund HCV programmes, although DAAs can be mass-produced at a low and sustainable cost. Unfortunately, although voluntary licensing agreements between originators and generic manufacturers enable low-income (and some lower-middle income countries) to buy generic versions of HIV and HCV medicines, most middle-income countries with large burdens of $\mathrm{HCV}$ infection and HIV/HCV co-infection are excluded from these agreements. Our commentary presents tactics from the HIV experience that treatment advocates can use to expand access to DAAs.

Discussion: A number of practical actions can help increase access to DAAs, including new research and development (R\&D) paradigms; compassionate use, named-patient and early access programmes; use of TRIPS flexibilities such as compulsory licences and patent oppositions; and parallel importation via buyers' clubs. Together, these approaches can increase access to antiviral therapy for people living with HIV and viral hepatitis in low-, middle- and high-income settings.

Conclusions: The HIV example provides helpful parallels for addressing challenges to expanding access to HCV DAAs. HCV treatment access - and harm reduction - should be massively scaled-up to meet the needs of PWID, and efforts should be made to tackle stigma and discrimination, and stop criminalization of drug use and possession.
\end{abstract}

Keywords: human immunodeficiency virus; hepatitis C virus; co-infection; access; patent; low- and middle-income countries; direct-acting antivirals; people who inject drugs

Received 21 August 2017; Accepted 20 December 2017; Published 9 April 2018

Copyright $\odot 2018$ The Authors. Journal of the International AIDS Society published by John Wiley \& sons Ltd on behalf of the International AIDS Society. This is an open access article under the terms of the Creative Commons Attribution License, which permits use, distribution and reproduction in any medium, provided the original work is properly cited.

\section{1 | INTRODUCTION}

Worldwide, an estimated 71 million people have chronic hepatitis $\mathrm{C}$ virus (HCV) infection; 2.3 million of them are HIV coinfected [1]. The highest prevalence of HCV infection - 82\% - is found among HIV-infected people who inject drugs (PWID) [2] HIV co-infection increases the risk for, and accelerates the rate of hepatitis $C$ disease progression, despite use of antiviral therapy [3]. In turn, HCV co-infection more than doubles the mortality rate among HIV-positive people [4]. Lower survival in HIV/ $\mathrm{HCV}$ co-infected PWID is due in part to structural barriers, such as criminalization; mandated drug treatment; [5] homelessness; stigma and discrimination in healthcare settings; lack of HIV education and support; provider concerns about adherence and drug resistance; lack of linkage between HIV treatment programmes and needle/syringe exchange programmes, and competing survival priorities (linked to poverty and marginalization) [6,7]. These factors, and others, have limited HCV treatment access for PWID, such as the historical exclusion of PWID from HCV clinical trials, which has led providers to withhold HCV treatment, due to lack of evidence, fears about poor adherence and concerns about post-treatment reinfection [8]. 
Recently, a pair of DAA clinical trials in people who were using and/or injecting drugs during HCV treatment reported adherence and cure rates similar to non-users [9,10]. Guidelines from the World Health Organization (WHO), the American Association for the Study of Liver Disease (AASLD)/ Infectious Diseases Society of America (IDSA), the European Association for the Study of the Liver (EASL), and the International Network for Hepatitis in Substance Users (INHSU) [1114] now recommend treatment for PWID. Nonetheless, regardless of their HIV status, PWID are less likely to be treated for HCV than non-injectors, often through policies that increase discrimination in healthcare by restricting access to DAAs based on recent drug use $[15,16]$.

DAAs are still too expensive for individual patients and as public health tools. Innovative approaches are needed to address complex regulatory requirements, intellectual property, and licensing agreements to improve access to affordable DAAs.

Our commentary presents tactics drawn from the HIV experience that treatment advocates can use to expand access to DAAs in different settings, and ensure that marginalized populations - including PWID - are not left behind. This is essential if the world is to reach the targets set by the WHO for elimination of hepatitis $C$ as a public health concern by $2030[17]$.

\section{DISCUSSION}

\subsection{Access challenges}

Affordable generic antiretrovirals (ARVs) for HIV treatment have made it possible to scale-up HIV treatment access, but geographic barriers and high prices limit access to DAAs. The $\mathrm{HCV}$ epidemic is concentrated in middle-income countries (MICs) [18], which will be home to the majority of HIV-positive people by 2020 [19]. However, global donors are reluctant to support HCV programmes, and are reducing HIV funding to these countries [20]. For example, the world's highest prevalence of HIV/HCV co-infection is found in Eastern Europe and Central Asia [2], a region that has been experiencing the deepest Global Fund cuts (which may reach 40\%-50\% in the coming years) [21].

Figure 1 shows some of the latest available pricing figures for sofosbuvir/daclatasvir. The scarcity of published DAA

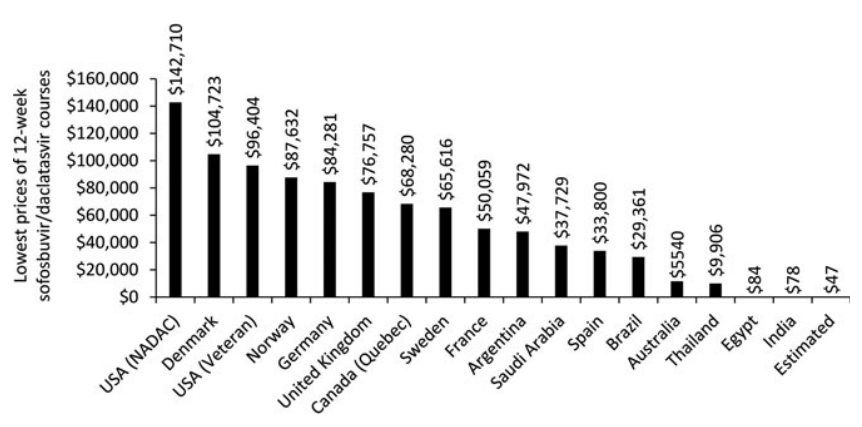

Figure 1. Lowest prices of sofosbuvir/daclatasvir 12-week courses in selected countries. Estimated: Minimum cost estimation for large-scale production. Prices are from September 2017 and shown in US\$. Used with permission and adapted from Hill [30]. prices makes it difficult to assess price evolutions in different settings. Nevertheless, the available data shows that generic $\mathrm{HCV}$ treatment can be produced affordably, and sustainably. A 12-week course of sofosbuvir and daclatasvir, including profit, could be sold for US \$47 [22,30]. However, Cipla, Hetero and Mylan in India - the main sources of $\mathrm{WHO}$-prequalified generic ARVs - and several other generic manufacturers have signed voluntary licenses for sofosbuvir with DAA originator company Gilead Sciences (directly) and for daclatasvir (for which the patent holder is Bristol-Myers Squibb) with the Medicines Patent Pool. According to a 2003 WHO report on cost-containment mechanisms for medicines, voluntary licenses allow patent holders to "license to other parties, on an exclusive or nonexclusive basis, the right to manufacture, import, and/or distribute a pharmaceutical product"; they are "usually made for strategic reasons (e.g. market entry) rather than as price gestures and they may not entail any price reduction" [24]. Although voluntary licenses improve access to affordable generic medicines in some countries, most MICs are excluded from these agreements (including China, Russia and Turkey, all with more than 500,000 HCV cases [25]), which forces them to pay high prices from originator companies. They also often prevent generic manufacturers who sign these agreements from selling to territories outside of the geographic scope of the license - even if a patent is successfully challenged. Although voluntary licenses signed with patent holders directly may not be transparent, voluntary licenses signed through the Medicines Patent Pool are transparent and public-health-oriented. For example, the Medicines Patent Pool license with Bristol-Myers Squibb for daclatasvir states that "generic daclatasvir can be made in any country as long as it is for sale in the countries covered by the agreement" [26]. Some generic manufacturers have decided not to sign voluntary licensing agreements (Pharco in Egypt, Beker in Algeria, and Pharma5 in Morocco). Generic DAAs from Pharco and Beker have demonstrated bio-equivalence [27], and Pharco is expecting WHO prequalification shortly.

MICs may therefore need to pursue several strategies to provide access to DAAs, including use of legal tools to remove patent barriers such as compulsory licenses (a legal mechanism under Trade-Related Aspects of Intellectual Property Rights, TRIPS, flexibilities that allow governments to produce or import patented medicines without the patent holder's permission, a strategy used by Malaysia in 2017 [28]) and patent oppositions. Low-income countries face different access challenges than MICs [29]. Although they may be included in voluntary licenses that allow them to purchase generic DAAs, their prices may still be too high, and lack of access to high-priced HCV diagnostics and limited infrastructure makes it challenging for these countries to bring HCV treatment to scale.

\subsection{New R\&D paradigms to provide accessible medicines}

The Drugs for Neglected Diseases initiative (DNDi) has been working with Pharco to develop an affordable, easy-to-use, highly efficacious and safe oral pan-genotypic regimen, for a public health approach, as part of a "test and cure" strategy [31]. DNDi has taken a non-exclusive license on ravidasvir (an investigational NS5A inhibitor), and intends to make it widely, following successful clinical trials and regulatory approval, 
available through sub-licenses to regional or local industrial partners.

\section{3 | Originator access programmes: compassionate use, named-patient and early access}

Compassionate use, named-patient, and early access programmes are not meant to address public health needs or support elimination campaigns (although they are vital for many individuals). Compassionate use programmes are initiated to serve unmet medical needs while regulators are reviewing dossiers; early access programmes provide medicines during pricing negotiations (e.g. to prevent patients on the verge of life-threatening liver disease situation from waiting).
Originators should offer compassionate use/early access programmes during negotiations and in countries where they have not sought marketing authorization and where there are no generics available. They should also be encouraged to provide no-cost access for people with advanced liver disease living in settings with access challenges.

\subsection{Using patent challenges to ensure access to affordable generic medicines}

Patent opposition is the process by which non-State actors challenge the legality of a patent. Treatment advocates have been opposing patents to secure access to affordable generic medicines, including for HIV drugs (tenofovir disoproxil

Table 1. HCV DAAs patent oppositions. Adapted and updated from the World Community Advisory Board on HCV Generics and Diagnostics [38]

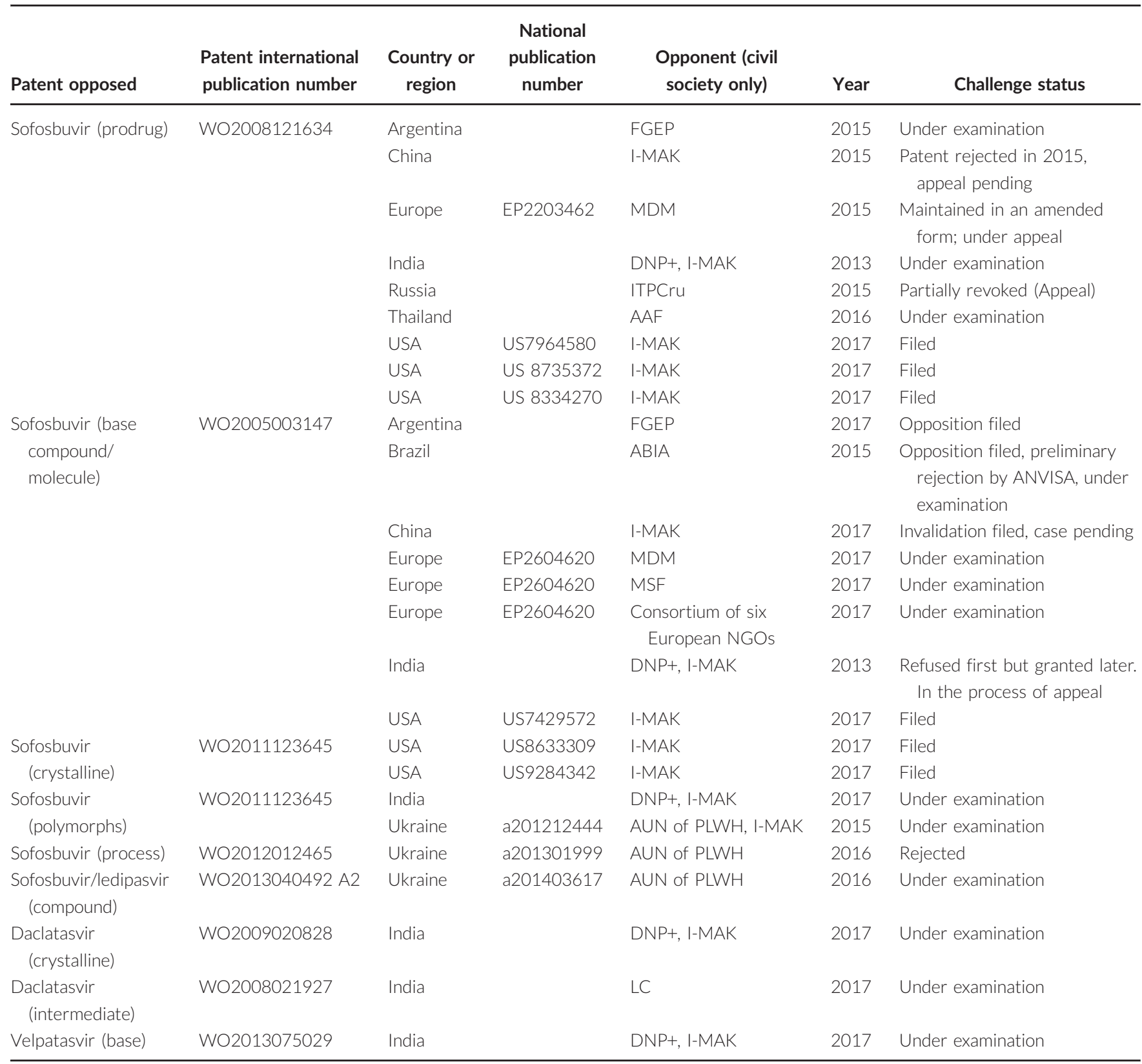


fumarate's patent was revoked in India in 2009) [32]. As recently recommended by the United Nations Secretary-General's High-Level Panel on Access to Medicines, countries should make full use of public health safeguards contained in the TRIPS agreement to ensure that patents and other intellectual property restrictions do not prevent access to affordable medicines [23].

Patent opposition is a powerful tool for civil society to oppose undeserved patents and secure access to affordable generic medicines when governments are unwilling or unable to do so. The profusion of patents covering a single medication and the absence of provisions for patent opposition in certain countries may remain challenging for the use of patent opposition as a public health tool. In addition, countries that have introduced additional exclusivity protection (such as data and market exclusivity) face delays in access to affordable generic drugs, even in the absence of patent protection.

Patents covering DAAs have been opposed by the Initiative for Medicines, Access \& Knowledge (I-MAK) and other civil society organizations in Argentina, Brazil, China, India, Russia and Ukraine [33], while HCV treatment rationing in highincome countries led Médecins du Monde (also known as Doctors of the World) and others to oppose patents on $\mathrm{HCV}$ medicines before the European patent office [34]. Patent oppositions have already led to the rejection of key patents on sofosbuvir in China and Ukraine [36], and to its substantial weakening in Brazil and Europe [34]. Gilead Sciences has appealed the decisions in India and Europe. Key patents on sofosbuvir and daclatasvir have also been rejected by the patent office in Egypt. Oppositions challenging patents covering daclatasvir and velpatasvir are under examination in India $[35,37]$. Table 1 provides a list of HCV treatment patent oppositions to date.

\subsection{Parallel importation via buyers' clubs}

Buyers' clubs leverage the TRIPS flexibility outlined in Article 60 - De Minimus Imports, which states "Members may exclude from the application of the above provisions small quantities of goods of a non-commercial nature contained in travellers' personal luggage or sent in small consignments" [39]. Most countries allow personal medication importation, including receiving a 3-month supply of medicine through the mail.

Reputable buyers' clubs can help patients navigate the unfamiliar and potentially dangerous process of personal importation, operating as an advocate/agent to comply with laws dictating that only pharmacists can sell medications, while the patient remains the legal buyer and importer. Buyers' clubs provide government and insurers with breathing space and a better negotiating position. In negotiations, delay and volume restriction are the primary tools. Drug companies know that the urgency to get medications to desperately ill patients means that governments and insurers simply cannot hold out indefinitely - and will eventually capitulate to public pressure. In countries where Buyers' clubs operate effectively (including in Australia, New Zealand, Italy, Switzerland), advantageous price negotiations for DAAs were finalized rapidly.

\section{3 | CONCLUSIONS}

The DAA era presents a fantastic opportunity to eliminate $\mathrm{HCV}$ - but low- and middle-income countries, and PWID in particular, are being left behind, without access to HCVrelated information, prevention and treatment. Indeed, despite being essential to reach the WHO targets for HCV elimination, expanding access to DAAs will need to be matched by efforts to address the structural barriers faced by PWID: systemic and structural discrimination, stigma and human rights violations [16].

The progress made around access to antiretroviral therapy for HIV provides helpful parallels when confronted with challenges for expanding access to DAAs for HCV treatment. HIV/HCV co-infection may represent a natural starting point for scaling up HCV treatment coverage, especially for PWID. Although lessons from HIV advocacy give us an understanding of the key pressure points to increase access to HCV antivirals (the DAAs) and eliminate HCV as a public health threat, achieving this victory will be impossible until PWID can access $\mathrm{HCV}$ prevention, care and treatment. This is particularly

\section{Table 2. Treatment advocate tactics to expand access to antiviral therapy}

\section{Tactics}

Pros and cons

New R\&D paradigms

Patent oppositions

Advocacy for the use of compulsory licenses

Parallel importation via buyers' clubs

Originator access programmes
+ Potentially very effective globally

- Depending on large financial resources, high-level scientific and clinical expertise and subject to a timeline of multiple years

+ Potentially very effective at the national or global level

- Depending on legal expertise and subject to a timeline of multiple years

+ Potentially very effective at the national or global level

- Depending on government action and strong political commitment

+ Fully legal and relatively simple approach that can increase access to patients locally, while helping countries negotiate lower prices at the national level

- Limited impact (relatively small number of people directly getting access through this approach)

+ Relatively easy to negotiate, taking advantage of drug originators corporate responsibility efforts and importance of public relations

- Limited impact (relatively small number of people getting access through this approach) 
important in Eastern Europe and Central Asia, where there are dramatic donor funding cuts, high HIV/HCV co-infection rates, and historically repressive drug policies. Drug policy reform, the fulfilment of human rights and the creation of non-criminalizing environments are critical enablers for any comprehensive attempt to address and reverse the twin epidemics of HIV and HCV among the community of PWID.

DAAs can be mass-produced at a low and sustainable cost. Unfortunately, although voluntary licensing agreements enable low-income (and some lower-middle income countries) to buy generic versions of HIV and HCV medicines, most middleincome countries with large burdens of $\mathrm{HCV}$ and $\mathrm{HIV} / \mathrm{HCV}$ co-infection are excluded from these agreements, and therefore face higher prices. A number of practical actions can help increase access to DAAs in low-, middle-, and high-income countries. The tactics presented in our commentary are summarized in Table 2. Together, they can contribute to increasing access to antiviral therapy for HIV and HCV in low- to high-income settings.

Unfortunately, the repressive laws that criminalize PWID continue to interfere with the treatment and harm reduction programmes that are essential to their health. These programmes are fully effective only when they operate in a supportive legal environment, where PWID know that they will not face police harassment or arrest. Stigma and discrimination within the medical community, including concerns about poor adherence, reinfection, and the lack of treatment settings adapted to the needs of PWID create additional barriers to treatment among PWID. Investment into the development of a medicine called "antistigmavir" may need to accompany expanded access to DAAs.

\section{AUTHORS' AFFILIATIONS}

${ }^{1}$ Médecins du Monde, Paris, France; ${ }^{2}$ Initiative for Access, Medicines and Knowledge, Oakland, CA, USA; ${ }^{3}$ International Treatment Preparedness Coalition, Marrakech, Morocco; ${ }^{4}$ Alliance for Public Health, Kiev, Ukraine; ${ }^{5}$ FixHepC, Hobart, Australia; ${ }^{6}$ European AIDS Treatment Group, Lisbon, Portugal; ${ }^{7}$ Drugs for Neglected Diseases initiative, Geneva, Switzerland; ${ }^{8}$ International AIDS Society, Geneva, Switzerland

\section{COMPETING INTERESTS}

PRK, OM, AB, LM and CG declare no competing interest. IAM works for DNDi, which has a partnership agreement with Pharco. JF runs a website called fixhepc.com that assists patients executing a personal medication importation of generic HCV medication. SM works for the International AIDS Society (IAS), which receives funding from a number of different sources, including from the biomedical industry.

\section{AUTHORS' CONTRIBUTIONS}

All authors contributed equally to drafting the content, editing and reviewing the manuscript.

\section{ACKNOWLEDGEMENTS}

The authors thank Tracy Swan for comments on a draft of this paper and Andrew Hill for the permission to reuse a figure presented at the World Hepatitis Summit 2017

\section{REFERENCES}

1. WHO. Global hepatitis report. 2017 [cited 2017 Jul 15]. Available from: http://apps.who.int/iris/bitstream/10665/255016/1/9789241565455-eng.pdf? ua $=1$
2. Platt L, Easterbrook P, Gower E, McDonald B, Sabin K, McGowan C, et al. Prevalence and burden of HCV co-infection in people living with HIV: a global systematic review and meta-analysis. Lancet Infect Dis. 2016;16(7):797-808.

3. Thein $\mathrm{HH}$, Yi Q, Dore GJ, Krahn MD. Natural history of hepatitis C virus infection in HIV-infected individuals and the impact of HIV in the era of highly active antiretroviral therapy: a meta-analysis. AIDS. 2008;22(15):1979-91.

4. May MT, Justice AC, Birnie K, Ingle SM, Smit C, Smith C, et al. Injection drug use and hepatitis $C$ as risk factors for mortality in HIV-infected individuals: the Antiretroviral Therapy Cohort Collaboration. J Acquir Immune Defic Syndr. 2015;69(3):348-54.

5. Wolfe D. Paradoxes in antiretroviral treatment for injecting drug users: access, adherence and structural barriers in Asia and the former Soviet Union. Int J Drug Policy. 2007;18(4):246-54.

6. Chakrapani V, Velayudham J, Shunmugam M, Newman PA, Dubrow R. Barriers to antiretroviral treatment access for injecting drug users living with HIV in Chennai, South India. AIDS Care. 2014;26(7):835-41.

7. Wood E, Kerr T, Tyndall MW, Montaner JS. A review of barriers and facilitators of HIV treatment among injection drug users. AIDS. 2008;22(11):1247-56.

8. Grady BP, Schinkel J, Thomas XV, Dalgard O. Hepatitis C virus reinfection following treatment among people who use drugs. Clin Infect Dis. 2013;57 (Suppl 2):S105-10.

9. Dore GJ, Altice F, Litwin AH, Dalgard O, Gane EJ, Shibolet O, et al. C-EDGE CO-STAR Study Group. Elbasvir-Grazoprevir to treat hepatitis C virus infection in persons receiving opioid agonist therapy: a randomized trial. Ann Intern Med. 2016;165(9):625-34.

10. Grebely J, Dalgard O, Conway B, Cunningham E, Bruggmann P, Hajarizadeh B, et al.; on behalf of the SIMPLIFY Study Group. Efficacy and safety of sofosbuvir/velpatasvir in people with chronic hepatitis C virus infection and recent injecting drug use: The SIMPLIFY study. EASL (Abstract FRI 234), 19-22 April 2017, Amsterdam, the Netherlands.

11. WHO. Guidelines for the screening, care and treatment of persons with chronic hepatitis C infection. 2016 [cited 2017 Jul 13]. Available from: http:// apps.who.int/iris/bitstream/10665/205035/1/9789241549615_eng.pdf

12. AASLD/IDSA. HCV Guidance: recommendations for testing, managing and treating hepatitis C. 2017 [cited 2017 Jul 17]. Available from: http://www.hcvgui delines.org

13. EASL. Recommendations on treatment of hepatitis C. 2016 [cited 2017 Jul 14]. Available from: http://www.easl.eu/medias/cpg/HCV2016/English-report.pdf 14. Grebely J, Robaeys G, Bruggmann P, Aghemo A, Backmund M, Bruneau J, et al. Recommendations for the management of hepatitis $C$ virus infection among people who inject drugs. Intl J Drug Policy. 2015;26(10):1028-38.

15. Wansom T, Falade-Nwulia O, Sutcliffe CG, Mehta SH, Moore RD, Thomas $\mathrm{DL}$, et al. Barriers to hepatitis $\mathrm{C}$ virus $(\mathrm{HCV})$ treatment initiation in patients with human immunodeficiency virus/HCV coinfection: lessons from the interferon era. Open Forum Infect Dis. 2017;4(1):ofx024.

16. Grebely J, Dore GJ, Morin S, Rockstroh JK, Klein MB. Elimination of HCV as a public health concern among people who inject drugs by 2030 - what will it take to get there? J Int AIDS Soc. 2017;20:22146.

17. WHO. Global Health Sector Strategy (GHSS) on viral hepatitis 2016-2021. 2016 [cited 2017 Nov 28]. Available from: http://www.who.int/hiv/strat egy2016-2021/en/

18. Woode ME, Abu-Zaineh M, Perriëns J, Renaud F, Wiktor S, Moatti JP. Potential market size and impact of hepatitis $C$ treatment in low- and middleincome countries. J Viral Hepat. 2016;23(7):522-34.

19. WHO. Increasing access to HIV treatment in middle-income countries. 2014 [cited 2017 Jul 17]. Available from: http://www.who.int/phi/publications/ WHO_Increasing_access_to_HIV_treatment.pdf

20. Henry J, Kaiser Family Foundation/UNAIDS. Financing the response to HIV in low- and middle-income countries: international assistance from donor governments. 2016 [cited 2017 Jul 17]. Available from: http://files.kff.org/attachme nt/Financing-the-Response-to-HIV-in-Low-and-Middle-Income-Countries-Interna tional-Assistance-from-Donor-Governments-in-2015

21. MSF. Open letter to the global fund to fight AIDS, TB and malaria. 2016 [cited $2017 \mathrm{Jul}$ 16]. Available from: https://www.msfaccess.org/content/msf-ope n-letter-global-fund-fight-aids-tb-and-malaria

22. Hill A, Barber M, Gotham D, et al. \$90-\$90-\$90: how we can achieve these access prices (2017). IAS 2017 (Abstract WESY0402), 24-27 July, Paris, France.

23. United Nations Secretary-General's High-Level Panel on Access to Medicines. Final report of the United Nations Secretary-General's High-Level Panel on Access to Medicines: promoting innovation and access to health technologies. 2016 [cited 2017 Jul 20]. Available from: http://www.unsgaccessmeds.org/ final-report/ 
24. WHO. Cost-containment mechanisms for essential medicines, including antiretrovirals, in China - Health Economics and Drugs Series No. 013. 2003 [cited 2017 Nov 28]. Available from: http://apps.who.int/medicinedocs/en/d/ Js4907e/3.5.htm

25. hepCoalition. Map crowd: online global data on hepatitis C. [cited 2017 Nov 28]. Available from: http://mapcrowd.org/en/gilead_s_voluntary_licence

26. MPP. The medicines patent pool signs licence with bristol-myers squibb to increase access to Hepatitis C medicine daclatasvir. [cited 2017 Dec 19]. Available from: https://medicinespatentpool.org/mpp-media-post/the-medicines-pate nt-pool-signs-licence-with-bristol-myers-squibb-to-increase-access-to-hepatitis-cmedicine-daclatasvir/

27. Hill AM, Tahat L, Mohammed MK, Nath S, Tayyem RF, Freeman JA, et al. Bioequivalent pharmacokinetics for generic and originator hepatitis $\mathrm{C}$ direct acting antivirals. AASLD (Abstract 1078), 20-24 October 2017, Washington, DC. USA.

28. Saez C. Malaysia grants compulsory licence for generic sofosbuvir despite gilead licence. 2017. IP Watch [cited 2017 Nov 29]. Available from: https:// www.ip-watch.org/2017/09/15/malaysia-grants-compulsory-licence-generic-sof osbuvir-despite-gilead-licence

29. World Trade Organization. Agreement on trade-related aspects of intellectual property rights. [cited 2017 Nov 28]. Available from: https://www.wto.org/ english/tratop_e/trips_e/trips_e.htm

30. Hill A. Access to hepatitis medicines. World Hepatitis Summit. 2 November 2017. Sao Paulo, Brazil. Personal communication.
31. DNDi. 2016. Drugs for neglected diseases initiative and pharco pharmaceuticals to test affordable hepatitis C regimen with support of Malaysian and Thai governments. 2016. [cited 2017 Aug 12]. Available at: https://www.dndi.org/ 2016/media-centre/press-releases/dndi-pharco-hepc-malaysia-thailand/

32. Patent Opposition Database. Tenofovir disoproxil fumarate download data. 2017 [cited 2017 Jun 27]. Available from: https://www.patentoppositions.org/ en/drugs/tenofovir-disoproxil-fumarate\#oppositions

33. Bagcchi S. Campaigners challenge patent applications for hepatitis C drug in five countries. BMJ. 2015;350:h2938.

34. Stafford N. Sofosbuvir faces fresh patent challenge in Europe. BMJ. 2017;356:j1632.

35. Patent Opposition Database. Velpatasvir. [cited 2017 Jun 27]. Available from: https://www.patentoppositions.org/en/drugs/velpatasvir

36. Kmietowicz Z. China rejects patent on hepatitis $C$ drug sofosbuvir. BMJ 2015;350:h3429.

37. Patent Opposition Database. Daclatasvir. [cited 2017 Nov 27]. Available from: https://www.patentoppositions.org/en/drugs/daclatasvir

38. World Community Advisory Board on HCV Generics and Diagnostics. Forging a path to $\mathrm{HCV}$ elimination: simpler tests and affordable generics. 2017 [cited 2017 Nov 28]. Available from: http://www.treatmentactiongroup. org/content/forging-path-hcv-elimination-simpler-tests-and-affordable-generics 39. World Trade Organization. Agreement on trade-related aspects of intellectual property rights. Annex 1C. 1994 [cited 2017 Aug 3]. Available from: https://www.wto.org/english/docs_e/legal_e/27-trips_01_e.htm 


\title{
What do clinicians need to watch for with direct-acting antiviral therapy?
}

\author{
Alessio Aghemo ${ }^{1,2 \$, *}$, Lionel Piroth ${ }^{3, *}$ and Sanjay Bhagani $i^{4, *}$ \\ ${ }^{\S}$ Corresponding author: Alessio Aghemo, Department of Biomedical Sciences, Humanitas University, Division of Internal Medicine and Hepatology, Department of \\ Internal Medicine, Humanitas Research Hospital, Via A. Manzoni 11320089 Rozzano, Milan, Italy. Tel: 00390282247006 (alessio.aghemo@hunimed.eu, www. \\ hunimed.eu) \\ *All authors contributed equally to this manuscript.
}

\begin{abstract}
Introduction: The introduction of drugs targeting the virus replication cycle has revolutionized treatment of chronic hepatitis $C$ virus. These drugs, called direct-acting antivirals, have brought about extremely high rates of virological cure and have increased the number of patients who can receive treatment due to the lack of absolute contraindications. A combination of different classes of direct-acting antivirals is the current standard of care. Although treatment administration and monitoring has been simplified in recent years, it is still relatively complex and mostly in the hands of specialists. Several factors must be assessed before starting treatment to maximize efficacy and minimize side effects of treatment. In this review, we describe the factors that impact on the efficacy and safety of antiviral treatment for hepatitis $\mathrm{C}$ and provide clear recommendations for clinicians prescribing direct-acting antivirals.

Methods: We reviewed literature to define best practice, based on factors associated with treatment efficacy and safety data to recommend treatment options, baseline and on-treatment assessments. The review included searches in PubMed, and the abstracts presented at the International Liver Congress TM and The Liver Meeting TM between January 2013 and September 2017.

Results: Clinical features that must be assessed before starting treatment include virological factors, such as hepatitis $C$ virus genotype, HIV and hepatitis B coinfection and host factors, such as concomitant medications, liver disease stage and renal function.

Conclusions: Patients who start antiviral treatment for chronic hepatitis C require a thorough clinical evaluation. There is a need for assessing factors that impact on the treatment schedule and duration or affect the pharmacokinetics of direct-acting antivirals.
\end{abstract}

Keywords: Hepatitis; HCV; Baseline; Safety; DAA; Coinfection

Received 28 September 2017; Accepted 18 January 2018; Published 9 April 2018

Copyright (c) 2018 The Authors. Journal of the International AIDS Society published by John Wiley \& sons Ltd on behalf of the International AIDS Society. This is an open access article under the terms of the Creative Commons Attribution License, which permits use, distribution and reproduction in any medium, provided the original work is properly cited.

\section{1 | INTRODUCTION}

Treatment of chronic hepatitis C virus ( $\mathrm{HCV}$ ) has been revolutionized by the introduction of drugs, called direct-acting antivirals (DAAs) [1,2], which target the virus replication cycle. These drugs target key steps in HCV replication: polyprotein cleavage by the NS3 protease (protease inhibitors, PIs); HCV RNA strain synthesis (NS5B polymerase inhibitors of two sorts; nucleoside analogues, NA, and non-nucleosides); and stabilization of the replication complex and viral release (NS5A inhibitors) [3,4]. A combination of different classes of DAAs is essential to obtain viral replication suppression and ultimately viral clearance.

Sustained virological response, defined as serum HCV RNA below the limit of detection 12 weeks after the end of therapy (SVR 12), is the goal of treatment. SVR 12 is a marker of virological and clinical cure as patients who reach this endpoint show decreased mortality and improved quality of life [5]. Until 2013, treatment of HCV was based on pegylated interferon, a drug that was introduced in 1986 and achieved SVR rates in the 50\% range while also being associated with significant side effects [5]. Currently, SVR 12 rates in the $90 \%$ to $95 \%$ range are achievable in most patient populations $[5,6]$.

While DAAs have greatly simplified the management of patients with chronic HCV infection, treatment of $\mathrm{HCV}$ is still relatively complex and mostly in the hands of specialists [7]. Although economic considerations are at least in part responsible for this restriction, there are still factors that modify the efficacy and safety of DAAs; these must be assessed before staring treatment. The therapeutic drug development process in HCV has been completed, and the only possible improvements to currently available DAAs will be in the form of 
optimization of treatment in groups where there are still gaps in knowledge. It is therefore important that knowledge around DAA-based HCV treatment is widely disseminated while we move towards simplification of pre-, on- and post-treatment monitoring and make treatments available widely outside of specialist care. In this review article, we will summarize the current knowledge on what clinicians should assess before, during and after DAA-based therapy $[8,9]$.

\section{2 | METHODS}

We conducted a PubMed search looking for articles assessing factors associated with DAA treatment efficacy and safety, restricted to articles published between January 2013 and September 2017. We also analysed the abstracts presented at the International Liver Congress ${ }^{\mathrm{TM}}$ and The Liver Meeting ${ }^{\mathrm{TM}}$. We used permutations of the following search terms "Hepatitis C treatment" "Direct Acting Antivirals" "Complications" "Monitoring" and "HIV." We restricted the search to abstracts/ articles published in English.

\section{$3 \mid$ RESULTS}

\section{1 | Pre-treatment assessment}

Before starting DAA therapy in patients with HCV infection, pre-treatment assessment should be aimed at determining factors that modify the safety and the efficacy of DAAs [5]. Factors that are known modifiers of efficacy and safety include: HCV genotype; liver disease severity; comorbid conditions that include coinfection with HBV, HIV and renal impairment; and concomitant medications. These factors determine the optimal treatment choice at the individual level (Figure 1 and Table 1).

\subsection{HCV genotype determination}

HCV circulates in seven different genotypes worldwide [10]. $\mathrm{HCV}$ genotype does not play a major role as a modifier of the

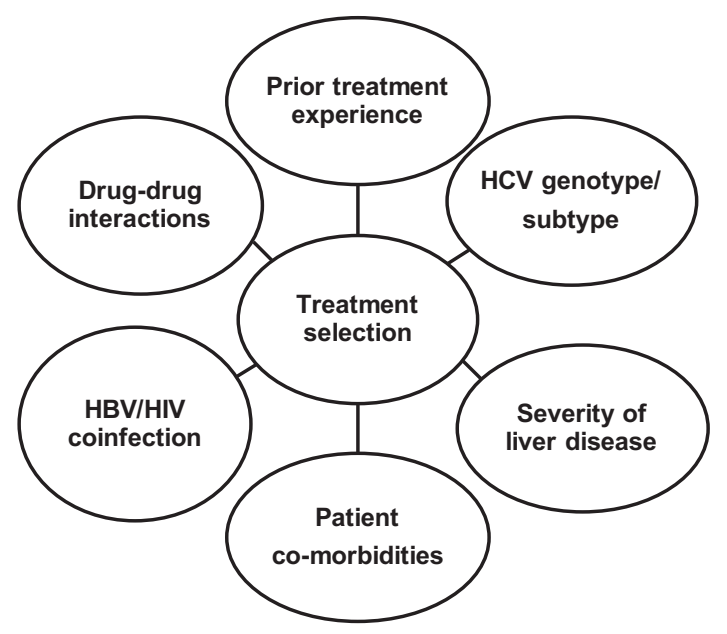

Figure 1. Pre-treatment variables that must be assessed before starting DAA therapy. natural course of the disease, but has a dramatic influence on the efficacy of pegylated interferon-based regimens [5]. Not all DAAs are affected in the same way by HCV genotype as some are pangenotypic while others are restricted in efficacy to specific HCV genotypes. Moreover, in patients with $\mathrm{HCV}$ genotype 1 infection, there is a need for subtyping. This is because subtype 1a, with a lower barrier to genotypic resistance with first- and second-generation PIs, requires extended treatment duration and/or the addition of ribavirin with the combination of grazoprevir/elbasvir, or use of sofosbuvir/ledipasvir or ritonavir-boosted paritaprevir/ombitasvir plus dasabuvir $[5,9]$.

The arrival of the next-generation potent DAA combinations with pangenotypic activity - sofosbuvir/velpatasvir (SOFNEL), glecaprevir/pibrentasvir (G/P) and sofosbuvir/velpatasvir/voxilaprevir (SOFNELNOX) - limits the need for HCV genotyping and subtyping. However, before abandoning HCV genotyping, we should bear in mind that access to pangenotypic regimens is not universal and optimal treatment schedules with G/P, SOFNEL and SOFNELNOX still varies according to HCV genotype [9]. With these three pangenotypic regimens, there is certainly a need for identifying genotype $3 \mathrm{HCV}$ (G3) patients. G/P requires 16 weeks of treatment in $\mathrm{G} 3$ patients who have failed a previous course of treatment, while SOF/ VEL requires the addition of ribavirin in G3 treatment-experienced patients and cirrhotic patients [5,9].

SOFNELNOX is less impacted by HCV genotype, as 12 weeks of treatment with this regimen are able to achieve >95\% SVR rates independently from HCV genotype, previous DAA failure or fibrosis stage [9] However, identifying patients with G3 infection is important since a short treatment duration of 8 weeks is sufficient in G3 treatment-naive patients with cirrhosis [9].

The European Association for the Study of the Liver (EASL) recommends: "Genotyping/subtyping should be performed with an assay that accurately discriminates subtype 1a from $1 \mathrm{~b}$, i.e. an assay using the sequence of the $5^{\prime}$ untranslated region plus a portion of another genomic region, generally the core-coding or the NS5B-coding regions." [5]. Other tests based on assessment of only one region of the HCV genome have been shown to be less accurate for the identification of genotype 1 subtype and thus should not be routinely performed if a DAA that is subtype susceptible must be used [5].

\section{3 $\quad$ Disease severity}

Identifying patients with cirrhosis or advanced fibrosis affects the choice of the treatment regimen and the post-treatment prognosis, as well as the post-treatment follow-up schedule [5]. In the past, assessment of disease severity was based on histological fibrosis staging by liver biopsy; this procedure is now unnecessary due to the risk of serious side effects, as well as the development of accurate non-invasive methods. Considerable evidence supports the use of non-invasive methods as first-line modality for liver disease staging [11]. Liver stiffness measurement can assess liver fibrosis and the presence of portal hypertension in patients with chronic hepatitis $C$ if consideration is given to factors that may adversely affect its performance, such as obesity, fasting status, other causes of liver disease and alanine aminotransferase (ALT) values [11]. 
Table 1. Interpretation of pre-treatment assessment in DAA candidates

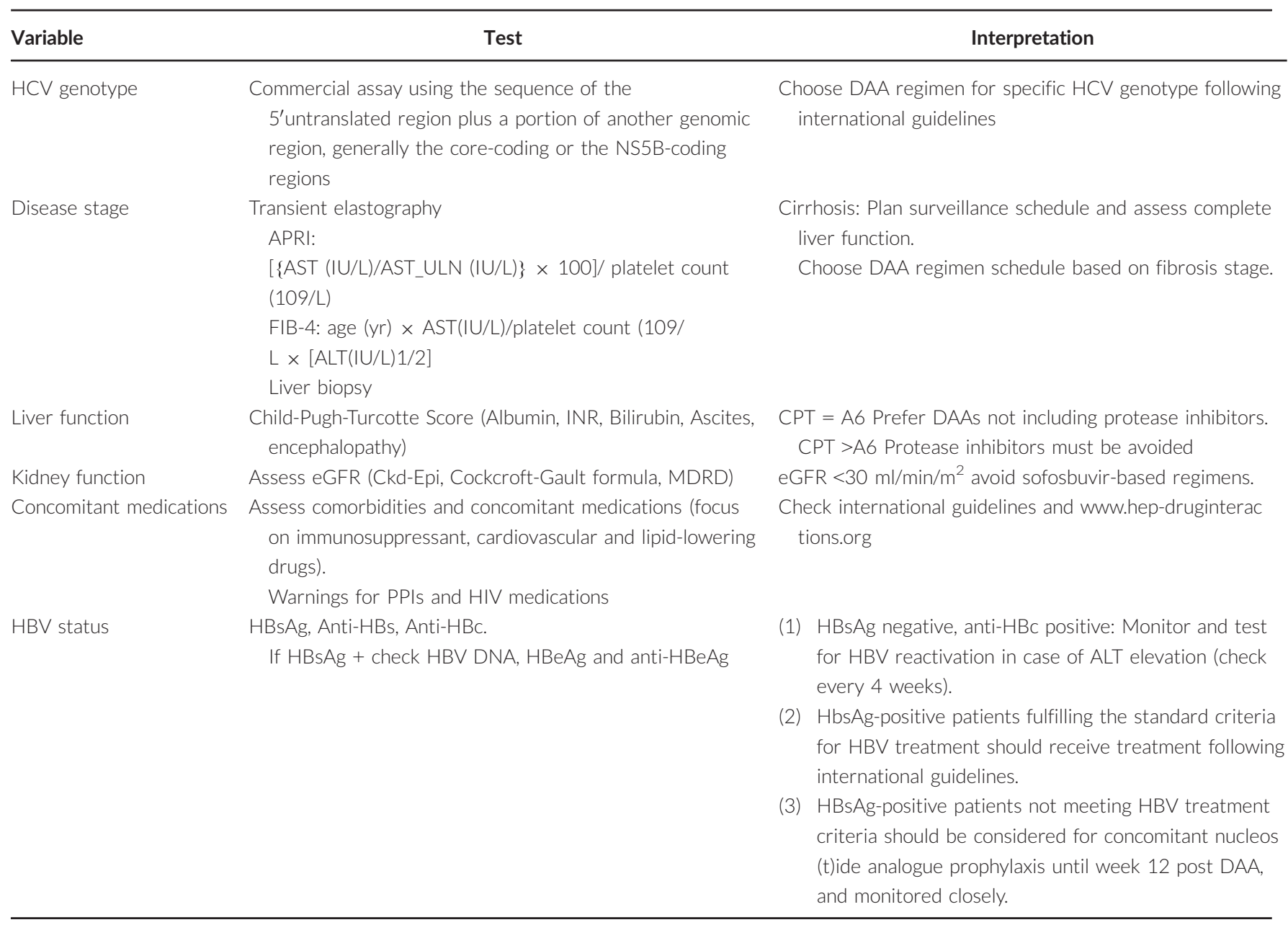

Transient elastography values $<10 \mathrm{KPa}$ can rule out the presence of advanced fibrosis and values $>12.5$ to $14 \mathrm{KPa}$ are suggestive of the presence of advanced fibrosis/cirrhosis. Screening for oesophageal varices is recommended in patients with elastography values $>20 \mathrm{KPa}$ and/or platelet count $<150,000 \mu \mathrm{L}$ [12]. Transient elastography is reproducible and has a high level of acceptability by patients, but is still not readily available worldwide and requires investment in expensive equipment and trained operators. In resource-limited settings, or where transient elastography is not available, World Health Organization (WHO) guidelines for HCV management [13] recommend using serum tests, such as the APRI, or FIB4 scores, which measure indirect markers of fibrosis, for example, ALT, aspartate aminotransferase (AST) and platelet count to assess fibrosis stage. All non-invasive methods to assess fibrosis stage must be performed before starting treatment. Their interpretation following achievement of an SVR can be tricky as, for example, early post-treatment reduction in liver stiffness may reflect resolution of liver inflammation [14] and could lead to misclassification of patients with advanced disease.

In patients with cirrhosis, precise definition of liver function to assess the prognosis of the disease is mandatory. The Child-Pugh-Turcotte score (CPT), which requires measurement of five clinical and laboratory variables (prothrombin time; albumin values; presence and degree of encephalopathy; presence and degree of ascites; and bilirubin levels), should be performed before the start of any DAA treatment. The CPT score divides patients into 3 classes: A when the score is 5 or 6, B when the score is 7 to 9 , and $C$ when it is 10 to 15 . In patients with CPT A5, all DAAs can be safely administered. By contrast, in patients with $\mathrm{CPT} B$ and $\mathrm{C}$, any DAA regimen that includes a NS3 protease inhibitor must be avoided because Pls are extensively metabolized in the liver by the CYP3A4 family of enzymes. Thus, in the presence of impaired liver function (CPT B and C) a $>100$ fold increase in the serum levels of PIs can be seen. The use of PIs in patients with CPT $B$ and $C$ class has resulted in cases of further liver function deterioration, hepatic decompensation and death [5,9]. No firm recommendation can be given in patients with CPT A6, where PIs appear to be safe. However, given that these patients might be unstable and CPT class might transition rapidly from $A$ to $B$, it is our opinion that PIs should not be the preferred option in this group of patients.

\subsection{Renal function}

From a pathophysiological point of view, there is a direct link between chronic HCV infection and kidney impairment [15]. 
Not only can HCV lead to the development of cryoglobulinemic glomerulonephritis, but it can also cause kidney impairment due to direct inflammation. Moreover, diabetes is more prevalent in HCV patients due to a direct link between viral infection and development of insulin resistance [15].

Overall, HCV infection is associated with a 43\% increase in the risk of developing chronic kidney disease (CKD) [15]. Kidney function can be measured easily by calculating the estimated glomerular filtration rate in $\mathrm{ml} / \mathrm{min}$ (eGFR). With respect to DAAs, it is mandatory to identify those patients with a CKD stage 4-5, i.e., eGFR $<30 \mathrm{~mL} / \mathrm{min} / 1.73 \mathrm{~m}^{2}$, as sofosbuvir should be used with caution in this subgroup [5]. Indeed, approximately $80 \%$ of sofosbuvir is renally excreted. The majority of the sofosbuvir dose recovered in urine is the dephosphorylation-derived nucleoside metabolite GS-331007 (78\%), while $3.5 \%$ is recovered as sofosbuvir. Renal clearance is the major elimination pathway for GS-331007 with a large part actively secreted [5]. Based on these findings, the current EASL recommendations for the treatment of $\mathrm{HCV}$ state that "no sofosbuvir dose recommendation can be given for patients with severe renal impairment (eGFR $<30 \mathrm{~mL} / \mathrm{min} / 1.73 \mathrm{~m}^{2}$ ) or with end-stage renal disease due to higher exposures (up to 20-fold) of GS-331007". This limitation currently affects only a small group of people (0.3\% of the general population), but still accounts for a significant knowledge gap in patients who have previously failed a PI-containing DAA regimen where the optimal retreatment option is the combination of SOFNEL/ vOX [9].

Preliminary real-life data where sofosbuvir was given to patients with CKD stage 4-5 have provided conflicting results with most not showing an increased rate of side effects [16]. However, in the Target report by Saxena and colleagues, the CKD stage 4-5 patients who received sofosbuvir-based regimens showed a 30\% rate of eGFR deterioration and an $18 \%$ incidence of serious adverse events, which were both statistically higher than that observed in patients with preserved kidney function [17]. For this reason, caution is warranted in using sofosbuvir in CKD stage 4-5 patients, and a thorough risk/benefit analysis should be performed before contemplating use $[5,9,18]$.

For DAA-naïve patients with CKD stage 4-5, DAA regimens not based on NS5B polymerase inhibitors, such as paritaprevir/ombitasvir/dasabuvir, grazoprevir/elbasvir and glecaprevir/ pibrentasvir, are the preferred treatment options that have proven safety and efficacy in phase III clinical trials, as well as in real-life cohorts [9]. The only drawback is that these regimens include a PI, which is unsafe and not recommended for patients with decompensated cirrhosis. An HCV patient with stage 4-5 CKD and decompensated liver disease is potentially untreatable with this option. Instead, if indicated, kidney and liver transplantation should be prioritized.

\subsection{Hepatitis B virus coinfection}

Although HCV and HBV share ways of transmission, coinfection with both viruses is generally rare. Epidemiological studies report a prevalence of $\mathrm{HBV} / \mathrm{HCV}$ coinfection in the $0.2 \%$ to $1.9 \%$ range, with higher rates in Eastern Asia [19]. From a clinical standpoint, HBV/HCV coinfection is associated with faster disease progression, higher rates of liver cancer and reduced survival. Most $\mathrm{HBV} / \mathrm{HCV}$-coinfected patients will show active HCV replication with related liver damage and a concomitant $\mathrm{HBeAg}$ negative chronic hepatitis state $(\mathrm{HBsAg}$ positivity, HBeAg negative, HBV DNA $<2000 \mathrm{IU} / \mathrm{mL}$ and lack of HBV-induced liver damage) [20-22]. This is the direct consequence of negative reciprocal interaction between HBV and $\mathrm{HCV}$ replication. Several reports in the pegylated interferon era showed that achievement of an SVR could derange this balance leading to HBV reactivation once HCV was cleared $[19,20,23]$.

The same was reported in HBV/HCV-coinfected patients receiving DAAs. Following the first FDA warning of 29 reported cases of $\mathrm{HBV}$ reactivation in DAA post-marketing analysis, several large cohort studies (but not all) have reported cases of reactivation in $\mathrm{HBV} / \mathrm{HCV}$-coinfected patients receiving DAAs with similar incidence to that reported with pegylated interferon-based treatments [24]. From 377 HBV/HCV-coinfected patients, Belperio and colleagues reported HBV reactivation in eight patients (2\%) [25]. Similarly, in a large systematic analysis of 1185 patients, the cumulative incidence of HBV reactivation was $14.1 \%$ in HBsAg-positive patients treated with DAAs [26].

Most importantly there is a need to assess the risk of reactivation in patients with isolated anti-HBc serological profile (HBsAg negative, anti-HBc positive), which represent more than 1 billion people worldwide [19]. Current evidence does not show a major risk of reactivation in patients with positive $\mathrm{HBc}$ antibodies, with the few cases reported in the literature being biased by confounding factors, such as HIV coinfection, concomitant use of immunosuppressive therapy or concomitant extra-hepatic malignancies [19,27].

Therefore, all patients starting DAAs need to be evaluated for HBV coinfection (HBsAg, anti-HBs, anti-HBc). For HBsAgpositive patients, definition of disease state is essential to understand the need for anti-HBV treatment.

The most recent EASL HBV clinical practice guidelines state that [19]:

(1) Patients fulfilling the standard criteria for HBV treatment should receive anti-HBV active nucleoside analogue (NA) treatment.

(2) HBsAg-positive patients undergoing DAA therapy should be considered for concomitant anti-HBV NA prophylaxis until week 12 post DAA, and monitored closely.

(3) HBsAg-negative, anti-HBc-positive patients undergoing DAA should be monitored (ALT testing every 2 to 4 weeks) and tested for HBV reactivation in case of ALT elevation.

\subsection{HIV/HCV coinfection}

Since HIV and HCV share the same routes of transmission, $\mathrm{HIV} / \mathrm{HCV}$ coinfection is not uncommon [28]. Although use of combination antiretroviral therapy ameliorates some of the risk of accelerated hepatic fibrosis and clinical decompensation, this does not revert back to the levels seen in HCV monoinfected patients [29]. This led to calls for wide access to anti-HCV therapy, even though the response rates following conventional interferon-based therapy were lower in coinfected patients than in HCV-monoinfected patients [30]. DAAbased therapy has changed this as registration trials and reallife cohorts suggest that HCV clearance rates are equivalent 
among HIV/HCV-coinfected individuals and HCV monoinfected patients [31].

For all these reasons, access by HIV/HCV-coinfected patients to all DAA therapy has been prioritized in many countries, whatever these patients' fibrosis stage. There are, however a number of important drug-drug interaction considerations to take into account before choosing an appropriate DAA regimen; this applies not only to antiretroviral therapy, but also to frequently prescribed co-medications for the management of multiple comorbidities in this group of patients $[5,9,32]$. Important drug-drug interactions may not just be related to cytochrome P450 isoenzymes, but are also associated with a myriad of drug-transporter proteins in the gastrointestinal tract, liver and the kidneys [32].

Indeed, interactions via renal drug transporters with DAAs, such as ledipasvir or velpatasvir, may increase the risk of renal impairment when combined with tenofovir DF [5,9].

\section{7 $\quad$ Drug-drug interactions}

Numerous and complex drug-drug interactions (DDIs) are possible with the HCV DAAs [33]. Once taken orally, DAAs must be absorbed and enter the blood circulation, a process regulated by gastric $\mathrm{pH}$ and gut transporters. Most of the DAAs will then be metabolized in the liver by the cytochrome P450 family of enzymes and then excreted either in the bile or by the kidney [5]. DAAs can be excreted from enterocytes to the gut lumen or from hepatocytes into the biliary system by proteins, such as P-glycoprotein 1 (P-GP1) or breast cancer-resistance protein (BCRP). These proteins and the gastric $\mathrm{pH}$, as well as enzymes from the cytochrome P450 family, can be induced or inhibited by other concomitant drugs that the patients might be taking. Therefore, the potential for drugdrug interactions is present in all patients planned for treatment with DAAs. This requires a thorough DDI risk assessment prior to starting therapy and before starting other medications during treatment. Data on potential DDIs can be found on the prescribing information for each DAA; a useful Internet resource is www.hep-druginteractions.org, where recommendations are regularly updated.

An exact list of all DDIs is beyond the scope of this review. However, clinicians should be aware of potential DDIs with anti-HIV drugs, as we have highlighted. Similarly, commonly prescribed drugs, such as proton pump inhibitors (PPIs), might lower the efficacy of some DAAs. PPIs may be associated with reduced efficacy of sofosbuvir/ledipasvir [34]. Velpatasvir is also impacted by gastric pH; for this reason, PPIs should be taken four hours after velapatsvir [5,9]. Other groups of patients that require careful evaluation of DDIs due to high risk of clinically significant interactions are recipients of organ transplantation and patients taking antiarrhythmic and/or antiplatelets and/or lipid-lowering medications [5,9].

However, DDIs are rarely a reason for not starting DAA treatment since therapeutic alternatives are usually possible and given the short duration of DAA-based therapy for HCV, many DDIs can be overcome or circumvented.

\section{8 $\quad$ On-treatment monitoring}

Treatment monitoring is aimed at assessing efficacy, safety and DDIs. Treatment monitoring was key during pegylated interferon-based regimens as rules for treatment duration and treatment stopping were defined by HCV RNA on treatment kinetics, and haematological and systemic side effects were common [35]. Given the high SVR rates achieved with DAA combinations and the current lack of a response guided treatment algorithm, monitoring of DAA treatment efficacy can be achieved by measuring HCV RNA at baseline and 12 weeks after the end of therapy to assess SVR12 $[5,36]$. In all cases, HCV RNA testing should be performed with a real-time PCR-based assay with a lower limit of detection of $\leq 15 \mathrm{IU} / \mathrm{mL}$ [5].

Monitoring for side effects is also of little to no practical use as new DAA regimens are generally well tolerated with less than $1 \%$ of patients discontinuing treatment for side effects or reporting serious adverse events [5,9]. However, monthly assessment of liver function status is necessary in patients with advanced liver disease. Kidney function should also be assessed monthly in patients with CKD stage 4-5 who receive sofosbuvir-based regimens, and regular haematological blood tests (every 4 weeks) should be done in patients who receive ribavirin.

\subsection{Monitoring of patients who achieved an SVR}

The achievement of an SVR 12 is the definition of cure as persistent and lifelong HCV RNA undetectability is maintained in $99.3 \%$ of patients [37]. Whether SVR patients need to be maintained on regular liver follow up is determined by the pre-treatment fibrosis stage (advanced fibrosis/cirrhosis vs. mild/moderate fibrosis) and/or the presence of comorbidities known to have an impact on disease progression rates and HCC development (diabetes, alcohol abuse, overweight, other causes of liver diseases) [5,9]. Non-cirrhotic patients who achieve an SVR should be retested for HCV RNA at 48 weeks post-treatment and if HCV RNA remains undetectable, then there is no need for further follow up [5]. Non-cirrhotic patients with comorbidities known to influence the residual risk of liver cancer or known to cause liver damage should remain under regular follow up with annual blood tests and liver ultrasound.

Cirrhotic patients who achieve an SVR have been shown to have comparable survival rates to the general population matched by age and sex. However, there is a residual risk of HCC development (0.3\%-1\% yearly incidence), which is influenced by age and presence of decompensated cirrhosis [3840]. Thus, patients with advanced fibrosis (METAVIR score F3) or pre-existing cirrhosis and an SVR should remain under surveillance for HCC every 6 months by ultrasound and for oesophageal varices by endoscopy if varices were present at pre-treatment endoscopy. The duration of HCC surveillance in these patients with advanced fibrosis or cirrhosis who achieve an SVR is indefinite [5].

In HIV-HCV-coinfected patients successfully treated with DAAs, considering the potential residual higher risk of progression and the lack of specific data in this population, there is still a need for close follow up following HCV cure. Another potential risk is reinfection due to persistent risk behaviour. Reported rates of reinfection following successful HCV treatment among patients at high risk are estimated at between $1 \%$ and $5 \%$ per year, higher particularly in men who have sex with men practicing "chemsex" [41]. Thus the ease of 
Interferon free therapy may increase the likelihood of reinfection. In order to maximize the benefit of therapy, the risks of reinfection should be emphasized to patients at risk, and behavioural modifications should be positively reinforced. HCV RNA should be closely monitored in patients with continued risk practices (for example, ongoing intravenous drug using, "chemsex" and mucousal-traumatic sexual practices).

\section{CONCLUSIONS}

The era of DAAs has revolutionized HCV therapy, with the vast majority of patients having access to treatment expected to be cured of HCV infection. Recently approved DAA combinations herald a new paradigm of shortened-duration pan-genotypic regimens. A number of factors pre-therapy still determine optimal regimens, duration of therapy, the need for additional ribavirin and on-treatment monitoring for toxicity, but this may not be required in the future as we move towards pan-genotypic regimens. As treatments get easier in terms of adverse effects, and shorter, on-treatment monitoring will also diminish for the vast majority of patients.

There is already a study underway to assess response without the need for on-treatment monitoring and clinic visits for non-cirrhotic patients (SMART-C study ClinicalTrials.gov Identifier: NCT03117569).

Economic considerations should also not impair access to these treatments for all patients infected with HCV. Future emphasis will be identifying all these patients with $\mathrm{HCV}$, increasing and facilitating access to therapy, to achieve the WHO goals to reduce incidence of new HCV infections by $90 \%$ and mortality by $65 \%$ by 2030 .

\section{AUTHORS' AFFILIATIONS}

${ }^{1}$ Department of Biomedical Sciences, Humanitas University, Pieve Emanuele, Milan, Italy; ${ }^{2}$ Division of Internal Medicine and Hepatology, Humanitas Clinical and Research Center, Rozzano, Milan, Italy; ${ }^{3}$ Infectious Diseases Department, University Hospital, INSERM, Dijon, France; ${ }^{4}$ Department of Infectious Diseases/HIV Medicine, Royal Free London Foundation Trust, Research Department of Infection, UCL, London, UK

\section{COMPETING INTERESTS}

A Aghemo has received honoraria, fees and travel grants from Abbvie, Gilead, MSD, Janssen, BMS and research grants from Gilead. S Bhagani has received honoraria, fees, travel grants and research grants from Abbvie, Gilead and ViiV. L Piroth has nothing to disclose.

\section{AUTHORS' CONTRIBUTIONS}

Alessio Aghemo, Lionel Piroth and Sanjay Bhagani designed the review, drafted the manuscript and critically revised it.

\section{REFERENCES}

1. Butt AA, Yan P, Shaikh OS, Chung RT, Sherman KE; ERCHIVES study. Sofosbuvir-based regimens in clinical practice achieve SVR rates closer to clinical trials: results from ERCHIVES. Liver Int. 2016;36(5):651-8.

2. Preda CM, Popescu CP, Baicus C, Voiosu TA, Manuc M, Pop CS, et al. Realworld efficacy and safety of ombitasvir, paritaprevir/r+dasabuvir+ribavirin in genotype 1b patients with hepatitis C virus cirrhosis. Liver Int. 2017; https://d oi.org/10.1111/liv.13550.

3. Aghemo A, De Francesco R. New horizons in hepatitis C antiviral therapy with direct-acting antivirals. Hepatology. 2013;58(1):428-38.
4. Pawlotsky JM. New hepatitis C therapies: the toolbox, strategies, and challenges. Gastroenterology. 2014;146(5):1176-92.

5. European Association for the Study of the Liver. EASL recommendations on treatment of hepatitis C 2016. J Hepatol. 2017;66(1):153-94.

6. D'Ambrosio R, Degasperi E, Colombo M, Aghemo A. Direct-acting antivirals: the endgame for hepatitis C? Curr Opin Virol. 2017;24:31-7.

7. Marshall AD, Cunningham EB, Nielsen S, Aghemo A, Alho H, Backmund M, et al. Restrictions for reimbursement of interferon-free direct-acting antiviral drugs for HCV infection in Europe. Lancet Gastroenterol Hepatol. 2018;3 (2):125-33 https://doi.org/10.1016/s2468-1253(17)30284-4

8. Pawlotsky JM, Hepatitis C. Drugs: is next generation the last generation? Gastroenterology. 2016;151(4):587-90.

9. HCV Guidance: Recommendations for Testing, Managing, and Treating Hepatitis C. 2017 [cited 2017 Sep 25]. Available from: http://uww.hcvguidelines. org/.

10. Aghemo A, Dore GJ, Hatzakis A, Wedemeyer H, Razavi H. Estimating HCV disease burden. J Viral Hepat. 2015;22(Suppl 4):1-3.

11. European Association for Study of Liver; Asociacion Latinoamericana para el Estudio del Higado. EASL-ALEH Clinical Practice Guidelines: non-invasive tests for evaluation of liver disease severity and prognosis. J Hepatol. 2015;63 (1):237-64.

12. de Franchis R, Faculty Baveno VI. Expanding consensus in portal hypertension: report of the Baveno VI Consensus Workshop: stratifying risk and individualizing care for portal hypertension. J Hepatol. 2015;63(3):743-52.

13. WHO. Guidelines for the screening, care and treatment of persons infected with chronic Hepatitis C infection, updated version 2016. 2017 [cited 2017 Dec 23]. Available from: http://www.who.int/hepatitis/publications/hepatitis-cguidelines-2016/en/

14. Chan J, Gogela N, Zheng H, Lammert S, Ajayi T, Fricker Z, et al. Direct acting antiviral therapy for hcv infection results in liver stuffness regression over 12 months post-treatment. Dig Dis Sci. 2018;63(2):486-492.

15. Cacoub P, Desbois AC, Isnard-Bagnis C, Rocatello D, Ferri C. Hepatitis C virus infection and chronic kidney disease: time for reappraisal. J Hepatol. 2016;65(1 Suppl):S82-94.

16. Saxena V, Khungar V, Verna EC, Levitsky J, Brown RS Jr, Hassan MA, et al. Safety and efficacy of current direct-acting antiviral regimens in kidney and liver transplant recipients with hepatitis C: results from the HCV-TARGET study. Hepatology. 2017;66(4):1090-101.

17. Saxena V, Koraishy FM, Sise ME, Lim JK, Schmidt M, Chung RT, et al. Safety and efficacy of sofosbuvir-containing regimens in hepatitis C-infected patients with impaired renal function. Liver Int. 2016;36(6):807-16.

18. De Nicola S, Aghemo A. The quest for safe and effective treatments of chronic hepatitis C in patients with kidney impairment. Liver Int. 2016;36 (6):791-3.

19. European Association for the Study of the Liver. EASL 2017 Clinical Practice Guidelines on the management of hepatitis B virus infection. J Hepatol. 2017:67(2):370-98.

20. Lampertico P, Maini M, Papatheodoridis G. Optimal management of hepatitis B virus infection - EASL Special Conference. J Hepatol. 2015;63 (5):1238-53.

21. Raimondo G, Brunetto MR, Pontisso P, Smedile A, Maina AM, Saitta C, et al. Longitudinal evaluation reveals a complex spectrum of virological profiles in hepatitis B virus/hepatitis C virus-coinfected patients. Hepatology. 2006;43 (1):100-7.

22. Aghemo A, Colombo M. Treatment of patients with dual hepatitis B and C: a step in the right direction. Gut. 2014;63(3):380-1.

23. Viganò M, Aghemo A, lavarone M, Rumi MG, Agnelli F, Lampertico P, et al. The course of inactive hepatitis $B$ in hepatitis-C-coinfected patients treated with interferon and ribavirin. Antivir Ther. 2009;14(6):789-96.

24. Bersoff-Matcha SJ, Cao K, Jason M, Ajao A, Jones SC, Meyer T, et al. Hepatitis B virus reactivation associated with direct-acting antiviral therapy for chronic hepatitis C virus: a review of cases reported to the U.S. food and drug administration adverse event reporting system. Ann Intern Med. 2017;166 (11):792-8.

25. Belperio PS, Shahoumian TA, Mole LA, Backus LI. Evaluation of hepatitis B reactivation among 62,920 veterans treated with oral hepatitis $C$ antivirals. Hepatology. 2017;66(1):27-36.

26. Chen G, Wang C, Chen J, Ji D, Wang Y, Wu V, et al. Hepatitis B reactivation in hepatitis $B$ and $C$ coinfected patients treated with antiviral agents: a systematic review and meta-analysis. Hepatology. 2017;66(1):13-26.

27. Ogawa E, Furusyo N, Murata M, Toyoda K, Hayashi T, Ura K. Potential risk of HBV reactivation in patients with resolved HBV infection undergoing directacting antiviral treatment for HCV. Liver Int. 2017; . https://doi.org/10.1111/liv. 13496. 
28. Platt L, Easterbrook P, Gower E, McDonald B, Sabin K, McGowan C, et al. Prevalence and burden of HCV co-infection in people living with HIV: a global systematic review and meta-analysis. Lancet Infect Dis. 2016;7:797-808.

29. Lo Re V 3rd, Kallan MJ, Tate JP, Locallo AR, Lim JK, Goetz MB, et al. Hepatic decompensation in antiretroviral-treated patients coinfected with HIV and Hepatitis C virus compared with hepatitis C virus-monoinfected patients: a cohort study. Ann Intern Med. 2014;160:369-79.

30. Bhagani S. Current treatment for chronić hepatitis C virus/HIV-infected individuals: the role of pegylated-interferon alpha and ribavirin. Curr Opin HIV AIDS. 2011;6:483-90.

31. Schlab S, Rockstroh JK. Advances in the treatment of HIV/HCV coinfection in adults. Expert Opin Pharmacother. 2018;19(1):49-64.

32. Soriano V, Labarga P, Fermandez-Montero JV, Mendoza C, BenletezGutlierrez L, Pena JM, et al. Drug interactions in HIV patients treated for hepatitis C. Expert Opin Drug Metab Toxicol. 2017;8:807-15.

33. Burger D, Back D, Buggisch P, Buti M, Craxí A, Foster G, et al. Clinical management of drug-drug interactions in HCV therapy: challenges and solutions. Hepatol. 2013;58(4):792-800.

34. Backus LI, Belperio PS, Shahoumian TA, Loomis TP, Mole LA. Real-world effectiveness and predictors of sustained virological response with all oral therapy in 21,242 hepatitis-C genotype 1 patients. Antivir Ther. 2017;22:481-93.
35. European Association for Study of Liver. EASL Clinical Practice Guidelines: management of hepatitis C virus infection. J Hepatol. 2014;60(2):392-420.

36. Maasoumy B, Vermehren J. Diagnostics in hepatitis C: the end of responseguided therapy? J Hepatol. 2016;65(1 Suppl):S67-81.

37. Aghemo A, Lampertico P, Colombo M. Assessing long-term treatment efficacy in chronic hepatitis B and C: between evidence and common sense. Hepatol. 2012;57(6):1326-35.

38. Bruno S, Di Marco V, lavarone M, Roffi L, Crosignani A, Calvaruso V, et al. Survival of patients with HCV cirrhosis and sustained virologic response is similar to the general population. J Hepatol. 2016;64(6):1217-23.

39. Bruno S, Di Marco V, lavarone M, Roffi L, Boccaccio V, Crosignani A, et al. Improved survival of patients with hepatocellular carcinoma and compensated hepatitis C virus-related cirrhosis who attained sustained virological response. Liver Int. 2017;37(10):1526-34.

40. van der Meer AJ, Feld JJ, Hofer H, Almasio PL, Calvaruso V, FernándezRodríguez CM, et al. Risk of cirrhosis-related complications in patients with advanced fibrosis following hepatitis C virus eradication. J Hepatol. 2017;66 (3):485-93.

41. Martinello M, Hajarizadeh B, Grebely J, Dore GJ, Matthews GV. HCV cure and reinfection among people with $\mathrm{HIV} / \mathrm{HCV}$ coinfection and people who inject drugs. Curr HIV/AIDS Rep. 2017;14(3):110-21. 


\title{
Is hepatitis $C$ virus elimination possible among people living with HIV and what will it take to achieve it?
}

\author{
Natasha K Martin ${ }^{1,2 \S}$, Anne Boerekamps ${ }^{3}$, Andrew M Hill ${ }^{4}$ and Bart J A Rijnders 3,5

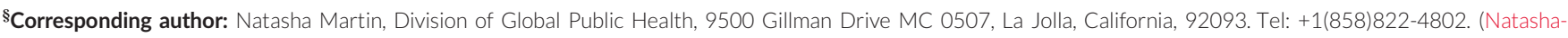 \\ martin@ucsd.edu)
}

\begin{abstract}
Introduction: The World Health Organization targets for hepatitis C virus (HCV) elimination include a $90 \%$ reduction in new infections by 2030. Our objective is to review the modelling evidence and cost data surrounding feasibility of HCV elimination among people living with HIV (PLWH), and identify likely components for elimination. We also discuss the real-world experience of HCV direct acting antiviral (DAA) scale-up and elimination efforts in the Netherlands.

Methods: We review modelling evidence of what intervention scale-up is required to achieve WHO HCV elimination targets among HIV-infected (HIV+) people who inject drugs (PWID) and men who have sex with men (MSM), review cost-effectiveness of HCV therapy among PLWH and discuss economic implications of elimination. We additionally use the real-world experience of DAA scale-up in the Netherlands to illustrate the promise and potential challenges of HCV elimination strategies in MSM. Finally, we summarize key components of the HCV elimination response among PWLH.

Results and discussion: Modelling indicates HCV elimination among HIV+ MSM and PWID is potentially achievable but requires combination treatment and either harm reduction or behavioural risk reductions. Preliminary modelling indicates elimination among HIV+ PWID will require elimination efforts among PWID more broadly. Treatment for PLWH and high-risk populations (PWID and MSM) is cost-effective in high-income countries, but costs of DAAs remain a barrier to scale-up worldwide despite the potential low production price (\$50 per 12 week course). In the Netherlands, universal DAA availability led to rapid uptake among HIV+ MSM in 2015/16, and a 50\% reduction in acute HCV incidence among HIV+ MSM from 2014 to 2016 was observed. In addition to HCV treatment, elimination among PLWH globally also likely requires regular HCV testing, development of low-cost accurate HCV diagnostics, reduced costs of DAA therapy, broad treatment access without restrictions, close monitoring for HCV reinfection and retreatment, and harm reduction and/or behavioural interventions.

Conclusions: Achieving WHO HCV Elimination targets is potentially achievable among HIV-infected populations. Among HIV+ PWID, it likely requires HCV treatment scale-up combined with harm reduction for both HIV+ and HIV-populations. Among HIV+ MSM, elimination likely requires both HCV treatment and behaviour risk reduction among the HIV+ MSM population, the latter of which to date has not been observed. Lower HCV diagnostic and treatment costs will be key to ensuring scale-up of HCV testing and treatment without restriction, enabling elimination.
\end{abstract}

Keywords: HCV; treatment; elimination; modelling

Received 5 July 2017; Accepted 28 December 2017; Published 9 April 2018

Copyright ( 2018 The Authors. Journal of the International AIDS Society published by John Wiley \& sons Ltd on behalf of the International AIDS Society. This is an open access article under the terms of the Creative Commons Attribution License, which permits use, distribution and reproduction in any medium, provided the original work is properly cited.

\section{1 | INTRODUCTION}

Viral hepatitis was the seventh leading cause of death worldwide in 2013, increasing from the tenth leading cause in 2010 [1]. The vast majority of morbidity and mortality attributable to viral hepatitis is due to hepatitis C virus ( $\mathrm{HCV}$ ) and hepatitis B Virus (HBV). In response to this increasing public health challenge, the World Health Organization recently released targets for HBV and HCV elimination by 2030 (see Table 1) [2]. Elimination is traditionally defined as a reduction to zero in the incidence of disease in a specific population or geographical location, with continued prevention efforts required to prevent the re-establishment of transmission [3]. Given this strict definition of elimination would require substantial economic and political resources and could be unattainable in most settings, the goal of "elimination" is often flexibly defined. The recent WHO elimination "as a public health threat" targets are comprised of a 90\% relative reduction in new infections and a $65 \%$ relative reduction in hepatitis-related mortality by 2030 .

Hence, to achieve the WHO incidence elimination targets, efforts must focus on both prevention of disease and prevention of transmission. The advent of highly effective HCV direct acting antiviral (DAA) therapy, with sustained viral response (SVR) exceeding 90\% in both HCV monoinfected and HIV/ $\mathrm{HCV}$ coinfected populations [4-8] has renewed optimism that 
Table 1. WHO hepatitis elimination goals: impact and service coverage targets [2]

WHO TARGET BY 2030

$\begin{array}{ll}\text { Impact Targets } & \\ \text { Incidence: New cases of } & 90 \% \text { relative reduction } \\ \text { chronic HBV and HCV } & \\ \text { Mortality: HBV and HCV deaths } & 65 \% \text { relative reduction } \\ \text { Service Coverage Targets } & \\ \text { HBV childhood vaccination coverage } & 90 \% \\ \text { HBV birth dose vaccination coverage } & 90 \% \\ \text { or other PMTCT initiative } & \\ \text { Screening of blood donations } & 100 \% \\ \text { Safe injections: \% of injections } & 90 \% \\ \text { administered with safety engineered } & \\ \text { devices in and out of health facilities } & \\ \text { Harm reduction: number of sterile } & 300 \\ \text { needles and syringes provided per } & \\ \text { person who inject drugs per year } & \\ \text { HBV and HCV diagnosis } & \\ \text { HBV and HCV treatment } & \end{array}$

PMTCT, prevention of mother to child transmission.

substantial reductions or elimination of end stage liver disease and HCV-related mortality is a possibility. The widespread use of HIV antiretroviral treatment for prevention has also led to speculation that HCV treatment could also be used for prevention. In addition, among people who inject drugs (PWID), a key risk group for $\mathrm{HCV}$, harm reduction interventions such as opiate substitution therapy (OST) and needle and syringe programs (NSP) have been the traditional backbone of HCV prevention. A recent Cochrane systematic review [9] found that OST reduces risk of $\mathrm{HCV}$ acquisition by $50 \%$ (risk ratio 0.50 $95 \% \mathrm{Cl} 0.40$ to 0.63 ) and combined with high coverage of NSP results in a $71 \%$ reduction in the risk of $\mathrm{HCV}$ acquisition (Risk Ratio $=0.2995 \% \mathrm{Cl}=0.13$ to 0.65 ).

The WHO strategy does not include discussion relating to elimination of viral hepatitis among HIV-infected populations specifically. Yet, because of the shared transmission routes many people living with HIV (PLWH) are coinfected with viral hepatitis. Globally, approximately $6.2 \%$ (3.4\% to $11.9 \%)$ of $\mathrm{PLWH}$ are coinfected with $\mathrm{HCV}$, equating to approximately 2.28 million (IQR 1.27 to 4.42) HIV/HCV coinfected individuals [10]. Indeed, PLWH are six times more likely to be infected with HCV compared to those not infected with HIV. The burden of HIV-HCV coinfection is particularly high among highrisk groups such as men who have sex with men (MSM) and PWID. Among HIV-infected individuals worldwide, it has been estimated that 2.4\% (IQR 0.8 to 5.8) are coinfected with $\mathrm{HCV}$ within general population samples, yet this rises to $6.4 \%$ (3.2 to 10.0 ) in MSM, and 82.4\% (55.2 to 88.5) in PWID [10].

As such, to achieve the WHO HCV elimination incidence reduction target among PWLH it is crucial to tackle transmission among HIV-infected MSM and PWID. However, although the prevention interventions required to eliminate $\mathrm{HCV}$ globally will be equally applicable to coinfected populations, the intervention level required and targeting may be different based on specific epidemic characteristics.

The objective of this paper is to review the modelling and cost evidence surrounding feasibility of $\mathrm{HCV}$ elimination among HIV-infected (HIV+) key populations such as MSM and PWID and identify the likely components required for $\mathrm{HCV}$ elimination among $\mathrm{PLWH}$. We use the real world experience of HCV DAA scale-up in the Netherlands through the Dutch Acute HCV in HIV Studies to illustrate the promise and potential challenges of $\mathrm{HCV}$ elimination strategies in a key population (MSM).

\section{METHODS}

This analysis is comprised of four parts: (i) A review of the theoretical mathematical modelling literature examining what prevention and treatment scale-up is required for HCV elimination among HIV-infected PWID and HIV-infected MSM populations. (ii) A review of the cost-effectiveness of $\mathrm{HCV}$ treatment for HIV-infected populations and discussion of cost considerations for elimination. (iii) A discussion of the realworld experience of HCV DAA scale-up among HIV+ MSM in the Netherlands (iv) A summary of probable and possible components of the HCV elimination response among PWLH.

\section{RESULTS AND DISCUSSION}

\subsection{Modelling the scale-up needed for HCV elimination among HIV-infected populations}

\subsubsection{HIV-infected PWID}

Numerous burden of disease models have shown that existing or modestly increased levels of treatment targeted at individuals with more advanced liver disease can achieve the WHO HCV mortality target (65\% reduction by 2030) in a variety of global settings. For example, a regional European Union model showed that HCV treatment only need to increase from 150,000 patients in 2015 to 187,000 patients in 2025 to achieve the mortality elimination target [11]. A separate multicountry analysis including some resource limited settings found that achieving the WHO HCV mortality target in Hungary, Indonesia, Lebanon, Pakistan and Romania is unlikely to be achieved with existing screening/treatment programs, but could be achieved with scaled-up screening and treatment [12]. These models of disease progression are particularly valuable in identifying the level and targeting of treatment required to reduce HCV mortality, but because they do not mechanistically incorporate disease transmission are unable to shed light on what is required to achieve the $\mathrm{WHO}$ incidence elimination target.

A wide body of literature since 2011 has utilized epidemic modelling to explore what level of prevention scale-up could result in control and elimination among PWID, and whether HCV treatment could be used for prevention. Several initial modelling studies in the UK and general PWID populations of varying prevalences have indicated that harm reduction alone is unlikely to achieve HCV elimination among PWID populations $[13,14]$. Subsequent studies have explored the potential 
of HCV treatment as prevention among PWID populations in a range of settings including North America, Europe, Asia and Australia [13,15-20]. Broadly speaking, these studies have generally found that scale up of HCV treatment to rates to below 100 per 1000 PWID annually, particularly in combination with harm reduction [13,16,21], can reduce HCV incidence by $90 \%$ by 2030 across a wide range of settings. Results have been consistent between high and low income settings examined, such as Vietnam [20].

In addition, modelling studies have pointed to several key additional elements which are required for achieving elimination among PWID: One Australian study highlighted the need for enhanced HCV screening among PWID in order to sustain $\mathrm{HCV}$ treatment rates required for elimination, a situation which is likely applicable to many global settings [22]. In addition, a modelling study in the rural U.S. emphasized the importance of retreatment of reinfection in achieving elimination targets [21]. As such, elimination strategies likely require regular testing [22], HCV treatment [13,15-20], harm reduction [13,16,21] and retreatment of reinfections [21].

Despite several studies modelling HIV and HCV coinfection transmission among PWID [23,24], to our knowledge as of 2017 no published study has explored what is required for HCV elimination among HIV-infected PWID in particular. Preliminary modelling presented at a recent international conference indicated that HCV treatment targeted at HIV-infected PWID in Andalusia, Spain would not achieve elimination among this population due to continued risk of HCV transmission from HIV-negative PWID populations [25]. Therefore, more generally, because the burden of $\mathrm{HCV}$ is high among HIV-uninfected PWID populations, and as HIV-infected PWID populations are likely to mix with HIV-uninfected PWID populations, elimination among HIV-infected PWID is probably only achievable if combination HCV prevention efforts are targeted both HIV+ and HIV- PWID populations.

\subsection{2 | HIV-infected MSM}

An HCV epidemic among HIV-infected MSM has been observed in the United States, Western Europe, Australia, Taiwan, Hong Kong and Japan, with HCV incidence and prevalence among HIV-infected MSM substantially higher than the HIV-uninfected MSM population [26,27]. A growing number of modelling studies since 2015 have explored what level of intervention (treatment and/or risk reduction) is required to eliminate HCV among HIV-infected MSM populations [28-31]. To date, these studies have focused exclusively on Western European settings (UK, Switzerland, Berlin and the Netherlands), and no studies have explored resource limited settings, in part because of the lack of epidemiological data on HCV epidemics among HIV+ MSM in these settings. However, the specific epidemic characteristics between the modelled settings has varied. One unifying characteristic is the relatively low rates of primary incidence among HIV+ MSM (1 to 2 per 100 person-years [26,32]) compared to PWID populations but high rates of reinfection (2 to 10 fold that of primary incidence [33-35]). Together these could pose a challenge for elimination efforts, where a relative reduction in $90 \%$ would translate to very low targets (0.1 to 0.2/100 person-years) which could be particularly hampered by high rates of reinfection. Nevertheless, the absolute numbers of HCV-HIV coinfected MSM are small, most diagnosed HIV+ MSM are linked to care in high-income settings where HCV epidemics among HIV+ MSM have been documented [36-38] so HCV elimination may be particularly feasible in this group.

As with PWID, modelling indicates the level of intervention required among HIV+ MSM to achieve the $\mathrm{WHO}$ elimination targets varies by epidemiological setting, particularly given substantial variation in incidence trends. For example, among HIV+ MSM incidence of HCV over the past decade has remained relatively stable in the UK and the Netherlands. In the UK, a modelling study indicated that scaled-up rates of DAA therapy (from $46 \%$ to $80 \%$ treated within a year of diagnosis and from 7\%/year to 20\%/year thereafter) could reduce incidence among HIV+ MSM over 60\% by 2030, but could not meet elimination targets [28]. Elimination targets could be reached when all those diagnosed receive treatment within 1 year of diagnosis, or if treatment scale-up is combined with a behavioural risk reduction [25].

In contrast, HCV incidence among HIV+ MSM has steadily increased over the past decade in Switzerland and Germany. In Switzerland, this has occurred alongside an increase in selfreported risk behaviour (unprotected anal intercourse). A recent modelling study in Switzerland projected that if these trends continue, elimination (or even reductions in $\mathrm{HCV}$ incidence) could not be achieved through HCV treatment alone, and requires additional reduction in high-risk behaviour (perhaps through behavioural interventions) [29]. Preliminary modelling in Berlin supports the Swiss findings. Germany is a unique setting in that universal access for DAAs has been available since 2014, and as such relatively high-treatment rates (>80\% HIV+ MSM treated after their acute diagnosis) have been achieved. However, the continued increase in HCV incidence among HIV+ MSM in Berlin and Germany overall (from 0.33/100 person-years in 1996 to 1999 to 2.28/ 100 person-years in 2008 to 2012 in Germany [39]) and high levels of reinfection (7 to 8 per 100 person-years [33]) mean that elimination by 2030 likely requires both further scale-up of HCV treatment and reductions in high-risk behaviour [31].

Finally, preliminary modelling in the Netherlands indicated immediate treatment of all diagnosed HIV+ MSM with DAAs could only result in moderate reductions in $\mathrm{HCV}$ incidence among HIV+ MSM (approximately 30\% within 15 years), but not reach $\mathrm{WHO}$ elimination targets [30]. However, the realworld observation of a halving of HCV incidence among HIV+ MSM from 2014 to 2016 with expansion of DAA therapy as described below has raised excitement about the potential for elimination via treatment as prevention among HIV+ MSM in the Netherlands, described later in this paper.

\subsection{Cost and cost-effectiveness implications of HCV testing and treatment scale-up for elimination among HIV-infected populations}

There is a wide body of evidence that HCV treatment is costeffective for HIV-infected populations, including HIV+ MSM with a risk of reinfection, [40-44] in high-income settings such as the United States and the UK. In addition, as mentioned previously, achieving HCV elimination among key risk groups such as HIV+ PWID, may require targeting the broader PWID population. Numerous economic evaluations have shown that $\mathrm{HCV}$ treatment is cost-effective for PWID populations in high- 
income settings [45-53] despite the potential risk of reinfection and higher mortality rates among PWID populations. Indeed, economic evaluations indicate treating PWID with an ongoing risk of transmission may accrue substantial economic benefits through prevention of transmission. In addition, an economic analysis in Australia found that HCV treatment scale-up to achieve the WHO targets among PWID was costeffective [15]. Unfortunately, no cost-effectiveness studies for HIV-infected populations or PWID have been performed in resource limited settings. However, economic analyses have shown that DAA therapy for the general population is costeffective India [54] and Egypt [55,56] where generic or low cost DAAs are available.

Despite the evidence HCV treatment is cost-effective, the high costs of HCV treatment [57] (> \$75,000 per 12 week treatment course for sofosbuvir+daclatasvir in the US and UK) remain a major barrier to HCV treatment scale-up. Prices vary widely depending on country and income status [57], and prices of innovator and generic medicines have fallen, but nevertheless remain prohibitively high for widespread scale-up in developed and developing countries alike.

Unfortunately, the high costs of HCV treatment have so far resulted in prioritization of $\mathrm{HCV}$ therapy (or restrictions on insurance reimbursement) even in developed countries [58,59]. In these settings, patients with more advanced liver disease and those coinfected with HIV have traditionally been prioritized for early treatment. Although this type of strategy will be effective in preventing HCV-related morbidity and mortality among PWLH, it undermines elimination efforts as PLWH will remain at risk of being infected or reinfected with $\mathrm{HCV}$ from individuals who remain untreated and are at risk of transmitting. For example, PWID with a risk of transmission tend to be younger with less advanced liver disease, and therefore prioritization strategies targeting individuals with advanced liver disease may fail to prevent the substantial amount of transmission from this group [60]. This is despite economic assessments indicating that treatment scale-up among PWID at or below the level required for elimination is cost-effective in settings like Australia, the UK and Netherlands [15,60,61]. In addition, models indicate early treatment for PWID is cost-effective compared to delay until cirrhosis, and may be more cost-effective than early treatment for those with no ongoing risk in settings with low-moderate (20/ 40\%) HCV prevalence among PWID due to substantial prevention benefits of early treatment of PWID [60]. Unfortunately, no economic evaluations have assessed whether scaled-up treatment to achieve HCV elimination among PWID is cost-effective in resource-limited settings.

However, although HCV therapy is likely cost-effective, the high costs per treatment results in a substantial budgetary impact in countries with a large HCV infected populations. This has resulted in HCV treatment restrictions even in resource rich countries in the U.S. and Europe [58,59]. Indeed, HCV treatment coverage is still low globally [62]. A recent analysis estimated that the percentage of people with HCV who were treated with DAAs in 2016 ranged from $8.1 \%$ in North America and North Africa/Middle East to $0.1 \%$ in subSaharan Africa [63]. Among 91 countries analyzed, 47 countries had more new HCV infections than individuals who achieved cure through HCV treatment in 2016 [63], indicating that these countries are failing to turn off the tap of new infections with treatment. Nevertheless, some countries are achieving very high-treatment rates among specific sub-populations, such as among HIV+ MSM in the Netherlands, discussed in the next section.

Promisingly, HCV DAA therapies could be produced as generics at a fraction of the current costs [64], particularly from within a country such as India due to its sizeable generic industry and low production costs. A recent analysis estimated the costs of generic HCV DAA production based on the costs of their active pharmaceutical ingredients. This analysis found that the combination treatment sofosbuvir and daclatasvir has an estimated generic cost of $\$ 50$ to 72 per 12-week course with a $10 \%$ to $50 \%$ profit margin (Hill A, unpublished results).

In addition, even the costs of HCV diagnosis and monitoring remain prohibitive in many developing countries [65]. For example, in India, generic HCV treatments are available for at or below $\$ 300$ per treatment course, yet HCV antibody and RNA testing costs an estimated $\$ 17$ and $\$ 108$, respectively [66]. In addition, with current treatment monitoring as suggested by the Indian national guidelines [67] (every 4 weeks with RNA tests at week 0, 12, and SVR12) the cost of treatment delivery could easily far exceed that of HCV treatment.

Finally, in many settings additional financing will be required to build the capacity of health services for diagnosis and treatment of HCV. However, the economic implications of this health systems strengthening (in terms of increased personnel, training, infrastructure, etc.) has not been estimated. It is possible that integration of HCV testing and treatment within HIV services will prove to be an effective and cost-effective approach $[68,69]$.

\subsection{HCV elimination among HIV-infected MSM in the real world: Dutch experience}

In the Netherlands, surveillance data indicate that among PLWH, the vast majority of acute HCV infection diagnoses occur among MSM [70]. In this section, we detail the Dutch experience of HCV direct-acting antiviral (DAA) scale-up and impact on acute HCV incidence and HCV prevalence among HIV+ MSM.

HIV and HCV care is well-organized in the Netherlands. All patients diagnosed with HIV are cared for by a team of infectious diseases physicians and specially trained HIV nurses in 26 treatment centres spread across the country. Screening for chronic HCV is universal at entry into HIV care and more than $99 \%$ of the HIV-infected patients in care in the Netherlands have been tested for HCV at least once [71]. Screening for incident HCV infections in MSM is performed by testing ALT (followed by HCV testing when a new ALT elevation is observed) twice a year. HCV/HIV coinfected MSM visit the HIV outpatient clinic at least twice a year. HCV infections can be treated by the infectious diseases physician so no referral to a hepatologist is needed. Facilitated by specially trained onsite data collectors, detailed clinical and laboratory data from consenting patients (98\%) are registered in a central database, comprising the AIDS Therapy Evaluation in the Netherlands (ATHENA) cohort. In addition, two prospective acute HCV treatment studies among HIV+ individuals have occurred (Dutch Acute HCV in HIV Studies, DAHHS1 (from 2013 to 2014) and DAHHS2 (2016-ongoing)) [72,73] in 17 centres providing care for $75 \%$ of the Dutch HIV+ MSM population. 
In the Netherlands, DAAs were available from September 2014 for HCV-infected patients with significant liver fibrosis or cirrhosis, and October 2015 regardless of fibrosis stage. This led to a very rapid uptake of HCV therapy among HIV+ MSM in the ATHENA cohort, with 79\% attaining SVR just 14 months after restrictions were lifted [74] and a substantial decrease in the pool of HCV RNA positive HIV-infected MSM in care in the Netherlands. Indeed, while in 2015 4.1\% (450 of 11070) of the HIV+ MSM in care were HCV RNA+, this decreased to $1.5 \%$ (176 of 11749) by the end of 2016. As of May 2017, less than $150 \mathrm{HCV}$ infected HIV+ MSM remain to be treated. With only $1.5 \%$ of the HIV+ MSM population currently remaining $\mathrm{HCV}$ infected, $\mathrm{HCV}$ elimination may become a reality. However, the residual group of infected patients is likely a more difficult to reach sub-group, and the risk of reinfection among HIV-positive MSM is high [33,34,75,76].

The data described above demonstrate that a very rapid decline in the prevalence of HCV can be achieved in a wellorganized healthcare system of a resource rich country. However, to achieve HCV elimination according to the WHO targets, the incidence of new HCV infections needs to decrease by $90 \%$ by 2030 [2]. We obtained data from the DAHHS studies to compare the incidence of acute HCV infections in the first year after universal DAA availability (2016) with the last year before DAA became available (2014). From 2014 to 2016, a 51\% decrease in acute HCV infections was observed [77]. Furthermore, this decrease contrasted with a significant increase in the percentage of positive syphilis $(+2.2 \%)$ and gonorrhoea (+2.85\%) tests in HIV-positive MSM observed at STD clinics across the country [78-80], indicating that the reduction in HCV was unlikely to be due to behavioural risk reduction.

While the substantial reduction in $\mathrm{HCV}$ incidence among $\mathrm{HIV}+\mathrm{MSM}$ observed after widespread scale-up of HCV treatment in the Netherlands is reason for optimism, an observational study cannot prove a causal relationship. Further modelling work will be required to disentangle the estimated impact of HCV treatment as prevention initiatives among $\mathrm{HIV}+\mathrm{MSM}$ in the Netherlands, and coverage required for elimination. We consider it unlikely that HCV treatment as prevention alone will result in a $90 \%$ reduction in the incidence of $\mathrm{HCV}$ (the WHO target) among HIV+ MSM in the Netherlands, and discuss additional steps likely required in the following section. Indeed, no further decline in the HCV incidence has been observed in 2017 so far [81]. In addition, we note that the Dutch experience is a specific example within a resource-rich country with well-coordinated HIV and $\mathrm{HCV}$ care. Whether the experience in the Netherlands will translate to other resource-limited settings requires further study.

\subsection{Probable and possible components required to achieve HCV elimination among PLWH}

In summary, despite the promise of $\mathrm{HCV}$ elimination using HCV treatment as prevention from both theoretical modelling studies and real-world observations in the Netherlands, numerous probable and possible barriers exist which could hamper HCV elimination efforts among PLWH (Table 2). As such, the following components are likely an important part of the HCV elimination response among PWLH (based on probable barriers):
1 Regular HCV testing of high-risk populations, both HIV+ and HIV-: Among HIV+ PWID, modelling indicates that elimination likely requires elimination efforts among the broader PWID population [25], yet worldwide an estimated $80 \%$ of HCV-infected individuals remain undiagnosed [62], a situation which may be worse among PWID. For example, in India only an estimated 5\% of HCV-infected PWID are diagnosed [82]. Consequently, the treatment scale-up required for elimination among PWID likely requires enhanced testing among both HIV+ and HIV- PWID [22]. Among HIV+ MSM, modelling indicates that regular testing of HIV+ MSM is also likely required for elimination. Testing of other MSM populations is described below under possible barriers.

2 Development of low cost, simple, reliable and accurate $\mathrm{HCV}$ diagnostics. Even in low-income countries with low cost DAAs, the price of HCV diagnostics remains a barrier [65]. In addition, the currently available diagnostic products are complex, many which require a cold chain and/or show poor accuracy among HIV-infected individuals [83].

3 Reduced costs for DAA treatment. Despite the availability of generic and low-cost DAAs in some resource limited settings, costs of DAA therapy in the vast majority of countries remains a barrier to widespread scale-up of $\mathrm{HCV}$ treatment [57,84,85]. Greater market transparency and price negotiations are required [84].

4 Broad access to HCV treatment without restrictions: Modelling studies indicate that restricting treatment for those with more advanced fibrosis and/or by drug use status, as is occurring in many settings [58,59], will likely have limited impact on preventing transmission among PWID populations [86], the vast majority who are younger with less advanced disease. In settings where HCV epidemics are predominantly PWID-driven, broad access to HCV treatment regardless of disease stage is therefore required for $\mathrm{HCV}$ elimination. Even in settings with substantial general population transmission, it is likely that restricting treatment for more advanced disease stages will mean that substantially more treatments are required to achieve elimination [87].

5 Close monitoring for reinfection and retreatment of reinfections: Treating those at risk of transmission, the target group for HCV treatment as prevention efforts, will result in reinfections. Among PWID, lower rates of reinfection compared to primary infection were reported in the IFNera [88], and reinfection rates among PWID on OST in DAA trials have been low (<3 per 100 person-years) [89]. However, modelling in a rural expanding epidemic setting in the United States indicates achieving the WHO elimination incidence target among PWID requires retreatment of reinfections [21]. Among HIV+ MSM, European studies indicate high incidence of $\mathrm{HCV}$ reinfection in HIV+ MSM (2 to 10 fold that of primary infection rates) in both the IFNera $[33,34,76]$ and DAA era [75]. As modelling studies have shown that more frequent testing for $\mathrm{HCV}$ and earlier initiation of HCV treatment could reduce the HCV epidemic among HIV-positive MSM [31,90] and given that those previously infected with $\mathrm{HCV}$ are a particularly high risk sub-population for transmission, reducing the time from reinfection to retreatment is important. This could be achieved by increasing the frequency of $\mathrm{HCV}$ reinfection 
screening and may require out of the box diagnostic strategies like a home-based diagnostic approach in which the patient collects dried blot spots that are sent to the lab for HCV RNA or antigen testing.

6 Harm reduction and other behavioural interventions to prevent infection/reinfection: Despite the importance of harm reduction such as OST and needle and syringe programs for preventing HCV infection among PWID [9], access to these interventions in many settings is poor, particularly in many resource limited settings [91]. Scale-up of harm reduction, as recommended by the WHO [2], is crucial. In addition, among HIV+ MSM, effective behavioural interventions to prevent $\mathrm{HCV}$ infection are urgently required, as modelling from several settings indicates elimination of $\mathrm{HCV}$ in this population without effective behavioural intervention will be unlikely [28,29,31]. Unfortunately, there is a lack of robust evidence surrounding the efficacy of behavioural change interventions targeting HCV risk among $\mathrm{HIV}+\mathrm{MSM}$. It is possible that some interventions developed to prevent HIV transmission among MSM may also be effective against $\mathrm{HCV}$, particularly those targeting unprotected anal intercourse [29,92]. There is an emerging body of literature examining the development of educational and counselling interventions targeted at MSM who engage in ChemSex [93-95], which may reduce the risk of acquiring $\mathrm{HCV}$ among this population. Further research is needed examining the development, acceptability, and efficacy of culturally sensitive behavioural change interventions for preventing HCV infection.

In addition, the following items would address possible barriers to elimination and therefore may be required for elimination among PWLH. We note that further evidence is required to support whether these items are necessary components of an elimination response:

\section{Table 2. Barriers to HCV elimination among PLWH}

Probable barriers to HCV elimination among PLWH:

- Low levels of diagnosis in many settings and risk populations [62]

- Lack of availability of low cost, simple, reliable and accurate HCV diagnostics for LMIC settings [65,83]

- High costs of DAA treatment [57]

- Restrictions on DAA accessibility by fibrosis stage and drug use status [58,59]

- Low levels of harm reduction availability for PWID in many settings [91]

- High reinfection incidence among HIV+ MSM [33,34,75,76]

- Lack of evidence-based interventions to reduce HCV infection among HIV+ MSM

Possible additional barriers:

- Transmission of HCV from HIV uninfected MSM, such as those on PrEP

- Spread of HCV clones with acquired DAA resistance [100]

- Lack of licensing for HCV treatment in the acute stage

- Cross border transmission of HCV, particularly among HIV+ MSM $[97,98]$ and between countries with different levels of DAA availability
1 Testing among HIV-negative MSM receiving HIV pre-exposure prophylaxis (PrEP): There is growing evidence of HCV infection among HIV-negative MSM receiving PrEP, a group which could contribute to HCV transmission to HIV+ MSM. In Amsterdam, the prevalence of chronic HCV among HIV-negative MSM in a PrEP implementation programme was $4 \%(15 / 375)$, comparable to the prevalence of $4.2 \%$ in HIV+ MSM [96]. In Antwerp, Belgium, HCV prevalence among HIV-negative MSM at the start of a PrEP project was $2 \%$, and several new HCV infections were diagnosed during follow-up in these PrEP users (Rijnders B, personal communication). The extent to which HIVnegative MSM (particularly on PrEP) contribute or will contribute to the HCV epidemic among HIV+ MSM in unclear, but increased epidemiological surveillance will shed light on the burden of disease in this group and help understand their potential importance to the HIV+ MSM epidemic.

2 Coordinated multi-country prevention and treatment effort: Among HIV+ PWID, the contribution of cross-border transmission and import/export of infections to the epidemic is unclear. Among HIV+ MSM, the highly connected nature of the HCV epidemic among HIV+ MSM in Western Europe and frequent travel of MSM between European cities has been documented [97,98]. Therefore, at least in Europe, local elimination of HCV among HIV+ MSM may require coordinated multi-country efforts.

3 Licensing for treatment in the acute stage: Currently none of the approved DAA regimens are licensed for the treatment of acute HCV. Depending on the regional legislations, this may result in a compulsory "wait for documented chronicity" policy and thus increase the duration of time for onwards HCV transmissions to occur. HIV modelling studies have highlighted the importance of the acute HIV stage on the HIV epidemic [99]. However, the importance of acute HCV infection in relation to the HCV epidemic among PLWH is unclear and further research is needed to determine to what degree and in what populations early treatment is required for achieving elimination targets.

4 Monitor if transmission of HCV clones with acquired DAA resistance occurs: It was recently shown that the $\mathrm{HCV}$ Q80K polymorphism, associated with DAA resistance, is frequently detected and transmitted among HIV+ MSM in the Netherlands [100]. As relapse with documented DAA resistance is rare, the chance of a patient developing ánd transmitting acquired DAA resistance is theoretically small and as far as we know has only been described in the context of treatment with a first generation protease inhibitor [101]. As such, further research is needed to ascertain the importance of resistance in the DAA era.

\section{4 | CONCLUSIONS}

Both theoretical modelling studies and emerging real world evidence from the Netherlands indicate that HCV elimination among HIV-infected key populations such as MSM and PWID is potentially achievable. Due to a number of factors, elimination of HCV among HIV+ MSM may be complex; and require both high coverage HCV treatment and behavioural 
interventions. Elimination among HIV+ PWID will likely require elimination efforts among PWID more broadly. In addition to HCV treatment as prevention initiatives, elimination among PLWH also likely requires regular HCV testing, development of low-cost accurate HCV diagnostics, reduced costs of DAA therapy, broad treatment access without restrictions, close monitoring for $\mathrm{HCV}$ reinfection and retreatment, and harm reduction and/or behavioural interventions.

Finally, we note that the vast majority of existing research is limited to high-income settings, and more research is required relating to $\mathrm{HCV}$ elimination among $\mathrm{PLWH}$ in resource limited settings. For example, more modelling work is needed to assess what scale-up is required for HCV elimination among PLWH populations in resource- limited settings where transmission routes may vary and the HCV epidemics among HIV-infected populations may differ. Many developing countries have high burdens of injecting drug use as well as high HCV among HIV-infected PWID $[10,102]$. Yet, their risks may be different from high-income settings. For example, an increasing number of analyses are focusing on HCV elimination among the general population in low or middle-income country settings such as Georgia and Pakistan [87,103], which have shown that even in settings with high numbers of PWID, transmission may be highly disseminated, with PWID experiencing risk both from injecting drug use and the broader community through iatrogenic transmission. Hence, the requirements for elimination in these settings where PWID experience multiple risks may be different than in other settings. In addition, data are lacking on HCV among MSM in resource-limited settings, and as such the magnitude of the problem and requirements for elimination are unclear. In addition to differences in epidemic characteristics, clearly economic considerations across resource-limited countries will vary substantially, and as such the requirements for achieving HCV elimination among PWLH in these resource limited settings requires further study.

\section{AUTHORS' AFFILIATIONS}

${ }^{1}$ Division of Global Public Health, University of California, San Diego, CA, USA ${ }^{2}$ School of Social and Community Medicine, University of Bristol, Bristol, United Kingdom; ${ }^{3}$ Department of Internal Medicine, Division of Infectious Diseases, Erasmus MC University Medical Center, Rotterdam, the Netherlands; ${ }^{4}$ Department of Translational Medicine, University of Liverpool, Liverpool, United Kingdom; ${ }^{5}$ Department of Medical Microbiology and Infectious Diseases, Erasmus MC University Medical Center, Rotterdam, the Netherlands

\section{FUNDING}

NKM is supported by the National Institute for Drug Abuse (grant number R01 DA037773-01A1) and the University of California San Diego Center for AIDS Research (CFAR), a National Institute of Health $(\mathrm{NIH})$ funded programme (grant number P30 Al036214) which is supported by the following NIH Institutes and Centers: NIAID, NCI, NIMH, NIDA, NICHD, NHLBI, NIA NIGMS and NIDDK. The views expressed are those of the authors and not necessarily those of the National Institutes of Health.

\section{DISCLAIMER}

NM has received unrestricted research grants from Gilead unrelated to this work and honoraria from Merck, Gilead and AbbVie. BJAR has received research grants from MSD related to this work, from Gilead unrelated to this work, travel grants from ViiV, Gilead, MSD, BMS, Janssen-Cilag, Pfizer and honoraria from MSD, BMS, Pfizer, Gilead, Janssen-Cilag, ViiV and GL-pharmaceuticals. $\mathrm{AB}$ and $\mathrm{AH}$ have nothing to declare.

\section{REFERENCES}

1. Stanaway JD, Flaxman AD, Naghavi M, Fitzmaurice C, Vos T, Abubakar I, et al. The global burden of viral hepatitis from 1990 to 2013: findings from the Global Burden of Disease Study 2013. Lancet. 388(10049):1081-8.

2. World Health Organization. Global health sector strategy on viral hepatitis, 2016-2021. 2016.

3. Dowdle WR. The principles of disease elimination and eradication. MMWR. 1999:48:23-7.

4. Wyles D, Bräu N, Kottilil S, Daar ES, Ruane P, Workowski K, et al. Sofosbuvir and velpatasvir for the treatment of HCV in patients coinfected with HIV-1: an open-label, phase 3 study. Clin Infect Dis. 2017;65:6-12.

5. Wyles DL, Ruane PJ, Sulkowski MS, Dieterich D, Luetkemeyer A, Morgan TR, et al. Daclatasvir plus sofosbuvir for HCV in patients coinfected with HIV-1. N Engl J Med. 2015;373(8):714-25.

6. Sulkowski MS, Eron JJ, Wyles D, Trinh R, Lalezari J, Wang C, et al. Ombitasvir, paritaprevir co-dosed with ritonavir, dasabuvir, and ribavirin for hepatitis $C$ in patients co-infected with HIV-1: a randomized trial. JAMA. 2015;313 (12):1223-31.

7. Naggie S, Cooper C, Saag M, Workowski K, Ruane P, Towner WJ, et al. Ledipasvir and sofosbuvir for HCV in patients coinfected with HIV-1. N Engl J Med. 2015:373(8):705-13.

8. Bhattacharya D, Belperio PS, Shahoumian TA, Loomis TP, Goetz MB, Mole LA, et al. Effectiveness of All-Oral Antiviral Regimens in 996 Human Immunodeficiency Virus/Hepatitis C Virus Genotype 1-Coinfected Patients Treated in Routine Practice. Clin Infect Dis. 2017;64(12):1711-20.

9. Platt L, Reed J, Minozzi S, Vickerman P, Hagan H, French C, et al. Effectiveness of needle/syringe programmes and opiate substitution therapy in preventing HCV transmission among people who inject drugs. Cochrane Database Syst Rev. 2016;2016(1):CD012021.

10. Platt L, Easterbrook P, Gower E, McDonald B, Sabin K, McGowan C, et al. Prevalence and burden of HCV co-infection in people living with HIV: a global systematic review and meta-analysis. Lancet Infect Dis. 2016;16(7):797-808.

11. Razavi H, Robbins S, Zeuzem S, Negro F, Buti M, Duberg AS, et al. Hepatitis $\mathrm{C}$ virus prevalence and level of intervention required to achieve the $\mathrm{WHO}$ targets for elimination in the European Union by 2030: a modelling study. Lancet Gastroenterol Hepatol. 2017:2(5):325-36.

12. Alfaleh FZ, Nugrahini N, Matičič M, Tolmane I, Alzaabi M, Hajarizadeh B, et al. Strategies to manage hepatitis $C$ virus infection disease burden - volume 3. J Viral Hepatitis. 2015;22:42-65.

13. Martin N, Hickman M, Hutchinson SJ, Goldberg DJ, Vickerman P. Combination interventions to prevent HCV transmission among people who inject drugs: modelling the impact of antiviral treatment, needle and syringe programmes, and opiate substitution therapy. Clin Infec Dis. 2013;57 Suppl 2:S39-45.

14. Vickerman P, Martin N, Turner K, Hickman M. Can needle and syringe programmes and opiate substitution therapy achieve substantial reductions in $\mathrm{HCV}$ prevalence? Model projections for different epidemic settings. Addiction. 2012;107:1984-95.

15. Scott N, McBryde ES, Thompson A, Doyle JS, Hellard ME. Treatment scaleup to achieve global HCV incidence and mortality elimination targets: a costeffectiveness model. Gut. 2017;66:1507-15.

16. Gountas I, Sypsa V, Anagnostou O, Martin N, Vickerman P, Kafetzopoulos E, et al. Treatment and primary prevention in people who inject drugs for chronic hepatitis C infection: is elimination possible in a high prevalence setting? Addiction. 2017;112:1290-9.

17. Cousien A, Tran VC, Deuffic-Burban S, Jauffret-Roustide M, Dhersin JS, Yazdanpanah Y. Hepatitis $C$ treatment as prevention of viral transmission and liver-related morbidity in persons who inject drugs. Hepatology. 2016;63:1090101.

18. Martin NK, Vickerman P, Grebely J, Hellard M, Hutchinson SJ, Lima VD, et al. HCV treatment for prevention among people who inject drugs: modeling treatment scale-up in the age of direct-acting antivirals. Hepatology. 2013;58 (5):1598-609.

19. Lima VD, Rozada I, Grebely J, Hull M, Lourenco L, Nosyk B, et al. Are interferon-free direct-acting antivirals for the treatment of $\mathrm{HCV}$ enough to control the epidemic among people who inject drugs? PLoS One. 2015;10(12):e0143836. 20. Durier N, Nguyen C, White LJ. Treatment of hepatitis C as prevention: a modeling case study in Vietnam. PLoS One. 2012;7(4):e34548.

21. Fraser H, Zibbell J, Hoerger T, Hariri S, Vellozzi C, Martin NK, et al. Scaling-up HCV prevention and treatment interventions in rural United Statesmodel projections for tackling an increasing epidemic. Addiction. 2018;113 (1):173-82.

22. Scott N, Doyle JS, Wilson DP, Wade A, Howell J, Pedrana A, et al. Reaching hepatitis $C$ virus elimination targets requires health system interventions to enhance the care cascade. Int J Drug Policy. 2017:47:107-16. 
23. Vickerman P, Martin NK, Hickman M. Understanding the trends in HIV and hepatitis $C$ prevalence amongst injecting drug users in different settings-Implications for intervention impact. Drug Alcohol Depend. 2012;123(1-3):122-31. 24. Birger RB, Le T, Kouyos RD, Grenfell BT, Hallett TB. The impact of HCV therapy in a high HIV-HCV prevalence population: a modeling study on people who inject drugs in Ho Chi Minh City, Vietnam. PLoS One. 2017;12(5): e0177195.

25. Martin N. Is viral hepatitis elimination possible and what will it take to achieve it? 4th International HIV/Viral Hepatitis Coinfection Meeting 2017. Paris, France. 23 July 2017, 2017.

26. Hagan H, Jordan AE, Neurer J, Cleland CM. Incidence of sexually transmitted hepatitis $C$ virus infection in HIV-positive men who have sex with men. AIDS. 2015;29(17):2335-45.

27. Jordan AE, Perlman DC, Neurer J, Smith DJ, Des Jarlais DC, Hagan H. Prevalence of hepatitis $\mathrm{C}$ virus infection among HIV+ men who have sex with men: a systematic review and meta-analysis. Int J STD AIDS. 2017;28(2):145-59. 28. Martin NK, Thornton A, Hickman M, Sabin C, Nelson M, Cooke GS, et al. Can hepatitis $\mathrm{C}$ virus ( $\mathrm{HCV}$ ) direct-acting antiviral treatment as prevention reverse the HCV epidemic among men who have sex with men in the United Kingdom? Epidemiological and Modeling Insights. Clin Infect Dis. 2016;62 (9):1072-80.

29. Salazar-Vizcaya L, Kouyos RD, Zahnd C, Wandeler G, Battegay M, Darling $\mathrm{KE}$, et al. Hepatitis $\mathrm{C}$ virus transmission among human immunodeficiency virusinfected men who have sex with men: modeling the effect of behavioral and treatment interventions. Hepatology. 2016;64(6):1856-69.

30. Hullegie S, Nichols B, Rijnders B, de Knegt R, Rockstroh R, Boucher C, et al. Is HCV elimination possible? A modeling study of HIV-positive MSM. Conference on Retroviruses and Opportunistic Infections (CROI) 2016, Boston, MA Feb 22-25 2016. Abstract \#536.

31. Martin N, Jansen K, Boesecke C, Boyd A, Schewe K, Baumgarten A, et al. Can HCV be eliminated among HIV-infected MSM in Berlin? Modeling a setting with increasing incidence and high treatment rates. American Association for the Study of Liver Diseases (AASLD), The Liver Conference 2017 Washington, DC. 19-21 Oct 2017. 2017.

32. Yaphe S, Bozinoff N, Kyle R, Shivkumar S, Pai NP, Klein M. Incidence of acute hepatitis $C$ virus infection among men who have sex with men with and without HIV infection: a systematic review. Sex Transm Infect. 2012;88(7):558-64.

33. Ingiliz P, Martin TC, Rodger A, Stellbrink HJ, Mauss S, Boesecke C, et al. $\mathrm{HCV}$ reinfection incidence and spontaneous clearance rates in HIV-positive men who have sex with men in Western Europe. J Hepatol. 2017;66(2):282-7.

34. Martin T, Martin NK, Hickman M, Vickerman P, Page EE, Everett R, et al. $\mathrm{HCV}$ reinfection incidence and treatment outcome among HIV-positive MSM in London. AIDS. 2013:27(16):2551-7.

35. Chaillon A, Anderson C, Martin T, Chachay E, Wyles D, Smith D, et al. Incidence of hepatitis C among HIV-infected men who have sex with men, 20002015. Conference on Retroviruses and Opportunistic Infections (CROI) 2017. Seattle, Washington. Feb 13-16, 2017. Oral Abstract 134.

36. Rice BD, Delpech VC, Chadborn TR, Elford J. Loss to follow-up among adults attending human immunodeficiency virus services in England, Wales, and Northern Ireland. Sex Transm Dis. 2011;38(8):685-90.

37. Public Health England. HIV in the UK 2016 Report. 2016 [Accessed 12 January 18]. Available from: https://http://www.gov.uk/government/uploads/sys tem/uploads/attachment_data/file/602942/HIV_in_the_UK_report.pdf

38. Risher K, Mayer K, Beyrer C. The HIV treatment cascade in men who have sex with men, people who inject drugs and sex workers. Curr Opin HIV AIDS. 2015:10(6):420-9.

39. Jansen $\mathrm{K}$, Thamm M, Bock CT, Scheufele R, Kücherer C, Muenstermann D, et al. High prevalence and high incidence of coinfection with hepatitis B, hepatitis $C$, and syphilis and low rate of effective vaccination against hepatitis $B$ in HIV-positive men who have sex with men with known date of HIV seroconversion in Germany. PLoS One. 2015;10(11):e0142515.

40. Linas BP, Barter DM, Leff JA, DiLorenzo M, Schackman BR, Horsburgh CR, et al. The cost-effectiveness of improved hepatitis $C$ virus therapies in HIV/hepatitis C virus coinfected patients. AIDS. 2014;28(3):365-76.

41. Campos N, Salomon JA, Servoss JC, Nunes DP, Samet JH, Freedberg KA, et al. Cost-effectiveness of treatment for hepatitis $\mathrm{C}$ in an Urban Cohort Coinfected with HIV. Am J Med. 2007;120(3):272-9.

42. Linas BP, Wong AY, Schackman BR, Kim AY, Freedberg KA. Cost-effective screening for acute hepatitis $\mathrm{C}$ virus infection in HIV-infected men who have sex with men. Clin Infect Dis. 2012;55(2):279-90.

43. Hartwell D, Jones J, Baxter L, Shepherd J. Peginterferon alfa and ribavirin for chronic hepatitis $\mathrm{C}$ in patients eligible for shortened treatment, re-treatment or in HCV/HIV co-infection: a systematic review and economic evaluation. Health Technol Assess. 2011;15(17):1-210.
44. Hornberger J, Torriani FJ, Dieterich DT, Bräu N, Sulkowski MS, Torres MR, et al. Cost-effectiveness of peginterferon alfa-2a $(40 \mathrm{kDa})$ plus ribavirin in patients with HIV and hepatitis C virus co-infection. J Clin Virol. 2006;36 (4):283-91.

45. Martin NK, Vickerman P, Miners A, Foster GR, Hutchinson SJ, Goldberg DJ, et al. The cost-effectiveness of HCV antiviral treatment for injecting drug user populations. Hepatology. 2012;55(1):49-57.

46. Sheerin IG, Green FT, Sellman JD. What is the cost-effectiveness of hepatitis $\mathrm{C}$ treatment for injecting drug users on methadone maintenance in New Zealand? Drug Alcohol Rev. 2004;23(3):261-72.

47. Thompson Coon J, Castelnuovo E. Pitt M. Cramp M. Siebert U. Stein K. Case finding for hepatitis $\mathrm{C}$ in primary care: a cost utility analysis. Fam Pract. 2006:23(4):393-406.

48. Stein K, Dalziel K, Walker A, Jenkins B, Round A, Royle P, et al. Screening for Hepatitis $C$ in injecting drug users: a cost utility analysis. J Public Health. 2004;26(1):61-71.

49. Wong JB, Sylvestre DL, Siebert U. Cost-effectiveness of treatment of hepatitis $C$ in injecting drug users. In: Jager J, et al., editors. Hepatitis $C$ and injecting drug use: impact, costs and policy options. Belgium: European monitoring centre for drugs and drug addiction; 2004. p. 219-41.

50. Leal P, Stein K, Rosenberg W. What is the cost utility of screening for hepatitis C virus (HCV) in intravenous drug users? J Med Screen. 1999;6(3):124 31.

51. Vickerman P, Miners A, Williams J. Assessing the cost-effectiveness of interventions linked to needle and syringe programmes for injecting drug users. NICE, Editor 2008: London.

52. Martin NK, Vickerman P, Miners A, Hickman M. How cost-effective is hepatitis C virus treatment for people who inject drugs? J Gastroenterol Hepatol. 2013;28(4):590-2.

53. Scott N, Iser DM, Thompson AJ, Doyle JS, Hellard ME. Cost-effectiveness of treating chronic hepatitis $\mathrm{C}$ virus with direct-acting antivirals in people who inject drugs in Australia. J Gastroenterol Hepatol. 2016;31(4):872-82.

54. Aggarwal R, Chen Q, Goel A, Seguy N, Pendse R, Ayer T, et al. Cost-effectiveness of hepatitis $C$ treatment using generic direct-acting antivirals available in India. PLoS One. 2017;12(5):e0176503.

55. Elsisi GH, Aburawash A, Waked E. Cost-effectiveness analysis of new HCV treatments in Egyptian cirrhotic and non-cirrhotic patients: a societal perspective. Value Health Reg Issues. 2017:13:7-15.

56. Obach D, Deuffic-Burban S, Esmat G, Anwar WA, Dewedar S, Canva V, et al. Effectiveness and cost-effectiveness of immediate versus delayed treatment of hepatitis C virus-infected patients in a country with limited resources: the case of Egypt. Clin Infect Dis. 2014;58(8):1064-71.

57. Iyengar S, Tay-Teo K, Vogler S, Beyer P, Wiktor S, de Joncheere K, et al. Prices, costs, and affordability of new medicines for hepatitis $C$ in 30 countries: an economic analysis. PLoS Med. 2016;13(5):e1002032.

58. Barua S, Greenwald R, Grebely J, Dore GJ, Swan T, Taylor LE. Restrictions for medicaid reimbursement of sofosbuvir for the treatment of hepatitis c virus infection in the United States. Ann Intern Med. 2015;163(3):215-23.

59. Marshall AD, Cunningham EB, Nielsen S, Aghemo A, Alho H, Backmund M, et al. Restrictions for reimbursement of interferon-free direct-acting antiviral drugs for HCV infection in Europe. Lancet Gastroenterol Hepatol. 2017; epub ahead of print.

60. Martin NK, Vickerman P, Dore GJ, Grebely J, Miners A, Cairns J, et al. Prioritization of HCV treatment in the direct-acting antiviral era: An economic evaluation. J Hepatol. 2016;65(1):17-25.

61. van Santen DK, de Vos AS, Matser A, Willemse SB, Lindenburg K, Kretzschmar ME, et al. Cost-Effectiveness of hepatitis $C$ treatment for people who inject drugs and the impact of the type of epidemic; extrapolating from Amsterdam, the Netherlands. PLoS One. 2016;11(10):e0163488.

62. WHO. Global hepatitis report 2017. 2017.

63. Hill A, Nath S, Simmons B. The road to elimination of hepatitis C: analysis of cures versus new infections in 91 countries. J Virus Erad. 2017:3(3): $117-23$.

64. Hill A, Khoo S, Fortunak J, Simmons B, Ford N. Minimum costs for producing hepatitis c direct-acting antivirals for use in large-scale treatment access programs in developing countries. Clin Infect Dis. 2014;58(7):928-36.

65. Graham CS, Swan T. A path to eradication of hepatitis C in low- and middle-income countries. Antiviral Res. 2015;119:89-96.

66. LTD MH. MetroEDOS. [Accessed 12 January 2018]. Available from: http:// edos.metropolisindia.com

67. Puri P, Anand AC, Saraswat VA, Acharya SK, Sarin SK, Dhiman RK, et al. Consensus statement of HCV task force of the Indian National Association for Study of the Liver (INASL). Part II: INASL Recommendations for Management of HCV in India. J Clin Exp Hepatol. 2014;4(2):117-40. 
68. Solomon S. Cost-saving of integrating HCV testing into HIV testing programs for PWID using respondent-driven recruitment. International Network on Hepatitis in Substance Users (INHSU) 2017. Jersey City, NJ. Oral Poster Presentation, 2017.

69. Ford N, Singh K, Cooke GS, Mills EJ, von Schoen-Angerer T, Kamarulzaman A, et al. Expanding access to treatment for hepatitis $\mathrm{C}$ in resource-limited settings: lessons from HIV/AIDS. Clin Infect Dis. 2012;54(10):1465-72.

70. van Sighem Al, Boender TS, Wit FWNM, Smit C, Matser A, Reiss P. Monitoring report 2016. Human Immunodeficiency Virus (HIV) Infection in the Netherlands. Stichting HIV Monitoring. 2016 [Accessed 12 January 2018]. Available from: http://www.hiv-monitoring.nl

71. Dutch Association of HIV-treating Physicians. National Dutch HIV Guideline, chapter 4.1. [Accessed 12 January 2018]. Available from: http://richtlijnhiv. nvhb.nl/index.php/Inhoud

72. Hullegie SJ, Claassen MA, van den Berk GE, van der Meer JT, Posthouwer D, et al. Boceprevir, peginterferon and ribavirin for acute hepatitis C in HIV infected patients. J Hepatol. 2016;64(4):807-12.

73. DAHHS2 study. [Accessed 12 January 2018]. Available from: http://www.c linicaltrials.gov/ct2/show/NCT01912495

74. Boerekamps A, Newsom A, Smit C, Reiss P, Richter C, van der Valk J, et al. Unrestricted DAA access in the Netherlands: rapid therapy uptake in $\mathrm{HIV}+\mathrm{HCV}+$ patients. Conference on Retroviruses and Opportunistic Infections (CROI) 2015. Seattle, Washington. Feb 13-16 2017. Abstract 136.

75. Ingiliz P, Christensen S, Berger F, Kimhofer T, Schewe K, Boesecke C, et al. HCV reinfection after successful DAA treatment: a GECCO analysis. Conference on Retroviruses and Opportunistic Infections (CROI) 2017. Seattle, Washington. Feb 13-16 2017. Abstract 567.

76. Lambers F, Prins M, Thomas X, Molenkamp R, Kwa D, Brinkman K, et al. Alarming incidence of hepatitis $C$ virus re-infection after treatment of sexually acquired acute hepatitis C virus infection in HIV-infected MSM. AIDS. 2011;25 (17):F21-7.

77. Boerekamps A, van den Berk G, Lauw F, Leyten E, Arends J, Kasteren M, et al. Substantial decline in acute HCV infections among Dutch HIV+MSM after DAA roll out. Conference on Retroviruses and Opportunistic Infections (CROI) 2015. Seattle, Washington. Feb 13-16 2017. Abstract 137LB, 2017.

78. Wees VM, van Aar F, van Oeffelen AAM, van den Broek IVF, de Op Coul ELM, Hofstraat SHI, et al. Sexually transmitted infections including HIV, in the Netherlands in 2016. 2016.

79. van Oeffelen AAM, van Aar F, van den Broek IVF, de Op Coul ELM, Woestenberg PJ, Heijne JCM, et al. Sexually transmitted infections including HIV, in the Netherlands in 2014. Rijksinstituut voor Volksgezondheid en Milieu RIVM. 2015. 80. Visser M, van Aar F, van Oeffelen AAM, van den Broek IVF, Op de Coul ELM, Hofstraat SHI, et al. Sexually transmitted infections including HIV, in the Netherlands in 2016. Rijksinstituut voor Volksgezondheid en Milieu RIVM. 2017.

81. Boerekamps A, Van den Berk GE, Fanny LN, Leyten EM, Van Kasteren ME, van Eeden $\mathrm{A}$, et al. Declining HCV incidence in Dutch HIV positive men who have sex with men after unrestricted access to HCV therapy. Clin Infect Dis. 2017; epub ahead of print.

82. Solomon SS, Mehta SH, Srikrishnan AK, Solomon S, McFall AM, Laeyendecker $\mathrm{O}$, et al. High burden of HCV disease and poor access to HCV services among people who inject drugs in India: A cross-sectional study among 14,481 drug users across India. Lancet Infect Dis. 2015;15(1):36-45.

83. Frontieres MS. Diagnosis and treatment of hepatitis C: a technical landscape. 2013 [Accessed 12 January 2018]. Available from: http://www.msfaccess. org/sites/default/files/MSF_assets/HepC/Docs/HepC_brief_TechnicalLandsca pe_ENG_2013.pdf

84. WHO. Global report on access to hepatitis $C$ treatment: Focus on overcoming barriers. 2016 [Accessed 12 January 2018]. Available from: http://apps.who. int/iris/bitstream/10665/250625/1/WHO-HIV-2016.20-eng.pdf.

85. Woode ME, Abu-Zaineh M, Perriëns J, Renaud F, Wiktor S, Moatti J. P Potential market size and impact of hepatitis $C$ treatment in low- and middleincome countries. J Viral Hepatitis. 2016;23(7):522-34.
86. Harris RJ, Martin NK, Rand E, Mandal S, Mutimer D, Vickerman P, et al. New treatments for hepatitis C virus ( $\mathrm{HCV}$ ): scope for preventing liver disease and HCV transmission in England. J Viral Hepatitis. 2016;23 (8):631-43.

87. Fraser $\mathrm{H}$. Investigating the impact of scaling-up screening, treatment, and prevention interventions targeting priority groups for hepatitis C virus elimination in Pakistan. International Network on Hepatitis in Substance Users (INHSU) 2017. Jersey City, NJ. Poster Presentation 45. 2017.

88. Aspinall A, Corson S, Doyle JS, Grebely J, Hutchinson SJ, Dore GJ, et al. Treatment of hepatitis C virus among people who are actively injecting drugs: a sysematic review and meta-analysis. Clin Infect Dis. 2013; 57 Suppl 2:S80-9.

89. Dore GJ. Hepatitis C Virus (HCV) Reinfection and Injecting Risk Behavior Following Elbasvir (EBR)/Grazoprevir (GZR) Treatment in Participants on Opiate Agonist Therapy (OAT): Co-STAR Part B. AASLD 2017, 2017.

90. Popping S, van Kampen J, Verbon A, Boucher C, van de Vijver D. Intensive hepatitis C monitoring in previously HCV infected HIV-positive MSM is a cost saving method to reduce the HCV epidemic. NCHIV 2016, abstract number O10. 2016 [Accessed 12 January 2018]. Available from: http://nchiv.org/abstracts/

91. Mathers BM, Degenhardt L, Ali H, Wiessing L, Hickman M, Mattick RP, et al. HIV prevention, treatment, and care services for people who inject drugs: a systematic review of global, regional, and national coverage. Lancet. 2010;375 (9719):1014-28.

92. Johnson W, Diaz RM, Flanders WD, Goodman M, Hill AN, Holtgrave D, et al. Behavioral interventions to reduce risk for sexual transmission of HIV among men who have sex with men. Cochrane Database Syst Rev. 2008; https://www.ncbi.nlm.nih.gov/pubmed/18646068.

93. Pakianathan MR, Lee MJ, Kelly B, Hegazi A. How to assess gay, bisexual and other men who have sex with men for chemsex. Sex Transm Infect. 2016;92(8):568-70.

94. Stuart D, Weymann J. ChemSex and care-planning: one year in practice. HIV Nursing. 2015:15:24-8.

95. Stuart D. Sexualised drug use by MSM (ChemSex): a toolkit for GUM/HIV staff. HIV Nursing. 2014;14(2):15.

96. Hoornenborg E, Achterbergh RCA, Schim van der Loeff MF, Davidovich U, Hogewoning A, de Vries HJC. MSM starting preexposure prophylaxis are at risk of hepatitis C virus infection. AIDS. 2017:31(11):1603-10.

97. Network TE. EMIS 2010: The European Men-Who-Have-Sex-With-Men Internet Survey, Findings from 38 countries. 2013, European Centre for Disease Prevention and Control: Stockholm.

98. van de Laar T, Pybus O, Bruisten S, Brown D, Nelson M, Bhagani S, et al. Evidence of a Large, International Network of HCV Transmission in HIV-Positive Men Who Have Sex With Men. Gastroenterology. 2009:136(5):1609-17.

99. Powers K, Ghani AC, Miller WC, Hoffman IF, Pettifor AE, Kamanga G, et al. The role of acute and early HIV infection in the spread of HIV and implications for tranmission prevention strategies in Lilongwe, Malawi: a modelling study. Lancet. 2011:378:256-68.

100. Newsum AM, Ho CKY, Lieveld FI, van de Laar TJW, Koekkoek SM, Rebers $\mathrm{SP}$, et al. The hepatitis C virus nonstructural protein $3 \mathrm{Q} 80 \mathrm{~K}$ polymorphism is frequently detected and transmitted among HIV-infected MSM in the Netherlands. AIDS. 2017;31(1):105-12.

101. Franco S, Tural C, Nevot M, Moltó J, Rockstroh Jürgen K, Clotet B, et al. Detection of a sexually transmitted hepatitis $C$ virus protease inhibitor-resistance variant in a human immunodeficiency virus-infected homosexual man. Gastroenterology. 2014;147(3):599-601.e1.

102. Degenhardt L, Charlson F, Stanaway J, Larney S, Alexander LT, Hickman $\mathrm{M}$, et al. Estimating the burden of disease attributable to injecting drug use as a risk factor for HIV, hepatitis C, and hepatitis B: findings from the Global Burden of Disease Study 2013. Lancet Infect Dis. 2016;16(12):1385-98.

103. Walker J. Projected impact and pathways to success of the hepatitis C virus elimination program in Georgia, 2015-2020. EASL Conference 2017, April 19-23 2017, Amsterdam, The Netherlands, Oral abstract. 2017. 


\title{
Research gaps in viral hepatitis
}

\author{
Anders Boyd ${ }^{1,2}$, Léa Duchesne ${ }^{1}$ and Karine Lacombe $3,4 \S$
}

§Corresponding author: Karine Lacombe, Service de Maladies Infectieuses, Hôpital Saint-Antoine, 184 rue du Faubourg Saint-Antoine, 75012 Paris, France. Tel: +33 1 492824 38. (karine.lacombe2@aphp.fr)

\begin{abstract}
Introduction: The World Health Organization has aimed for global elimination of both hepatitis B virus (HBV) and hepatitis C virus (HCV) by 2030. Treatments available to cure HCV and control HBV, as well as vaccination to prevent HBV infection, have certainly allowed for such bold goals, yet the final steps to usher in elimination require further evidence.

Discussion: We broadly discuss the needs for three major public health approaches. First, an effective vaccine exists for HBV and mass-vaccination campaigns have resulted in decreases in hepatitis B surface antigen seroprevalence and overall rates of liver-related morality. Still, HBV vaccination coverage is poor in certain regions of the world, while the reasons for such low coverage require further study. A prophylactic vaccine is probably needed to eliminate HCV, but is not being readily developed. Second, identifying HBV/HCV infected individuals remains a priority to increase awareness of disease status, particularly for key populations. Research evaluating large-scale implementation of novel, rapid and mobile point-of-care tests would be helpful to determine whether increased awareness is achievable in these settings. Third, antiviral therapy allows for strong HBV suppression and HCV cure, while its access depends on financial factors among many others. Although there is strong evidence to treat key populations and specific groups with progressed disease, as stated in current guidelines, the advantages of extending treatment eligibility to decrease onward spread of HBV/HCV infection and prevent further burden of disease are lacking "real world" evidence. Novel anti-HBV treatments are being developed to target intrahepatocellular HBV replication, but are still in the early phases of clinical development. Each of the strategies mentioned above has specific implications for HIV infection.

Conclusions: There are certainly effective tools to combat the spread of viral hepatitis and treat infected individuals - yet how they are able to reach key populations, and the infrastructure required to do so, continue to represent the largest research gap when evaluating the progress towards elimination. Continuously adapted and informed research is required to establish the priorities in achieving elimination goals.
\end{abstract}

Keywords: hepatitis B virus; hepatitis C virus; public health; testing; antivirals; eradication

Received 1 October 2017; Accepted 20 December 2017; Published 9 April 2018

Copyright (c) 2018 The Authors. Journal of the International AIDS Society published by John Wiley \& sons Ltd on behalf of the International AIDS Society. This is an open access article under the terms of the Creative Commons Attribution License, which permits use, distribution and reproduction in any medium, provided the original work is properly cited.

\section{1 | INTRODUCTION}

The 2015 update of the Global Burden of Diseases study has ranked chronic viral hepatitis and its underlying conditions, such as cirrhosis and liver cancer, among the top 20 causes of death, steeply increasing from 1990 to 2015 [1]. Nevertheless, an extensive array of tools is available to combat hepatitis $B$ virus (HBV) and hepatitis $C$ virus $(\mathrm{HCV})$. HBV vaccination is effective at preventing infection. Individuals with chronic HBV-infection are able to reduce circulating HBV with almost no risk of developing resistance when using the potent nucleoside/nucleotide analogues (NA) entecavir, tenofovir disoproxil fumarate (TDF), or the more recent tenofovir alafenamide [2]. Novel direct-acting antivirals (DAAs) have allowed for short-term and effective treatment against HCV and are known to induce high rates of sustained virological response (SVR) [3].

With these effective means at hand, the World Health Organization (WHO) has aimed to achieve global elimination of both infections by 2030. However, elimination implies strengthening existing tools - more efficient screening policies, wider access to care and management of liver disease, and antiviral agents that ultimately halt the virus. In this commentary, we broadly highlight some recent advances, and room for improvement, in three public health strategies geared towards HBV and HCV elimination that also include HIV coinfected individuals: vaccination, testing and treatment.

\section{DISCUSSION}

\subsection{Preventing ongoing transmission}

With an effective HBV vaccine, many large-scale vaccination campaigns have been able to dramatically change the spectrum of liver-associated disease. For instance, widespread vaccination in China has led to substantial decreases in incident HBV infections and the prevalence of hepatitis B surface antigen (HBsAg)-positive serology [4]. Moreover, recent data from 
Taiwan have confirmed that immunization in infants reduces the risk of hepatocellular carcinoma ( $\mathrm{HCC}$ ) during adulthood [5]. Worldwide three-dose HBV vaccine coverage has increased to $84 \%$ [6], yet a considerable proportion of the global population could still benefit from vaccination [7]. Understanding the logistic, financial, and cultural constraints to vaccine access would help further the use of this highly-effective, preventative measure.

Timely birth-dose vaccination ( $<24$ hours after birth) among infants born to HBsAg-positive mothers has shown to prevent mother-to-child transmission. Birth-dose coverage is unfortunately lagging at $<40 \%$ for many countries, with the lowest coverage in Africa at 10\% [6]. As one-fifth of infants vaccinated at birth and born to hepatitis B "e" antigen ( $\mathrm{HBeAg}$ ) positive mothers become infected [8], this strategy requires further improvement. Treating highly viraemic mothers with TDF has been explored as a strategy to decrease transmission rates. However, these studies have been limited to mostly Asia [9] and further evaluation is needed in other regions with higher liver disease burden, such as Africa.

No prophylactic vaccine is available for HCV infection, while the virus' genetic variability and capacity to escape host immune responses make vaccine development a formidable challenge $[10,11]$. Recent findings on the viral envelope structure and innovative experimental animal models have uncovered new opportunities for HCV vaccine research [12]. Nevertheless, there is ongoing debate whether HCV vaccination would even be useful towards elimination. Significant reduction in HCV incidence could be incurred from widespread access to DAA in key populations [13], yet this "treatment-as-prevention" (TasP) approach has only been evaluated with models strongly dependent on HCV baseline prevalence, treatment coverage, transmission network structure, harm reduction uptake and post-treatment changes in behaviour $[14,15]$. "Real-world" evaluations could test the accuracy of these assumptions. Models of TasP have also demonstrated cost-effectiveness among key populations [16]. It remains unknown if TasP is still cost-effective for other countries, especially those without voluntary licence agreements, where current DAA prices are prohibitive. Existing models have indicated that a vaccine, even if partially effective, could reduce HCV incidence at a lower cost than TasP $[17,18]$ and without requiring specialized care.

\section{2 | Identifying undiagnosed infection}

\subsection{1 | Infection unawareness}

A targeted testing approach is not explicitly recommended for HBV [19], with the broad exception of testing all those "who do not know their status" [6], but is recommended for HCV based on risk or birth cohort [20]. HIV infection is also identified as a risk factor due to shared routes of transmission [21,22]. With this in mind, the 2017 WHO Global Hepatitis Report estimated that an alarming 91\% of HBsAg-positive and $80 \%$ of HCV-positive individuals were unaware of their infection [6]. These estimates are considerably higher than the roughly 30\% of HIV-infected individuals unaware of their infection [23]. Most undiagnosed cases of HBV and HCV in high-income countries (HIC) belong to marginalized groups not covered by conventional screening programmes [20].
Undiagnosed cases in low- to middle-income countries (LMIC) are also found in these key populations, but the greater problem lies in limited centralized diagnostic facilities, cost of testing, lacking public education and awareness, and need for skilled health professionals [24,25]. Improving general understanding of viral hepatitis and its health consequences are also central to increasing disease awareness and could be addressed via public health campaigns [26].

\subsubsection{Novel rapid-testing techniques}

Despite the paucity of studies in LMIC, data support the costeffectiveness of $\mathrm{HBV}$ testing in key populations (i.e. migrants) for HIC and in general for low-income countries with high HBsAg-positive seroprevalence [7]. Developing easy to use and affordable screening tools would allow a considerable scale-up in testing. Transportable in size and straightforward in use, point-of-care (POC) systems could widen testing availability and specificity have been validated in both $\mathrm{HIC}$ and LMIC [27]. Anti-hepatitis B surface and anti-hepatitis B core antibody status are also needed to determine HBV infection phase; however, rapid tests detecting these antibodies are either lacking or inadequate [27,28].

PCR is the gold standard approach to evaluate viral replication. HCV RNA and HBV-DNA are not often assessed due to high costs, heavy burden in human resources, which then restrains their availability [7]. Some less-costly molecular assays that could be easier to implement in LMIC are being developed, including a new semi-quantitative real-time PCR approach able to discriminate samples with HBV DNA levels above or below the clinically-relevant threshold of $2000 \mathrm{IU} / \mathrm{ml}$ [29]. However, field validation must be performed before concluding their usefulness in resource-limited settings. POC assays could extend viral load testing and increase those aware of having active HCV-infection. The stringent technical requirements to quantify HCV RNA offer little leeway for an inexpensive, portable POC test that must also be resistant to extreme environmental conditions and have a turnaround time of $<1$ hour. Systems have been developed, such as GeneXpert and Genedrive, that are able to accurately quantify HCV RNA and HBV-DNA [30,31], but the high cost of performing these assays limits its immediate appeal for LMIC. Other novel POCs targeting alternative markers of viraemic activity, such as Daktari and HCV core antigen detection [32], may pave the way for more affordable HCV POC tests. Next generation, microchip-sized diagnostics have been emerging in which innovations in nanotechnology, bioengineering and microfluid dynamics are combined [33]. Mobile tests using this technology could provide the low-cost, accuracy, and fully-automated features required for POC assays, yet are still in the early stages of development. In order to incorporate any of these diagnostic tools in screening guidelines, more comprehensive data on their accuracy, feasibility, acceptability and cost-effectiveness would be needed.

\subsection{Implications of antiviral therapy}

\subsection{1 $\mid$ Need for antiviral treatment}

The principle goal of NA treatment is suppressing HBV DNA to a level that is associated with reduced rates of liver-related 
morbidity and mortality. Each phase of chronic HBV-infection is associated with a varying degree of viral activity and risk of severe clinical outcomes. Accordingly, HBeAg-positive or -negative chronic hepatitis B patients or those with compensate or decompensate cirrhosis are strongly recommended to initiate treatment [2]. For other phases of infection, there is still debate on when to initiate treatment. Patients early on in infection (i.e. HBeAg-positive chronic HBV infection) occasionally exhibit mild-to-severe liver fibrosis with highly active antiHBV T-cell responses [34] and thus could benefit from early treatment. Other factors also drive the decision to treat, such as family risk of HCC (at high risk of disease) and older age (more willing to adhere to lifelong therapy) [35]. In addition, certain patients (i.e. HBV mono-infected individuals in subSaharan Africa) are oftentimes not recommended for treatment based on most guidelines, but demonstrate increased risk of HCC [36]. TDF-containing antiretroviral therapy should be initiated as early as possible for all HIV-HBV co-infected patients $[37,38]$. Despite these recommendations, there is a dearth of clear, large-scale evidence that delaying therapy affects HCC incidence or liver-related mortality in these subgroups [35].

EASL practice guidelines have recently incorporated a section on stopping treatment [2], yet criteria for discontinuation remain rather ambiguous. It should be stressed that this practice is highly discouraged for HIV-HBV co-infected patients due to its association with severe clinical outcomes [39,40]. In brief, patients should discontinue treatment if they have sustained HBsAg-loss. Treatment could be discontinued in (i) $\mathrm{HBeAg}$-positive chronic HBV patients who achieved HBeAgseroconversion, undetectable HBV-DNA and normalized transaminases and underwent at least 12 months of consolidation therapy, and to a lesser extent, (ii) HBeAg-negative patients with at least 3 years of virological suppression. Since these latter two groups have variable rates of virological and clinical relapse, close virological monitoring is strongly encouraged. Predicting those at risk of failing discontinuation is difficult considering that no available marker has the capacity to do so, with the possible exception of very low HBsAg titres [41]. Whether other biomarkers, such as circulating HBV RNAs, could address, this issue remains speculative.

$\mathrm{HCV}$ treatment aims to cure infection and prevent further $\mathrm{HCV}$-associated complications. The most recent EASL guidelines recommend broadening access to DAA treatment, focusing on HCV-infected individuals with significant fibrosis/ cirrhosis, extrahepatic manifestations, HCV recurrence after liver transplantation, and risk of further transmission [3]. These guidelines are applied similarly to HIV-HCV co-infected patients, yet special consideration should be given to drugdrug interactions with other antiretroviral agents. Given the high SVR rates achieved with current regimens, there is strong advocacy for treating all HCV-infected individuals. However, the cost burden of effective DAAs, especially for single-payer healthcare systems, and its distribution remain obstacles for universal treatment [42].

Systematic reviews are available in which the distribution of HBV phases and HCV genotypes are provided worldwide $[43,44]$. Since recommendations for treatment initiation vary slightly between European, American, and Pacific liver associations, as well as WHO, applying epidemiological data to estimate the number of individuals needing treatment, and of them who is receiving treatment, is not straightforward. In fact, the WHO Global Hepatitis Report assesses the treatment gap for HBV as "unknown" while for HCV, it considers that all infected patients are in need of treatment [6]. A more nuanced understanding of this step in the cascade-of-care is necessary.

\subsubsection{Novel treatments for chronic hepatitis B}

With the success of DAA and along the lines of programmes aimed at HIV cure, there has been substantial momentum in developing therapeutic regimens to cure HBV [45]. The major impediment to such a goal is the eradication of covalentlyclosed circular DNA (ccc-DNA), the template used to transcribe all viral proteins, which cannot be achieved with current NAs [46]. Given that NAs only inhibit DNA polymerase activity, agents targeting other steps in the replication cycle are needed to further suppress intrahepatic replication. Development is underway of agents involved in blocking HBV entry via the sodium taurocholate co-transporting polypeptide cell receptor (myristoylated pre-S peptides, cyclophilin inhibitors), inhibiting gene expression at the mRNA level (short interfering RNAs), affecting core protein assembly (core protein allosteric modulators), and others (reviewed in [47]). These agents are still in the early clinical trial phases and have yet to be assessed in HIV-HBV co-infected patients.

HBV infection is known to exert a wide range of immunological deficiencies, including, but certainly not limited to, depletion of virus-specific cytotoxic $T$ lymphocytes and increased $T$ cell exhaustion [48]. There is then active interest in developing agents that elicit or restore antiviral immunity. Current therapeutic strategies have been engineered to affect both innate (toll-like receptor agonists) and adaptive (checkpoint inhibitors) arms of the immune system, but again are mostly experimental [47]. Considering that these approaches may require a highly orchestrated immune response, as is the case with interferon-based therapies [49], their efficacy could be reduced in immunocompromised HIV-HBV co-infected patients [50].

\subsection{3 | Antiviral-induced virological response and clinical outcomes}

Concomitant reductions in HCC incidence are generally observed with effective HBV suppression from NA-based therapy, yet this risk is not completely abrogated [51]. A low proportion of treated individuals with adequate viral suppression do develop HCC during treatment, questioning the adequacy of current antiviral agents. HBV DNA viral loads or quantitative HBsAg are also poor predictors of these events and perhaps other replicative biomarkers could more accurately establish disease risk [52]. Likewise, decreases in incident HCC have been observed in HIV-HBV co-infected patients over the past decade [53] as use of more potent anti-HBV agents has increased, yet the implications of suppressed HBV DNA is unclear [54].

There are conflicting results on the risk of developing HCC after DAA-induced SVR, with some studies reporting a higher HCC incidence rate $[55,56]$ and others, including a meta-analysis, finding no or even a reduced rate [57-59]. Compensated cirrhosis is a well-known prognostic factor for HCC [60]. 
Recent research on HCV-induced epigenetic and transcriptional changes could further elucidate the mechanisms of developing HCC [61], but still require further study. Similarly, the consequences of $\mathrm{HCV}$ eradication on extrahepatic manifestations, such as diabetes or cardiovascular diseases, also need clarification. Data on DAA use and HCC incidence are starting to emerge in HIV-HCV co-infected patients and suggest that the risk of HCC may not be higher after HCV cure [62]. Previous data from the pegylated-interferon era have also suggested that co-infected patients are not privy to HCC after SVR [63].

\subsubsection{Access to treatment for infected populations}

Scaling-up access to antiviral therapy has slowly begun in recent years with price negotiations, generic formulations, and localized production [6,64]. Still, potent anti-HBV treatments, such as TDF, are limited to HIV-HBV co-infected patients in Sub-Saharan Africa [24] or is not provided for more than a given amount of time. Cost of anti-HCV treatments has been greatly reduced, allowing for more widespread access, but continue to pose financial burdens for some LMIC [65].

Severe clinical outcomes in individuals infected with viral hepatitis cannot, however, be reduced by treatment alone, but will require effective healthcare services. Many barriers in accessing these services currently exist [66], with many more studies on HCV than HBV-infection [67]. First, prioritization of distributing and reimbursing NAs and DAAs are based on constrained resources or little empirical evidence for some countries $[6,68,69]$. Future research must aim to understand the epidemic of viral hepatitis, its disease progression and impact on quality of life in order to substantiate evidencedbased policies. Second, some countries only allow specialists to prescribe DAAs, while many key populations have difficulty in accessing these services. Integrating HCV testing in healthcare services reaching key populations (HIV clinics, harm reduction, in-prison services) and permitting community nurses or primary healthcare services to provide DAAs have shown increases in linkage to and retention in care [70-72]. However, the impact of such strategies in other settings is potentially offset by other systemic and individual barriers. Negative perceptions of HCV treatment, penalization and stigmatization of drug use and, in some countries, sexual preferences are all social factors discouraging key populations from consulting healthcare services [7]. Third, practitioners may be reluctant to treat individuals at high-risk of reinfection. Rates of reinfection among persons who inject drugs are rather variable, but are mostly lower when enrolled in harm-reduction programmes [73]. Nevertheless, harm reduction services might not reach non-opioid dependent persons and persons who formerly injected drugs, representing a major reservoir of infection [74]. High reinfection incidence has been observed in HIV-positive men who have sex with men, while the behavioural data to corroborate ongoing sexual risk behaviours as the underlying reason for this finding are scarce [75]. Specific post-treatment interventions aimed at reducing $\mathrm{HCV}$ re-infected are strongly needed. Finally, few countries have established a national viral hepatitis plan [76], making it difficult to guide clinicians on the most appropriate line of care.

\section{3 | CONCLUSIONS}

Notwithstanding the tools able to successfully prevent, suppress, and cure viral hepatitis, the most efficient way of their use requires considerable research. In the short-term, HBV vaccine coverage should be increased to all regions of the world, while the reasons for reluctance to vaccinate could provide insights on accomplishing this goal. Cheaper and easier technology to test for viral hepatitis should be developed and used in campaigns to increase infection awareness in key populations. Treatment must be accessible to infected individuals to prevent disease progression. Finally, it is likely that a combination of these tools is required for elimination of viral hepatitis $[7,77]$. Although the WHO Global Hepatitis Report has clearly laid out the needs at each step of the viral hepatitis cascade-of-care, continuous and informed research could help prioritize these shifting needs for policy makers and stakeholders alike.

\section{AUTHORS' AFFILIATIONS}

${ }^{1}$ INSERM, UMR_S1136, Institut Pierre Louis d'Epidémiologie et de Santé Publique, Paris, France; ${ }^{2}$ Department of Infectious Diseases, Research and Prevention, Public Health Service of Amsterdam, Amsterdam, Netherlands; ${ }^{3}$ Department of Infectious and Tropical Diseases, Saint-Antoine Hospital, AP-HP, Paris, France; ${ }^{4}$ Sorbonne Universités, INSERM, UPMC Univ Paris 06, Institut Pierre Louis d'épidémiologie et de Santé Publique (IPLESP UMRS 1136), Paris, France

\section{COMPETING INTERESTS}

$\mathrm{AB}$ has received research grants from the Agence nationale de recherche sur le sida et les hépatites virales (ANRS), SIDACTION, and personal fees from Gilead Sciences, Inc. LD has no conflict of interest to declare. $K L$ has received research grants from the ANRS and SIDACTION; personal fees and non-financial support from Gilead Sciences, Inc; personal fees and non-financial support from Abbvie; personal fees from Janssen; grants, personal fees and non-financial support from MSD.

\section{AUTHORS' CONTRIBUTIONS}

$A B$ and $L D$ drafted the manuscript. $K L$ gave critical revisions. All authors approved the final version of this manuscript.

\section{FUNDING}

The authors report no funding in relation to the present commentary.

\section{REFERENCES}

1. GBD 2016 Causes of Death Collaborators. Global, regional, and national age-sex specific mortality for 264 causes of death, 1980-2016: a systematic analysis for the Global Burden of Disease Study 2016. Lancet. 2017;390 (10100):1151-210.

2. European Association for the Study of the Liver. EASL 2017 Clinical Practice Guidelines on the management of hepatitis B virus infection. J Hepatol. 2017;67(2):370-98.

3. European Association for the Study of the Liver. EASL recommendations on treatment of hepatitis C 2016. J Hepatol. 2017;66(1):153-94.

4. Liang X, Bi S, Yang W, Wang L, Cui G, Cui F, et al. Reprint of: epidemiological serosurvey of Hepatitis B in China-declining HBV prevalence due to Hepatitis B vaccination. Vaccine. 2013;2731 Suppl 9:J21-8.

5. Chang M-H, You S-L, Chen C-J, Liu C-J, Lai M-W, Wu T-C, et al. Long-term effects of hepatitis B immunization of infants in preventing liver cancer. Gastroenterology. 2016;151(3):472-80.e1.

6. World Health Organization. Global hepatitis report, 2017 [Internet] [cited 17 December 2017]. Available from: http://www.who.int/hepatitis/publi cations/global-hepatitis-report2017/en/ 
7. Nayagam S, Thursz M, Sicuri E, Conteh L, Wiktor S, Low-Beer D, et al. Requirements for global elimination of hepatitis B: a modelling study. Lancet Infect Dis. 2016;16(12):1399-408.

8. Lee C, Gong Y, Brok J, Boxall EH, Gluud C. Hepatitis B immunisation for newborn infants of hepatitis B surface antigen-positive mothers. Cochrane Database of Systematic Reviews. 2006, Issue 2. Art. No.: CD004790. DOI:10.1002/ 14651858.CD004790.pub2.

9. Hyun MH, Lee Y-S, Kim JH, Je JH, Yoo YJ, Yeon JE, et al. Systematic review with meta-analysis: the efficacy and safety of tenofovir to prevent mother-tochild transmission of hepatitis B virus. Aliment Pharmacol Ther. 2017;45 (12):1493-505.

10. Echeverría N, Moratorio G, Cristina J, Moreno P. Hepatitis C virus genetic variability and evolution. World J Hepatol. 2015;7(6):831-45.

11. Petrovic D, Dempsey E, Doherty DG, Kelleher D, Long A. Hepatitis C virus-T-cell responses and viral escape mutations. Eur J Immunol. 2012;42 (1):17-26.

12. Fauvelle C, Colpitts CC, Keck Z-Y, Pierce BG, Foung SKH, Baumert TF. Hepatitis $C$ virus vaccine candidates inducing protective neutralizing antibodies. Expert Rev Vaccines. 2016;15(12):1535-44.

13. Martin NK, Vickerman P, Dore G, Hickman M. The HCV epidemics in key populations (including PWID, prisoners, and MSM): the use of DAAs as treatment for prevention. Curr Opin HIV AIDS. 2015;10(5):374-80.

14. Zelenev A, Li J, Mazhnaya A, Basu S, Altice FL. Hepatitis C virus treatment as prevention in an extended network of people who inject drugs in the USA: a modelling study. Lancet Infect Dis. 2017; DOI: 10.1016/S1473-3099(17)30676-X. 15. Metzig C, Surey J, Francis M, Conneely J, Abubakar I, White PJ. Impact of hepatitis $\mathrm{C}$ treatment as prevention for people who inject drugs is sensitive to contact network structure. Sci Rep. 2017;7:1833.

16. Leask JD, Dillon JF. Review article: treatment as prevention - targeting people who inject drugs as a pathway towards hepatitis $C$ eradication. Aliment Pharmacol Ther. 2016;44(2):145-56.

17. Scott N, McBryde E, Vickerman P, Martin NK, Stone J, Drummer H, et al. The role of a hepatitis $C$ virus vaccine: modelling the benefits alongside directacting antiviral treatments. BMC Med. 2015;20(13):198.

18. Stone J, Martin NK, Hickman M, Hellard M, Scott N, McBryde E, et al. The potential impact of a hepatitis $C$ vaccine for people who inject drugs: is a vaccine needed in the age of direct-acting antivirals? PLoS ONE. 2016;11(5): e0156213.

19. World Health Organization. Guidelines for the prevention, care and treatment of persons with chronic hepatitis B infection [cited 17 December 2017]. Available from: http://www.who.int/hepatitis/publications/hepatitis-b-guidelines/en/

20. Grebely J, Dore GJ, Morin S, Rockstroh JK, Klein MB. Elimination of HCV as a public health concern among people who inject drugs by 2030 - what will it take to get there? J Int AIDS Soc. 2017;20(1):22146.

21. Platt L, Easterbrook P, Gower E, McDonald B, Sabin K, McGowan C, et al. Prevalence and burden of HCV co-infection in people living with HIV: a global systematic review and meta-analysis. Lancet Infect Dis. 2016;16(7): 797-808.

22. Degenhardt L, Peacock A, Colledge S, Leung J, Grebely J, Vickerman P, et al. Global prevalence of injecting drug use and sociodemographic characteristics and prevalence of HIV, HBV, and HCV in people who inject drugs: a multistage systematic review. Lancet Glob Health. 2017;5(12):e1192-207.

23. World Health Organization. HIV/AIDS [Internet] [cited 17 December 2017]. Available from: http://www.who.int/mediacentre/factsheets/fs360/en/ 24. Lemoine M, Eholié S, Lacombe K. Reducing the neglected burden of viral hepatitis in Africa: strategies for a global approach. J Hepatol. 2015;62(2):469-76. 25. Reipold EI, Trianni A, Krakower D, Ongarello S, Roberts T, Easterbrook P, et al. Values, preferences and current hepatitis B and C testing practices in lowand middle-income countries: results of a survey of end users and implementers. BMC Infect Dis. 2017;17 Suppl 1:702.

26. Shimakawa Y, Pourette D, Bainilago L, Enel C, Sombié R, Rado R, et al. Improving communication about viral hepatitis in Africa. Lancet Infect Dis. 2017; 17(7):688-9.

27. Bottero J, Boyd A, Gozlan J, Lemoine M, Carrat F, Collignon A, et al. Performance of rapid tests for detection of $\mathrm{HBsAg}$ and anti-HBsAb in a large cohort. France. J Hepatol. 2013;58(3):473-8.

28. Bottero J, Boyd A, Gozlan J, Carrat F, Lemoine M, Rougier H, et al. Effectiveness of hepatitis B rapid tests toward linkage-to-care: results of a randomized, multicenter study. Eur J Gastroenterol Hepatol. 2016;28(6):633-9.

29. Castéra-Guy J, Rubbo P-A, Kania D, Lemoine M, Van de Perre P, Tuaillon E. Semi-quantitative real-time PCR: a useful approach to identify persons with low replicative chronic hepatitis B. J Virol Methods. 2017;244:1-3.

30. Gupta E, Agarwala P, Kumar G, Maiwall R, Sarin SK. Point -of -care testing (POCT) in molecular diagnostics: performance evaluation of GeneXpert HCV
RNA test in diagnosing and monitoring of HCV infection. J Clin Virol. 2017:88:46-51.

31. Llibre A, Shimakawa Y, Mottez E, Ainsworth S, Buivan T-P, Firth R, et al. Clinical validation of a rapid point of need HCV molecular test. $J$ Hepatol. 2017;66(1):S98

32. World Health Organization. Guidelines on hepatitis B and C testing [cited 17 December 2017]. Available from: http://www.who.int/hepatitis/publications/ guidelines-hepatitis-c-b-testing/en/

33. Duchesne L, Lacombe K. Innovative technologies for point-of-care testing of viral hepatitis in low-resource and decentralized settings. J Viral Hepat. 2017; doi: 10.1111/jvh.12827.

34. Kennedy P, Litwin S, Dolman G, Bertoletti A, Mason W. Immune tolerant chronic hepatitis B: the unrecognized risks. Viruses. 2017;9(5):96.

35. Zoulim F, Mason WS. Reasons to consider earlier treatment of chronic HBV infections. Gut. 2012;61(3):333-6.

36. Shimakawa Y, Lemoine M, Njai HF, Bottomley C, Ndow G, Goldin RD, et al. Natural history of chronic HBV infection in West Africa: a longitudinal population-based study from The Gambia. Gut. 2016;65(12):2007-16.

37. Kouamé G-M, Boyd A, Moh R, Badje A, Gabillard D, Ouattara E, et al. Higher mortality despite early ART in HIV and hepatitis B virus coinfected patients with high HBV replication. Clin Infect Dis. 2018;66(1):112-20.

38. European AIDS Clinical Society. EACS Guidelines [cited 17 December 2017]. Available from: http://www.eacsociety.org/guidelines/eacs-guidelines/eacsguidelines.html

39. Boyd A, Houghtaling L, Moh R, Chekaraou MA, Gabillard D, Eholié SP, et al. Clinical outcomes during treatment interruptions in human immunodeficiency virus-hepatitis B virus co-infected patients from Sub-Saharan Africa. Am J Trop Med Hyg. 2017;97(6):1936-42.

40. Tedaldi E, Peters L, Neuhaus J, Puoti M, Rockstroh J, Klein MB, et al. Opportunistic disease and mortality in patients coinfected with hepatitis B or C virus in the strategic management of antiretroviral therapy (SMART) study. Clin Infect Dis. 2008;47(11):1468-75.

41. Sarin SK, Kumar M, Lau GK, Abbas Z, Chan HLY, Chen CJ, et al. Asian-Pacific clinical practice guidelines on the management of hepatitis B: a 2015 update. Hepatol Int. 2016;10(1):1-98.

42. Iyengar S, Tay-Teo K, Vogler S, Beyer P, Wiktor S, de Joncheere K, et al. Prices, costs, and affordability of new medicines for hepatitis $C$ in 30 countries: an economic analysis. PLoS Med. 2016;13(5):e1002032.

43. Messina JP, Humphreys I, Flaxman A, Brown A, Cooke GS, Pybus OG, et al. Global distribution and prevalence of hepatitis C virus genotypes. Hepatology. 2015;61(1):77-87.

44. Ott JJ, Horn J, Krause G, Mikolajczyk RT. Time trends of chronic HBV infection over prior decades - a global analysis. J Hepatol. 2017;66(1):48-54.

45. Zeisel MB, Lucifora J, Mason WS, Sureau C, Beck J, Levrero M, et al. Towards an HBV cure: state-of-the-art and unresolved questions-report of the ANRS workshop on HBV cure. Gut. 2015;64(8):1314-26.

46. Boyd A, Lacombe K, Lavocat F, Maylin S, Miailhes P, Lascoux-Combe C, et al. Decay of ccc-DNA marks persistence of intrahepatic viral DNA synthesis under tenofovir in HIV-HBV co-infected patients. J Hepatol. 2016;65(4):68391.

47. Testoni B, Durantel D, Zoulim F. Novel targets for hepatitis B virus therapy. Liver Int. 2017;37 Suppl 1:33-9.

48. Protzer U, Maini MK, Knolle PA. Living in the liver: hepatic infections. Nat Rev Immunol. 2012;12(3):201-13.

49. Kao J-H. HBeAg-positive chronic hepatitis B: why do I treat my patients with pegylated interferon? Liver Int. 2014;34 Suppl 1:112-9.

50. Boyd A, Piroth L, Maylin S, Maynard-Muet M, Lebossé F, Bouix C, et al. Intensification with pegylated interferon during treatment with tenofovir in HIV-hepatitis B virus co-infected patients. J Viral Hepat. 2016;23(12):101726.

51. Papatheodoridis GV, Chan HL-Y, Hansen BE, Janssen HLA, Lampertico P. Risk of hepatocellular carcinoma in chronic hepatitis B: assessment and modification with current antiviral therapy. J Hepatol. 2015;62(4):956-67.

52. Van Hees S, Michielsen P, Vanwolleghem T. Circulating predictive and diagnostic biomarkers for hepatitis B virus-associated hepatocellular carcinoma. World J Gastroenterol. 2016;22(37):8271-82.

53. Béguelin C, Moradpour D, Sahli R, Suter-Riniker F, Lüthi A, Cavassini M, et al. Hepatitis delta-associated mortality in HIV/HBV-coinfected patients. J Hepatol. 2017;66(2):297-303.

54. Boyd A, Lacombe K, Girard P-M. An improved understanding of severe liver morbidity in HIV-infected individuals. AIDS. 2016;30(11):1843-5.

55. Reig M, Mariño Z, Perelló C, Iñarrairaegui M, Ribeiro A, Lens S, et al. Unexpected high rate of early tumor recurrence in patients with HCV-related HCC undergoing interferon-free therapy. J Hepatol. 2016;65(4):719-26. 
56. Conti F, Buonfiglioli F, Scuteri A, Crespi C, Bolondi L, Caraceni P, et al. Early occurrence and recurrence of hepatocellular carcinoma in HCV-related cirrhosis treated with direct-acting antivirals. J Hepatol. 2016;65(4):727-33.

57. The AN. Lack of evidence of an effect of direct-acting antivirals on the recurrence of hepatocellular carcinoma: data from three ANRS cohorts. J Hepatol. 2016;65(4):734-40.

58. Waziry R, Hajarizadeh B, Grebely J, Amin J, Law M, Danta M, et al. Hepatocellular carcinoma risk following direct-acting antiviral HCV therapy: a systematic review, meta-analyses, and meta-regression. J Hepatol. 2017;67(6):1204-12.

59. Ioannou GN, Green PK, Berry K. HCV eradication induced by direct-acting antiviral agents reduces the risk of hepatocellular carcinoma. J Hepatol. 2018;68(1):25-32.

60. European Association for the Study of the Liver. Clinical Practice Guidelines Management of Hepatocellular [cited 17 December 2017]. Available from: http://www.easl.eu/research/our-contributions/clinical-practice-guidelines/detail/ management-of-hepatocellular-carcinoma-eas--eortc-clinical-practice-guidelines/ report/3

61. Jühling F, Bandiera S, Hamdane N, Thumann C, Durand SC, Saghire HE, et al. Hepatitis C virus-induced epigenetic and transcriptional changes persist post cure. J Hepatol. 2017;66(1):S21.

62. Merchante N, Rodríguez-Arrondo F, Revollo B, Merino E, Ibarra S, Galindo $\mathrm{MJ}$, et al. Hepatocellular carcinoma after sustained virological response with interferon-free regimens in HIV/HCV-coinfected patients. AIDS. 2018: in press 63. Merchante N, Merino E, Rodríguez-Arrondo F, Tural C, Muñoz J, DelgadoFernández $M$, et al. HIV/hepatitis C virus-coinfected patients who achieved sustained virological response are still at risk of developing hepatocellular carcinoma. AIDS. 2014;28(1):41-7.

64. Hill A, Simmons B, Gotham D, Fortunak J. Rapid reductions in prices for generic sofosbuvir and daclatasvir to treat hepatitis C. J Virus Erad. 2016;2 (1):28-31.

65. Assefa Y, Hill PS, Ulikpan A, Williams OD. Access to medicines and hepatitis $\mathrm{C}$ in Africa: can tiered pricing and voluntary licencing assure universal access, health equity and fairness? Glob Health. 2017;13(1):73.

66. PerIman DC, Jordan AE, Uuskula A, Huong DT, Masson CL, Schackman $\mathrm{BR}$, et al. An international perspective on using opioid substitution treatment to improve hepatitis C prevention and care for people who inject drugs: structural barriers and public health potential. Int J Drug Policy. 2015;26 (11):1056-63.

67. Zhou K, Fitzpatrick T, Walsh N, Kim JY, Chou R, Lackey M, et al. Interventions to optimise the care continuum for chronic viral hepatitis: a systematic review and meta-analyses. Lancet Infect Dis. 2016;16(12):1409-22.

68. Marshall AD, Cunningham EB, Nielsen S, Aghemo A, Alho H, Backmund M, et al. Restrictions for reimbursement of interferon-free direct-acting antiviral drugs for HCV infection in Europe. Lancet Gastroenterol Hepatol. 2017; DOI:10.1016/S2468-1253(17)30284-4.

69. Martin NK, Vickerman P, Hickman M. How to eliminate HCV infection by antiviral treatment. J Hepatol. 2017;67(1):5-6.

70. Wade AJ, Veronese V, Hellard ME, Doyle JS. A systematic review of community based hepatitis C treatment. BMC Infect Dis. 2016;16:202.

71. Radley A, Tait J, Dillon JF. DOT-C: a cluster randomised feasibility trial evaluating directly observed anti-HCV therapy in a population receiving opioid substitute therapy from community pharmacy. Int J Drug Policy. 2017;47:12636.

72. Bruggmann P, Litwin AH. Models of care for the management of hepatitis $\mathrm{C}$ virus among people who inject drugs: one size does not fit all. Clin Infect Dis. 2013;57 Suppl 2:S56-61.

73. Grebely J, Hajarizadeh B, Dore GJ. Direct-acting antiviral agents for HCV infection affecting people who inject drugs. Nat Rev Gastroenterol Hepatol. 2017; 14(11):641-51.

74. Nelson PK, Mathers BM, Cowie B, Hagan H, Des Jarlais D, Horyniak D, et al. Global epidemiology of hepatitis B and hepatitis C in people who inject drugs: results of systematic reviews. Lancet. 2011;378(9791):571-83.

75. Martinello M, Hajarizadeh B, Grebely J, Dore GJ, Matthews GV. HCV cure and reinfection among people with HIV/HCV coinfection and people who inject drugs. Curr HIV/AIDS Rep. 2017;14(3):110-21.

76. World Health Organization. Global policy report on the prevention and control of viral hepatitis [cited 17 December 2017]. Available from: http://www. who.int/hiv/pub/hepatitis/global_report/en/

77. Lanini S, Easterbrook PJ, Zumla A, Ippolito G. Hepatitis C: global epidemiology and strategies for control. Clin Microbiol Infect. 2016;22(10):833-8. 


\section{AUTHOR INDEX}

\begin{tabular}{lr}
\hline A & \\
\hline Aghemo, A. & 44 \\
Altice, F.L. & 26 \\
Andrieux-Meyer, I. & 38 \\
\hline B & \\
\hline Basenko, A. & 38 \\
Beguelin, C. & 26 \\
Bhagani, S. & 44 \\
Boerekamps, A. & 51 \\
Boyd, A. & 60 \\
Bulterys, M. & 4 \\
\end{tabular}

C

Chevaliez, S.

Chkhartishvili, N.

17

26

D

Doyle, J.S.

Duchesne, L.

F

Feld, J.J.

Fourati, S.

Freeman, J.

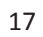

17

38

\begin{tabular}{ll}
\hline $\mathbf{G}$ \\
\hline Grillon, C.
\end{tabular}

\section{H}

Harris, M.

Hellard, M.E.

Hendrickx, G.

Hetherington, K.L.

Hill, A.M.

Hirnschall, G.O.

Hutin, Y.J-F.

$\mathrm{J}$

Jauffret-Roustide, M.

$\mathrm{K}$

Klein, M.B.

Krishtel, P.R.

1,26

38

$\mathbf{L}$

Lacombe, $\mathrm{K}$.

Lazarus, J.V.

Luhmann, N.

$1,26,60$

9

\section{M}

Martin, N.K.

Maticic, M.

Matthews, G.V.

Mellouk, O.

Mendão, L.

Morin, S.
P

Pedrana, A.E.

Piroth, L.

Prins, $M$.

26

44

26

$R$

Rauch, A. 26

Reic, T.

Rijnders, B.J.A.

\section{S}

Sacks-Davis, R.

Saeed, S.

$\begin{array}{ll}\text { Simojoki, K. } & 9 \\ \text { Stumo, S.R. } & 9\end{array}$

T

Tallada, J.

9

V

van der Valk, M. 
Journal Information

\section{About the journal}

The Journal of the International AIDS Society, an official journal of the Society, provides a peerreviewed, open access forum for essential and innovative HIV research, across all disciplines. All articles published by the Journal of the International AIDS Society are freely accessible online. The editorial decisions are made independently by the journal's Editors-in-Chief.

Website: www.jiasociety.org

elSSN: 1758-2652

\section{Contact details}

\section{Editorial office:}

Avenue de France, 23

$\mathrm{CH}-12 \mathrm{O} 2$ Geneva

Switzerland

Email: editorial@jiasociety.org

Tel: +41(0) 227100800

\section{Publisher}

The Journal of the International AIDS Society is published by John Wiley \& Sons Ltd on behalf of the International AIDS Society

John Wiley \& Sons Ltd

9600 Garsington Road

Oxford, OX42DQ UK

Telephone: +441865776868

Email: customer@wiley.com

\section{Production Editor}

Jose Pedro Costa Moreira (email: jcostamore@wiley.com)

\section{Abstracting and Indexing Services}

The Journal of the International AIDS Society is indexed in a variety of databases including PubMed, PubMed Central, MEDLINE, Science Citation Index Expanded and Google Scholar. The journal's impact factor is $6.296\left({ }^{*} 2016\right.$ Journal Citation Report ${ }^{\circledR}$ Science Edition - a Clarivate Analytics product)

\section{Advertising, sponsorship and donations}

Please contact the editorial office if you are interested in advertising on our journal's website. We also gladly receive inquiries on sponsorship and donations to support open access publications from authors in low- and middle-income countries.

\section{Supplements}

The Journal of the International AIDS Society publishes supplements and thematic series on its own initiative or based on proposals by external organizations or authors. Inquiries can be sent to the editorial office at editorial@jiasociety.org.

All articles submitted for publication in supplements are subject to peer review. Published supplements are freely accessible online and can also be produced in print.

\section{Disclaimer}

The Publisher, International AIDS Society and Editors cannot be held responsible for errors or any consequences arising from the use of information contained in this journal; the views and opinions expressed do not necessarily reflect those of the Publisher, International AIDS Society and Editors, neither does the publication of advertisements constitute any endorsement by the Publisher, International AIDS Society and Editors of the products advertised.

\section{Copyright and Copying}

The content in this supplement is published under the Creative Commons Attribution license ("CC-BY"). The license allows third parties to share the published work (copy, distribute, transmit) and to adapt it under the condition that the authors are given credit, and that in the event of reuse or distribution, the terms of this license are made clear. Authors retain the copyright of their articles, with first publication rights granted to the Journal of the International AIDS Society.

\section{Wiley's Corporate Citizenship Initiative}

Wiley's Corporate Citizenship Initiative seeks to address the environmental, social, economic, and ethical challenges faced in our business and which are important to our diverse stakeholder groups. Since launching the initiative, we have focused on sharing our content with those in need, enhancing community philanthropy, reducing our carbon impact, creating global guidelines and best practices for paper use, establishing a vendor code of ethics, and engaging our colleagues and other stakeholders in our efforts. Follow our progress at www.wiley.com/go/citizenship.

\section{Research4Life}

Wiley is a founding member of the UN-backed HINARI, AGORA, and OARE initiatives. They are now collectively known as Research4Life, making online scientific content available free or at nominal cost to researchers in developing countries.

Please visit Wiley's Content Access - Corporate Citizenship site: www.wiley.com/WileyCDA/Section/id-390082.html
Editors

Editors-in-Chief:

Susan Kippax (Australia)

Kenneth H. Mayer (United States)

Annette Sohn (Thailand)

Executive Editor:

Marlène Bras (Switzerland)

\section{Deputy Editors:}

Laith Abu-Raddad (Oatar)

Jenny Anderson (Australia)

Ruanne Barnabas (United States)

Trevor Crowell (United States)

Morna Cornell (South Africa)

Nabila El-Bassel (United States)

Omar Galárraga (United States)

Anna Grimsrud (South Africa)

Andrew Grulich (Australia)

Martin Holt (Australia)

Rami Kantor (United States)

Sheri Lippman (United States)

Matthew Mimiaga (United States)

Kate Mitchell (United Kingdom)

Kenneth Ngure (Kenya)

Nittaya Phanuphak (Thailand)

Luis Soto-Ramirez (Mexico)

Colette Smith (United Kingdom)

Lara Vojnov (Switzerland)

Iryna Zablotska (Australia)

Associate Managing Editor:

Elisa de Castro Alvarez (Switzerland)

Editorial Assistants:

Douglas Fraser (Switzerland)

Annika C. Green (Switzerland)

\section{Editorial Board}

Laith J. Abu-Raddad (Qatar) Joseph Amon (United States) Jintanat Ananworanich (United States) Judith D. Auerbach (United States)

Françoise Barré-Sinoussi (France)

Linda-Gail Bekker (South Africa)

Chris Beyrer (United States)

Andrew Boulle (South Africa)

Carlos Cáceres (Peru)

Pedro Cahn (Argentina)

Elizabeth Connick (United States)

Mark Cotton (South Africa)

Jocelyn DeJong (Lebanon)

Diana Dickinson (Botswana)

Sergii Dvoriak (Ukraine)

Paul Flowers (United Kingdom)

Nathan Ford (South Africa)

Omar Galárraga (Mexico)

Beatriz Grinsztejn (Brazil)

Huldrych Günthard (Switzerland)

Diane Havlir (United States)

Adeeba Kamarulzaman (Malaysia)

Rami Kantor (United States)

Sukhontha Kongsin (Thailand)

Kathleen MacQueen (United States)

Navid Madani (United States)

Kenneth Mayer (United States)

Nelly Mugo (Kenya)

Paula Munderi (Uganda)

Christy E. Newman (Australia)

Richard Parker (United States)

Linda Richter (South Africa)

Jürgen Rockstroh (Germany)

Sean Rourke (Canada)

Naomi Rutenberg (United States)

Gabriella Scarlatti (Italy)

Mauro Schechter (Brazil)

Lorraine Sherr (United Kingdom)

Colette Smith (United Kingdom)

Papa Salif Sow (Senegal)

Tim Spelman (Australia)

Ndèye Coumba Touré-Kane (Senegal)

Sten Vermund (United States)

Ian Weller (United Kingdom)

Alan Whiteside (Canada)

David P. Wilson (Australia)

Iryna Zablotska (Australia) 


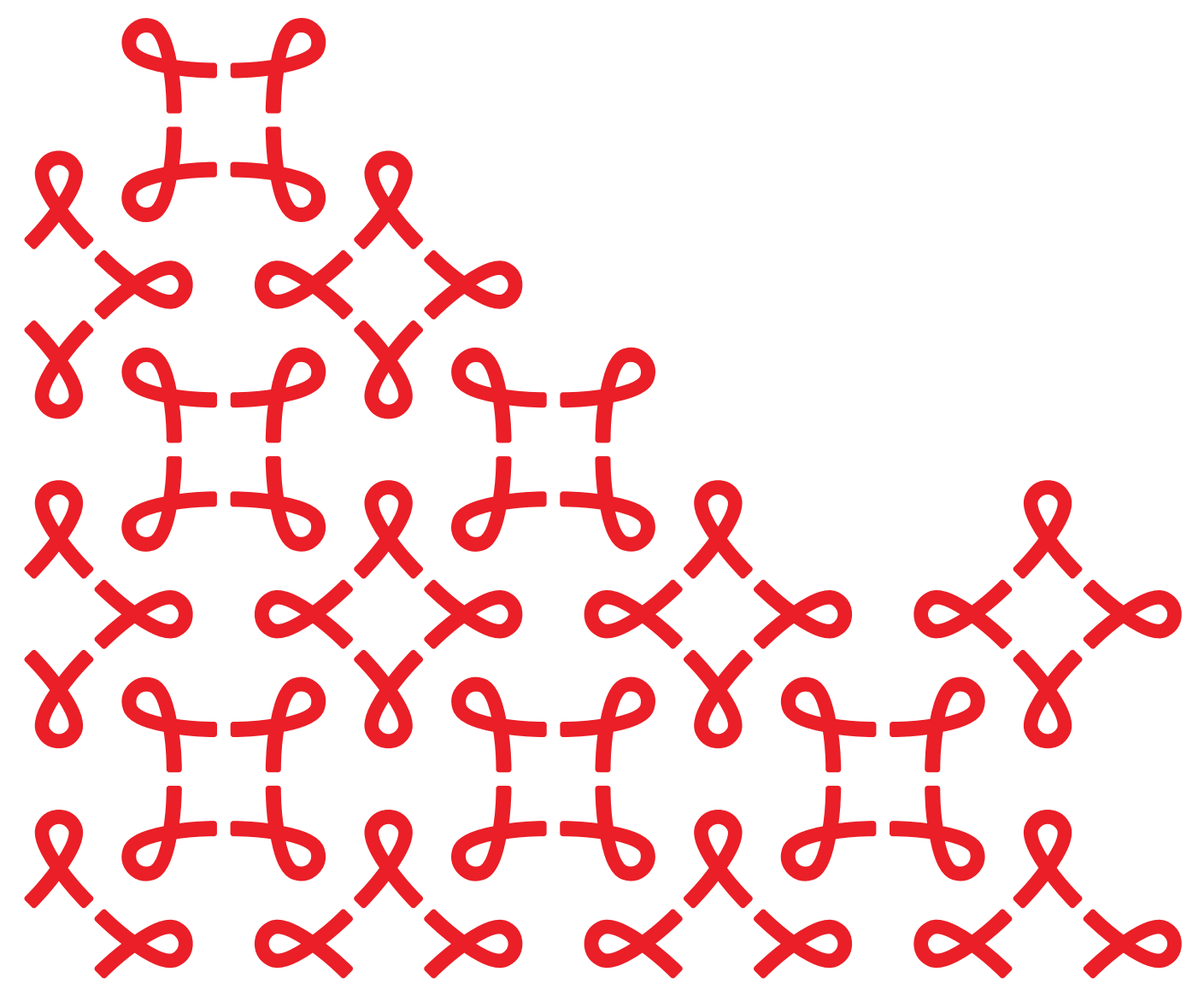

